\title{
Infrared spectra of complex organic molecules in astronomically relevant ice mixtures
}

\author{
IV. Methylamine ${ }^{\star}$

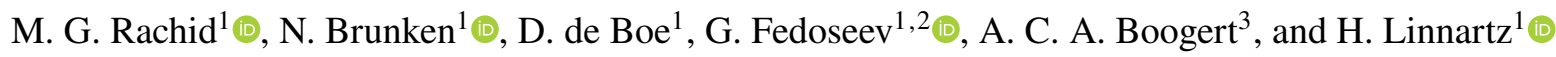 \\ ${ }^{1}$ Laboratory for Astrophysics, Leiden Observatory, Leiden University, PO Box 9513, NL2300 RA Leiden, The Netherlands \\ e-mail: rachid@strw.leidenuniv.nl \\ ${ }^{2}$ Research Laboratory for Astrochemistry, Ural Federal University, Kuibysheva St. 48, 620026 Ekaterinenburg, Russia \\ ${ }^{3}$ Institute for Astronomy, University of Hawai'i at Mānoa, 2680 Woodlawn Drive, Honolulu, HI 96822, USA
}

Received 10 March 2021 / Accepted 12 June 2021

\begin{abstract}
Context. In the near future, high spatial and spectral infrared (IR) data of star-forming regions obtained by the James Webb Space Telescope may reveal new solid-state features of various species, including more intriguing classes of chemical compounds. The identification of complex organic molecules (COMs) in the upcoming data will only be possible when laboratory IR ice spectra of these species under astronomically relevant conditions are available for comparison. For this purpose, systematic series of laboratory measurements are performed, providing high-resolution IR spectra of COMs. Here, spectra of pure methylamine $\left(\mathrm{CH}_{3} \mathrm{NH}_{2}\right)$ and methylamine-containing ices are discussed.

Aims. The work is aimed at characterizing the mid-IR $\left(500-4000 \mathrm{~cm}^{-1}, 20-2.5 \mu \mathrm{m}\right)$ spectra of methylamine in pure and mixed ices to provide accurate spectroscopic data of vibrational bands that are most suited to trace this species in interstellar ices.

Methods. Fourier transform infrared spectroscopy is used to record spectra of $\mathrm{CH}_{3} \mathrm{NH}_{2}$ in the pure form and mixed with $\mathrm{H}_{2} \mathrm{O}, \mathrm{CH}_{4}$, and $\mathrm{NH}_{3}$, for temperatures ranging from 15 to $160 \mathrm{~K}$. The IR spectra in combination with HeNe laser $(632.8 \mathrm{~nm})$ interference data of pure $\mathrm{CH}_{3} \mathrm{NH}_{2}$ ice was used to derive the IR band strengths of methylamine in pure and mixed ices.

Results. The refractive index of amorphous methylamine ice at $15 \mathrm{~K}$ was determined as being $1.30 \pm 0.01$. Accurate spectroscopic information and band strength values are systematically presented for a large set of methylamine-containing ices and different temperatures. Selected bands are characterized and their use as methylamine tracers is discussed. The selected bands include the following: the $\mathrm{CH}_{3}$ antisymmetric stretch band at $2881.3 \mathrm{~cm}^{-1}(3.471 \mu \mathrm{m})$, the $\mathrm{CH}_{3}$ symmetric stretch band at $2791.9 \mathrm{~cm}^{-1}(3.582 \mu \mathrm{m})$, the $\mathrm{CH}_{3}$ antisymmetric deformation bands, at 1455.0 and $1478.6 \mathrm{~cm}^{-1}(6.873$ and $6.761 \mu \mathrm{m})$, the $\mathrm{CH}_{3}$ symmetric deformation band at $1420.3 \mathrm{~cm}^{-1}$ $(7.042 \mu \mathrm{m})$, and the $\mathrm{CH}_{3}$ rock at $1159.2 \mathrm{~cm}^{-1}(8.621 \mu \mathrm{m})$. Using the laboratory data recorded in this work and ground-based spectra of ices toward YSOs (Young Stellar Objects), upper-limits for the methylamine ice abundances are derived. In some of these YSOs, the methylamine abundance is less than $4 \%$ relative to $\mathrm{H}_{2} \mathrm{O}$.
\end{abstract}

Key words. astrochemistry - molecular data - methods: laboratory: molecular - methods: laboratory: solid state ISM: molecules - techniques: spectroscopic

\section{Introduction}

Amino acids are key molecules to life on Earth. Whereas such species have been found in meteorites, already more than half a century ago (Kvenvolden et al. 1970), the simplest amino acid, glycine $\left(\mathrm{NH}_{2} \mathrm{CH}_{2} \mathrm{COOH}\right)$ still has not been unambiguously detected in the interstellar medium (ISM). Its formation pathways in the gas phase and in the solid state have been a matter of ongoing debate (Elsila et al. 2007). A direct consequence of this has been that several molecules, regarded as potential glycine precursors, have become a target in new surveys with the ultimate goal being point out sources that may host glycine at a detectable level. Recent examples include the search for amino acetonitrile $\left(\mathrm{NH}_{2} \mathrm{CH}_{2} \mathrm{CN}\right)$ by Belloche et al.

\footnotetext{
^ Tables from Appendices B and C are only available at the CDS via anonymous ftp to cdsarc.u-strasbg. fr $(130.79 .128 .5)$ or via http://cdsarc.u-strasbg.fr/viz-bin/cat/J/A+A/653/A116
}

(2008), methanimine $\left(\mathrm{CH}_{2} \mathrm{NH}\right)$ by Suzuki et al. (2016), hydroxylamine $\left(\mathrm{NH}_{2} \mathrm{OH}\right)$ by McGuire et al. (2015), and methylamine $\left(\mathrm{CH}_{3} \mathrm{NH}_{2}\right)$ by Ohishi et al. (2019). Such species are expected to have a solid state origin and in this respect methylamine is of special interest, as in recent laboratory work by Ioppolo et al. (2021), it was shown to form nonthermally, under dark cloud conditions (i.e., without impacting UV photons) in a chain of solid-state reactions that also leads to glycine. Fully in line with these experiments was the recent detection of both species in the comet 67P/Churyumov-Gerasimenko (Altwegg et al. 2016), whose composition is considered to reflect the chemical material of the prestellar core from which our Solar System originated (Mumma \& Charnley 2011). For these reasons, we aim in this study to provide high resolution solid-state infrared (IR) spectra of methylamine ice, both pure and embedded in astronomically relevant ice matrices. These data are currently lacking and these allow one to search for frozen methylamine in the ISM, also adding further options to optimize the search for interstellar glycine. 
The first $\mathrm{CH}_{3} \mathrm{NH}_{2}$ detection dates back to 1974 when it was identified toward Sgr B2 and Orion A (Kaifu et al. 1974; Fourikis et al. 1974). Since then, methylamine has also been detected in other high mass star-forming regions (Bøgelund et al. 2019; Ohishi et al. 2019) and in our own Solar System, in the material from the comets Wild 2 and 67P/Churyumov-Gerasimenko (Glavin et al. 2008; Goesmann et al. 2015; Altwegg et al. 2016). Also recently, Ohishi et al. (2019) used the radio telescope Nobeyama to search for methylamine toward several hot molecular cores, which resulted in the detection of a new $\mathrm{CH}_{3} \mathrm{NH}_{2}$ source, G10.47+0.03, the richest methylamine source up to date.

Several interstellar reaction pathways toward methylamine have been proposed, both in the gas phase and in the solid state. In the gas phase, $\mathrm{CH}_{3} \mathrm{NH}_{2}$ can be formed by the reaction of a methyl radical cation with ammonia, followed by dissociative recombination (Leung et al. 1984; Herbst 1985; Maeda \& Ohno 2006). The photolysis of gaseous mixtures containing $\mathrm{CH}_{4}, \mathrm{NH}_{3}$, and $\mathrm{H}_{2} \mathrm{O}$ is also effective to form methylamine (Gardner \& McNesby 1980; Ogura et al. 1988, 1989). Gardner \& McNesby (1980) demonstrated that the condensation of a gaseous $\mathrm{CH}_{4}: \mathrm{NH}_{3}: \mathrm{H}_{2} \mathrm{O}$ mixture followed by UV irradiation provided a solid-state channel resulting in the formation of methylamine. This solid-phase reaction has been included in a gas-grain chemical network by Garrod et al. (2008), who pointed out that the $\mathrm{CH}_{3}$ and $\mathrm{NH}_{2}$ radicals can be formed on the ice grains by $\mathrm{UV}$ or cosmic rays (CR), indicating that methylamine can be formed at very early stages inside dark molecular clouds. Additionally, Theulé et al. (2011) demonstrated that the hydrogenation of $\mathrm{HCN}$ can lead to the formation of $\mathrm{CH}_{3} \mathrm{NH}_{2}$ at $15 \mathrm{~K}$. The mechanism for this synthesis involves multiple hydrogenation steps, possibly passing through the intermediate methanimine $\left(\mathrm{CH}_{2} \mathrm{NH}\right)$. The electron irradiation of $\mathrm{CH}_{4}: \mathrm{NH}_{3}$ ices was also shown to form methylamine in the solid phase (Kim \& Kaiser 2011; Förstel et al. 2017).

Similar to $\mathrm{NH}_{3}$, methylamine can act as an electron donor at low temperatures, forming salts and complexes in the solid state (Bossa et al. 2009, 2010; Kayi et al. 2011; Noble et al. 2014). Bossa et al. (2009) showed that $\mathrm{CH}_{3} \mathrm{NH}_{2}$ thermally reacts with $\mathrm{CO}_{2}$ at temperatures between 50 and $70 \mathrm{~K}$, forming methylammonium methylcarbamate $\left[\left(\mathrm{CH}_{3} \mathrm{NH}_{3}^{+}\right]\left[\mathrm{CH}_{3} \mathrm{NHCOO}^{-}\right]\right)$, which can be converted to glycine (Gly) under UV photolysis:

\section{$\mathrm{CO}_{2}+2 \mathrm{CH}_{3} \mathrm{NH}_{2} \rightarrow\left[\mathrm{CH}_{3} \mathrm{NH}_{3}^{+}\right]\left[\mathrm{CH}_{3} \mathrm{NHCOO}^{-}\right]$}

$$
\left[\mathrm{CH}_{3} \mathrm{NH}_{3}^{+}\right]\left[\mathrm{CH}_{3} \mathrm{NHCOO}^{-}\right] \stackrel{\mathrm{h} v}{\longrightarrow} \mathrm{CH}_{3} \mathrm{NH}_{2}+\text { Gly. }
$$

More recently, Mahjoub \& Hodyss (2018) also showed that methylamine can thermally react with carbonyl sulfide (OCS) in the solid phase to form the methylammonium methylthiocarbamate salt $\left[\mathrm{CH}_{3} \mathrm{NH}_{3}^{+}\right]\left[\mathrm{CH}_{3} \mathrm{NHOCS}^{-}\right]$. The salt formation by nitrogen-bearing molecules is of great importance since these reactions can result in an increase of their sublimation temperatures, "locking" these species on ices at relatively high temperatures (Bossa et al. 2009).

Many solid-state routes have been shown to result in $\mathrm{CH}_{3} \mathrm{NH}_{2}$ formation, and given its relevance as an amino acid precursor, it is essential to study this species' solid-state spectral features. The mid-IR spectrum of solid $\mathrm{CH}_{3} \mathrm{NH}_{2}$ has been reported in the literature in pure form and isolated in $\mathrm{Ar}$ and $\mathrm{Kr}$ matrices (Durig et al. 1968; Wolff 1970; Durig \& Zheng 2001). The infrared spectra of some $\mathrm{CH}_{3} \mathrm{NH}_{2}$-containing ices are reported in previous works (Bossa et al. 2009; Kayi et al. 2011; Vinogradoff et al. 2013), but a systematic study of the mid-infrared spectrum of methylamine recorded for different astrochemical relevant conditions is still lacking. To address this sparsity of laboratory data, we present the spectra of methylamine in mixtures containing $\mathrm{H}_{2} \mathrm{O}, \mathrm{CH}_{4}$, and $\mathrm{NH}_{3}$ for temperatures ranging from 15 up to $160 \mathrm{~K}$. The molecules used in the studied samples are amongst the most abundant detected species in water-rich interstellar ices (Boogert et al. 2015), moreover $\mathrm{CH}_{4}$ and $\mathrm{NH}_{3}$ are expected to be solid-state precursors of methylamine (Kim \& Kaiser 2011; Förstel et al. 2017; Ioppolo et al. 2021). The chosen ice compositions aim to simulate the conditions in which methylamine is expected to be present in icy dust grains. This permits tracking changes in the spectral appearance of vibrational modes with alterations in the ice morphology. The IR bands that carry the highest potential as tracers of methylamine in interstellar ices are selected for in-depth spectral surveys. These IR features are characterized in terms of peak position and full width at half maximum (FWHM), and their relative band strengths in ices at $15 \mathrm{~K}$ are derived.

The data presented here are part of a series of laboratory experiments supporting upcoming observations with the James Webb Space Telescope (JWST) within the framework of "ICE AGE", a JWST ERS program. The Mid-InfraRed instrument (MIRI) on board JWST will provide infrared spectra of starforming regions between 5 and $28.5 \mu \mathrm{m}$. These data allow one to identify new species in ices and increasing our insight about the morphology and thermal history of ices in space. The secure assignment of the solid-state features in JWST spectra will only be possible when combined with laboratory spectra of ices recorded for similar astrophysical conditions. The data presented here is publicly available ${ }^{1}$, and spectra of ices recorded for intermediate temperatures can be supplied upon request.

This manuscript is organized in the following way: Sect. 2 provides information on the measurements and applied methodology, including details on the band strength measurements. Section 3 presents the overall IR spectra and focuses on bands that might be useful for astronomical identification of solid methylamine. This is illustrated in Sect. 4 discussing the potential of these IR features for tracing solid methylamine. The final section summarizes this work with a conclusion. The essential data resulting from this work are available from the Appendices. Appendix A presents the IR spectra of pure and mixed methylamine ices as well as graphical representations of the relative band strengths and peak position versus FWHM for the selected bands. Appendix B provides data on the peak position and FWHM for these methylamine bands in different ice samples. Appendix C provides the integrated absorbance of the analyzed methylamine bands.

\section{Methodology}

The experiments have been performed with two setups. The infrared spectra were recorded with our HV (High Vacuum) setup. Details of this system and methodology are available from Terwisscha van Scheltinga et al. (2018) and Rachid et al. (2020). Over the last year, this setup has been fully upgraded, replacing the high vacuum by an UHV system. The new IRASIS (InfraRed Absorption Setup for Ice Spectroscopy) system allows to record IR ice spectra and simultaneously to perform laser interference measurements to determine ice thickness. For both setups, all relevant experimental information is provided below.

The infrared measurements of the pure $\mathrm{CH}_{3} \mathrm{NH}_{2}$ ice and $\mathrm{CH}_{3} \mathrm{NH}_{2}$ mixed in $\mathrm{H}_{2} \mathrm{O}, \mathrm{NH}_{3}$, and $\mathrm{CH}_{4}$ ices are conducted with

https://icedb.strw.leidenuniv.nl/ 
the HV setup in a high vacuum stainless steel chamber that operates with a base pressure of $\sim 3 \times 10^{-7}$ mbar. Inside the chamber, an IR transparent zinc selenide ( $\mathrm{ZnSe}$ ) window is mounted on a copper holder connected to a cold finger and is maintained at $15 \mathrm{~K}$ by a closed-cycle He cryostat. Pure or premixed gases, contained in a $2 \mathrm{~L}$ glass bulb with a total pressure of 20 mbar, are admitted into the chamber through a precalibrated needle valve and background deposited onto the substrate. The ices are grown for approximately $30 \mathrm{~min}$, which results in ices with total column densities of $1-3 \sim 10^{18}$ molecules $\mathrm{cm}^{-2}$. After deposition, the ice is heated at a rate of $25 \mathrm{~K} \mathrm{~h}^{-1}$ until its complete sublimation. During both the deposition and ice heating, mid-IR spectra (20-2.5 $\mu \mathrm{m}, 500-4000 \mathrm{~cm}^{-1}$ at resolution $0.5 \mathrm{~cm}^{-1}$, averaged over 256 scans) are acquired continuously using a Varian 670 Fourier transform spectrometer. During a single spectrum acquisition period, the ice is heated by roughly $3.5 \mathrm{~K}$. Apart from temperatures close to crystallization or the thermal desorption point, this barely affects band profiles.

The gas mixtures are prepared in a separate mixing system by the sequential addition of gases or vapor components in a $2 \mathrm{~L}$ glass bulb. This is done by adding a certain gas/vapor into the glass balloon and freezing this component by immersing the balloon in a liquid nitrogen bath. The freezing of a component gas ensures that this component cannot diffuse into the volume from which the upcoming component is added. For all measurements, the bulb is prepared by filling it with a total pressure of 20 mbar. For gaseous mixtures, each component's partial pressure in the mixture corresponds to the desired ratio in the ice sample. The estimated error in each component ratio following this method is $\leq 10 \%$. The gases and liquids used for preparing the gaseous mixtures are $\mathrm{CH}_{3} \mathrm{NH}_{2}$ (Sigma Aldrich, anhydrous $\geq 99.99 \%$ ), $\mathrm{H}_{2} \mathrm{O}$ (Milli-Q, Type I), $\mathrm{CH}_{4}$ (Linde Gas 99.995\%), and $\mathrm{NH}_{3}$ (Sigma Aldrich, anhydrous $\geq 99.99 \%$ ).

The measurements of the methylamine band strengths are performed in the new experimental setup, IRASIS. This setup allows for the simultaneous acquisition of infrared spectra and laser interference measurements of the growing ice. Figure 1 shows a schematic picture of IRASIS. The central stainless chamber is kept at ultra-high vacuum (base pressure $\sim 2 \times 10^{-9}$ mbar) by a turbomolecular pump (Turbovac i350) prepumped by a rotary vane pump supplied with an oil filter. Compared to the previous HV setup, the measurements performed on IRASIS are less sensitive to water ice growth caused by background gas deposition. In the center of the chamber, a Germanium $(\mathrm{Ge})$ substrate is attached to the tip of the cryostat's cold finger. The cryostat head system is mounted onto a rotatable platform, which allows the sample's rotation by $360^{\circ}$. The ice is deposited on both sides of the substrate, and the thickness on each side is monitored during growth by using a HeNe laser $(\lambda=632.8 \mathrm{~nm})$ interference pattern. The ice thickness (d) is related to the number of interference fringes (m) by (Tempelmeyer \& Mills Jr 1968):

$$
d=\frac{m \lambda}{2 \sqrt{n^{2}-\sin ^{2} \theta}},
$$

where $\lambda$ is the wavelength of the laser, $n$ is the refractive index of the ice, and $\theta$ is the incident angle of the laser beam. Since the Ge substrate is opaque for the light at $632.8 \mathrm{~nm}$, each laser beam probes only the ice growing on one side of the substrate. The reflected light beams are measured by two separate photodetectors (Thorlabs PDA36A2) connected to a data acquisition card (National Instruments) that is controlled using a LabView program, which enables the simultaneous data acquisition from

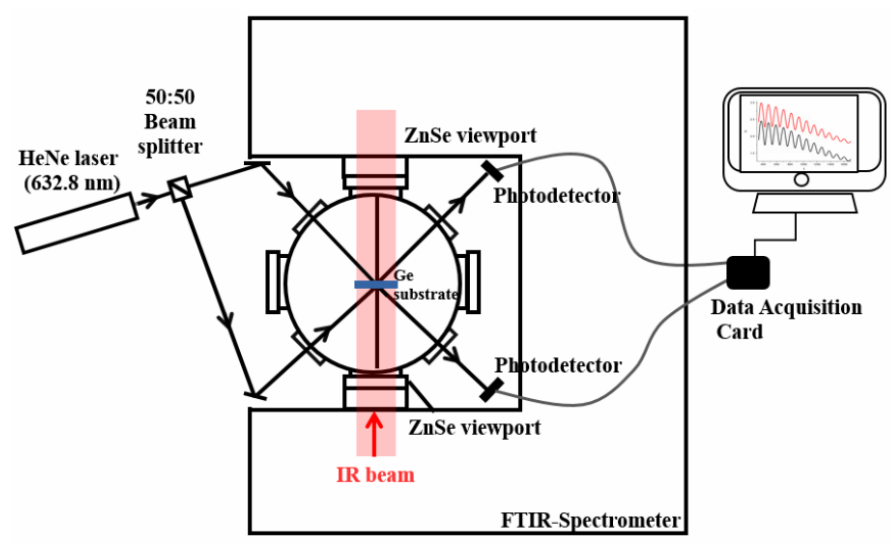

(a)

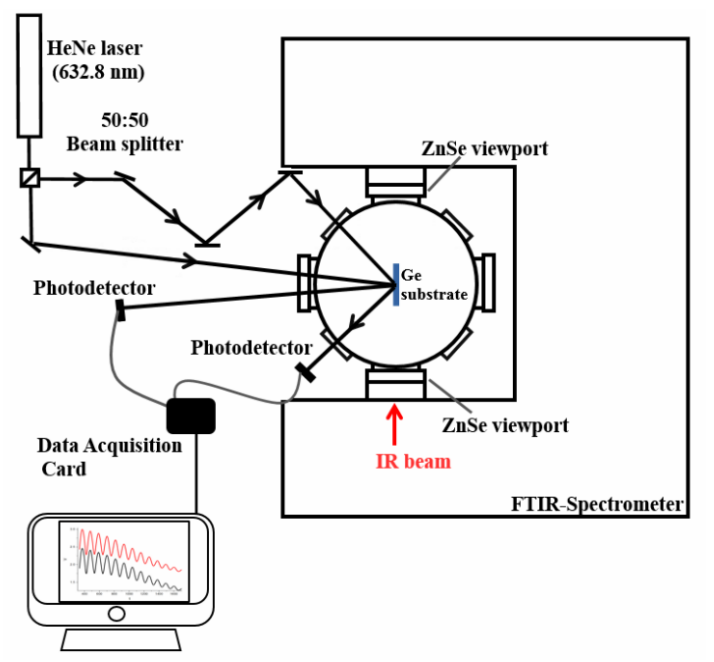

(b)

Fig. 1. Schematic picture of the new IRASIS setup. (a) Configuration in which the IR and thickness measurements are performed simultaneously. The laser beam impinges on the substrate at an angle $45 \pm 3^{\circ}$ on one side of the substrate and $42 \pm 3^{\circ}$ on the other side. (b) Configuration for refractive index measurements only: the substrate is rotated by $90^{\circ}$ and the laser hits the substrate at two different angles (for this work $\theta_{0}=5.8^{\circ} \pm 0.5^{\circ}$ and $\theta_{1}=50.0^{\circ} \pm 0.5^{\circ}$ ).

both detectors. Figure 1a shows the experimental configuration for simultaneous acquisition of infrared spectra and laser interference measurements (in the measurements described here $\theta_{0}=45^{\circ} \pm 3^{\circ}$ and $\theta_{1}=42^{\circ} \pm 3^{\circ}$ ).

The refractive index of pure methylamine ice at $15 \mathrm{~K}$ is derived by a double-laser interference technique that employs two laser beams hitting the ice sample (in a same spot) at different angles and generating two interference patterns (for details, see Tempelmeyer \& Mills Jr 1968; Romanescu et al. 2010; Beltrán et al. 2015; Hudson et al. 2017). The period of the interference patterns and the incidence angles of the two laser beams are related to the refractive index of the ice by:

$n=\sqrt{\frac{\sin ^{2} \theta_{0}-\gamma^{2} \sin ^{2} \theta_{1}}{1-\gamma^{2}}}$

where $\gamma=\frac{T_{1}}{T_{0}}$ is the ratio between the two periods $T_{1}$ and $T_{0}$ of the interference signals generated by the two laser beams 


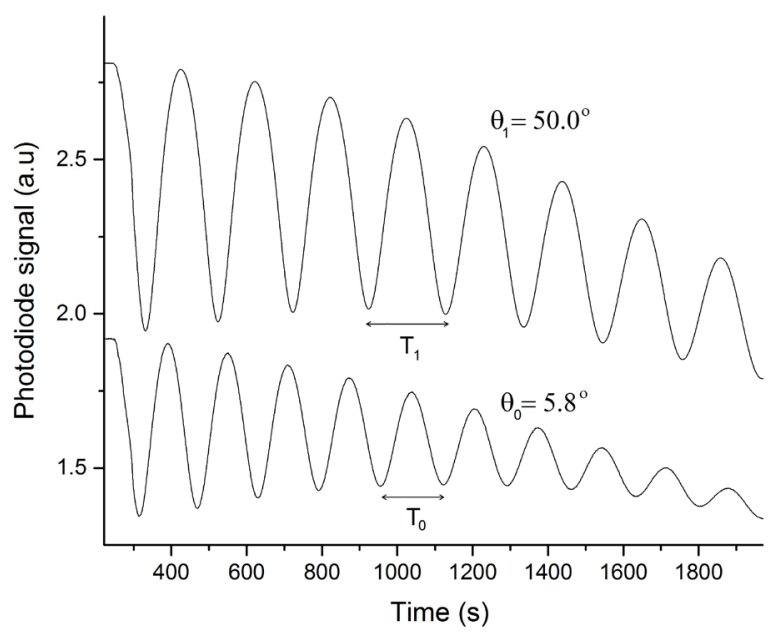

Fig. 2. Interference pattern obtained during ice growth. In this work, the employed laser beams hit the substrate at angles $\theta_{0}=5.8^{\circ} \pm 0.5^{\circ}$ and $\theta_{1}=50.0^{\circ} \pm 0.5^{\circ}$.

(see Fig. 2), impacting on the substrate at angles $\theta_{1}$ and $\theta_{0}$, respectively.

Since the refractive index measurements are more sensitive to the accuracy in the incident angle around $50^{\circ}$, these measurements are performed using a different optical configuration, in which the sample holder is rotated by $90^{\circ}$ (Fig. 1b). In this configuration, the uncertainty in the angle is smaller, as the angle can be determined by measuring the laser beam over larger distances from the substrate. In this work, the laser beams hit the substrate at angles $5.8^{\circ} \pm 0.5^{\circ}$ and $50.0^{\circ} \pm 0.5^{\circ}$.

\subsection{Ice samples}

Under interstellar ice conditions, $\mathrm{CH}_{4}$ and $\mathrm{NH}_{3}$ are embedded in a $\mathrm{H}_{2} \mathrm{O}$ rich matrix, formed at very early stages of stellar evolution, still in the molecular cloud stage (Boogert et al. 2015; Linnartz et al. 2015; Fedoseev et al. 2015; Qasim et al. 2020). To simulate more realistic astronomical conditions, the studied ices are prepared by mixing methylamine with $\mathrm{H}_{2} \mathrm{O}, \mathrm{CH}_{4}$, and $\mathrm{NH}_{3}$, in binary, tertiary, and quaternary mixtures containing these molecules.

To analyze the effects of methylamine dilution on the IR spectral features, three different concentrations were prepared: $1: 5,1: 10$, and 1:20, which means that for each methylamine molecule in the ice sample, there are 5, 10, or 20 molecules of the other ice component(s). The deposition rates (and consequently the column densities) of the different species in the ices are derived by considering the weighted deposition rate of all the species in the gaseous mixture. Based on previous work (Terwisscha van Scheltinga et al. 2018), the uncertainty in this approach is estimated to amount to 10 percent for the accuracy with which a gas mixture can be prepared, and, upon deposition, another 10 percent uncertainty is added to account for changes in the deposition rate of the individual components. This results in propagated uncertainties of 14,17 and 20 percent in the column densities of the two, three, and four-component ices. For the uncertainty in the ratio between two species in the deposited ice, this number translates into values of 20,24 , and 28 percent, respectively. The IR spectra of all the ice samples are recorded from 15 to $160 \mathrm{~K}$. The desorption of matrix components during the ice heating changes the relative methylamine concentration in the sample, causing methylamine bands to appear stronger or
Table 1. Characteristics of the analyzed ice samples (composition, mixing ratios, methylamine column density, and temperature range).

\begin{tabular}{lccc}
\hline \hline Mixture & $\begin{array}{c}\text { Mixing } \\
\text { ratios }\end{array}$ & $\begin{array}{c}\mathrm{N}_{\mathrm{CH}_{3} \mathrm{NH}_{2}}\left(10^{17} \mathrm{~cm}^{-2}\right) \\
\text { range (K) }\end{array}$ & $\begin{array}{c}\text { Temperature } \\
\text { range }\end{array}$ \\
\hline $\mathrm{CH}_{3} \mathrm{NH}_{2}: \mathrm{H}_{2} \mathrm{O}$ & $1: 5$ & $4.5 \pm 0.6$ & $15-150$ \\
$\mathrm{CH}_{3} \mathrm{NH}_{2}: \mathrm{H}_{2} \mathrm{O}$ & $1: 10$ & $2.5 \pm 0.3$ & $15-150$ \\
$\mathrm{CH}_{3} \mathrm{NH}_{2}: \mathrm{H}_{2} \mathrm{O}$ & $1: 20$ & $1.3 \pm 0.2$ & $15-150$ \\
$\mathrm{CH}_{3} \mathrm{NH}_{2}: \mathrm{CH}_{4}$ & $1: 5$ & $3.7 \pm 0.5$ & $15-45$ \\
$\mathrm{CH}_{3} \mathrm{NH}_{2}: \mathrm{CH}_{4}$ & $1: 10$ & $2.0 \pm 0.3$ & $15-45$ \\
$\mathrm{CH}_{3} \mathrm{NH}_{2}: \mathrm{CH}_{4}$ & $1: 20$ & $1.0 \pm 0.1$ & $15-45$ \\
$\mathrm{CH}_{3} \mathrm{NH}_{2}: \mathrm{NH}_{3}$ & $1: 5$ & $4.4 \pm 0.6$ & $15-115$ \\
$\mathrm{CH}_{3} \mathrm{NH}_{2}: \mathrm{NH}_{3}$ & $1: 10$ & $2.4 \pm 0.3$ & $15-115$ \\
$\mathrm{CH}_{3} \mathrm{NH}_{2}: \mathrm{NH}_{3}$ & $1: 20$ & $1.3 \pm 0.2$ & $15-115$ \\
\hline $\mathrm{CH}_{3} \mathrm{NH}_{2}: \mathrm{H}_{2} \mathrm{O}: \mathrm{CH}_{4}$ & $1: 5: 5$ & $2.2 \pm 0.4$ & $15-150$ \\
$\mathrm{CH}_{3} \mathrm{NH}_{2}: \mathrm{H}_{2} \mathrm{O}: \mathrm{CH}_{4}$ & $1: 10: 10$ & $1.2 \pm 0.2$ & $15-150$ \\
$\mathrm{CH}_{3} \mathrm{NH}_{2}: \mathrm{H}_{2} \mathrm{O}: \mathrm{NH}_{3}$ & $1: 5: 5$ & $2.5 \pm 0.4$ & $15-150$ \\
$\mathrm{CH}_{3} \mathrm{NH}_{2}: \mathrm{H}_{2} \mathrm{O}: \mathrm{NH}_{3}$ & $1: 10: 10$ & $1.3 \pm 0.2$ & $15-150$ \\
$\mathrm{CH}_{3} \mathrm{NH}_{2}: \mathrm{CH}_{4}: \mathrm{NH}_{3}$ & $1: 5: 5$ & $2.2 \pm 0.4$ & $15-115$ \\
$\mathrm{CH}_{3} \mathrm{NH}_{2}: \mathrm{CH}_{4}: \mathrm{NH}_{3}$ & $1: 10: 10$ & $1.2 \pm 0.2$ & $15-115$ \\
\hline $\mathrm{CH}_{3} \mathrm{NH}_{2}: \mathrm{H}_{2} \mathrm{O}: \mathrm{CH}_{4}: \mathrm{NH}_{3}$ & $3: 10: 10: 10$ & $2.3 \pm 0.4$ & $15-150$ \\
\hline
\end{tabular}

Notes. For more information on the uncertainty of the ice mixtures, see Sect. 2.1.

have a different profile because of new intermolecular interactions in the ice. Due to these changes and the fact that we do not have precise information about the new mixing ratio, quantitative analyses of the methylamine bands are made until the majority of the ice matrix components have desorbed. The composition, ice mixing ratio, column density of methylamine in the ice, and temperature range of all studied samples are listed in Table 1.

\subsection{Band strength of the methylamine IR features}

As described previously, the refractive index of the pure methylamine ice can be derived through a double laser interference technique. A representative data obtained in this way is shown in Fig. 2. The procedure to obtain the periods of the generated signals ( $T_{0}$ and $T_{1}$ for Eq. (2)) and the position of the constructive interference for thickness measurements (Eq. (1)) are made using a personal Python script. The interference pattern is initially baseline corrected using a Savitzky-Golay filter, followed by the adjust of a sine function, whose periods are employed to calculate n (Eq. (2)). Other methods for deriving the period from an interference pattern consist of measuring the number of fringes in a large interval of time, averaging a large number of individual periods, or adjusting the signal using a multiparameter function containing polynomial terms and a periodic term modulated by an exponential decay. These methods yield refractive index values consistent with the method used in this work within their uncertainties. In this work, the refractive index for pure methylamine ices is measured at $15 \mathrm{~K}$ (amorphous) and at $123 \mathrm{~K}$ (crystalline), being these values $1.30 \pm 0.01$ and $1.40 \pm 0.01$, respectively. The later value was measured for calculating the molar refraction of methylamine, necessary for deriving the ice density thought the Lorentz-Lorenz relation, as described below.

A pure ice's column density (in molecules per $\mathrm{cm}^{2}$ ) as function of its thickness can be written as:

$N=\frac{d \rho N_{\mathrm{A}}}{M}$, 
Table 2. Calculated IR band strengths (A) of amorphous methylamine ice at $15 \mathrm{~K}$.

\begin{tabular}{cccc}
\hline \hline $\begin{array}{c}\text { Peak position } \\
\left(\mathrm{cm}^{-1}\right)\end{array}$ & $\begin{array}{c}\text { Integrated region } \\
\left(\mathrm{cm}^{-1}\right)\end{array}$ & Assignment & $\begin{array}{c}A \\
\left(10^{-18} \mathrm{~cm} \mathrm{molec}^{-1}\right)\end{array}$ \\
\hline 2881.3 & $2893-2870$ & $\mathrm{CH}_{3}$ antisymmetric stretch & $2.6 \pm 0.5$ \\
2791.8 & $2825-2765$ & $\mathrm{CH}_{3}$ symmetric stretch & $3.8 \pm 0.6$ \\
1478.6 & $1500-1467$ & $\mathrm{CH}_{3}$ antisymmetric def. & $1.1 \pm 0.2$ \\
1455.0 & $1467-1440$ & $\mathrm{CH}_{3}$ antisymmetric def. & $0.7 \pm 0.1$ \\
1420.3 & $1432-1407$ & $\mathrm{CH}_{3}$ symmetric def. & $0.20 \pm 0.03$ \\
1159.2 & $1215-1130$ & $\mathrm{CH}_{3}$ rock & $1.5 \pm 0.2$ \\
\hline
\end{tabular}

where $d$ is the sample thickness (in $\mathrm{cm}$ ), $\rho$ is the mass density (in $\mathrm{g} \mathrm{cm}^{-3}$ ), $N_{\mathrm{A}}$ is the Avogadro's number, and $M$ is the ice component's molar mass (in $\mathrm{g} \mathrm{mol}^{-1}$ ). Using Eq. (3) and the Lambert-Beer law, the band strength (A) of a given IR feature is given by (Yamada \& Person 1964):

$A=\frac{2.3 M}{\rho d N_{A}} \int_{v} \operatorname{abs}_{v} \mathrm{~d} v$,

where $A$ is given in $\mathrm{cm}$ molecule ${ }^{-1}$, and $\int_{\nu} a b s_{\nu} \mathrm{d} v$ is the integrated absorbance of the band (i.e., the band area).

The pure methylamine band strength measurements are performed by growing relatively thin ices (typically 2-4 fringes in the interference pattern) and recording spectra at $1.0 \mathrm{~cm}^{-1}$ resolution. The ice thickness and area of the IR bands are monitored simultaneously, and a linear adjustment of the thickness $\times$ time and band area $\times$ time yields good linear relations $\left(R^{2}\right.$ bigger than 0.98). By using the slope of such linear relations and Eq. (4), the band strength of a given feature can be calculated as:

$A=\frac{2.3 M \alpha}{\rho N_{\mathrm{A}} \beta}$

where $\alpha$ is the variation of integrated band absorbance (band area) in time, and $\beta$ is the variation of ice thickness in time. In the derivation of the pure ice band strengths, the methylamine mass density ( $\rho$ in Eq. (5)) is the main source of uncertainty. To the best of our knowledge, the density of amorphous methylamine ice has not been reported in the literature, only the value for orthorhombic $\mathrm{CH}_{3} \mathrm{NH}_{2}$ at $123 \mathrm{~K}$ is available (Atoji \& Lipscomb 1953). The methylamine density at $15 \mathrm{~K}$ can be estimated using the Lorentz-Lorenz relation in a molar version:

$R_{\mathrm{M}}=\frac{M}{\rho}\left(\frac{n^{2}-1}{n^{2}+2}\right)$

where $R_{\mathrm{M}}, M, \rho$, and $\mathrm{n}$ are respectively the molar refraction, the molar mass, the mass density, and the refractive index of the molecule under analysis. The molar refraction can be estimated from the individual chemical bonds' molar refraction (Denbigh 1940; Hudson et al. 2020) or from Eq. (6) using the density and refractive index for crystalline methylamine at $123 \mathrm{~K}$. Following the second approach, Eq. (6) yields $R_{\mathrm{M}}=8.86 \mathrm{~cm}^{3} \mathrm{~mol}^{-1}$ when $n=1.40 \pm 0.01$ and $\rho=0.85 \mathrm{~g} \mathrm{~cm}^{-3}$ (from Atoji \& Lipscomb 1953) are employed. Using this molar refraction value, a pure amorphous methylamine density of $0.66 \mathrm{~cm}^{-3}$ is obtained. This density is used in Eq. (5) for deriving methylamine band strengths, and in the case that a more accurate measurement of the amorphous methylamine density becomes available, the bands strengths derived here can be re-scaled. Table 2 shows the calculated methylamine band strengths and the wavelength region that is used for the calculation of the band areas. All the spectra are baseline corrected before area calculations.

\subsection{Relative band strengths}

The light absorption profile of a molecule changes depending on the chemical environment surrounding the species. This is well known from studies analyzing the IR band profiles of molecules in different liquid or solid mixtures. Once the band profile changes, the IR apparent band strengths may change significantly. For a better quantification of methylamine in astrophysical ice analogs, the relative band strengths are calculated. In this work, the relative band strength $(\eta)$ is the ratio between the apparent band strength of a given band when embedded in an ice mixture and the corresponding band strength in the pure ice:

$\eta=\frac{A^{\prime}}{A}$

where $A^{\prime}$ is the apparent band strength for a band in a given mixture and $\mathrm{A}$ is the band strength of the same band in pure methylamine ice at $15 \mathrm{~K}$. The apparent band strength values and their uncertainties for the methylamine bands are graphically displayed in Appendix A.

\section{Results and discussion}

This section presents a set of representative mid-IR spectra of the methylamine-containing ices analyzed in this work. Changes in the IR absorbance profile of pure methylamine and mixed ices are described, and some ideas concerning the origins of these changes are pointed out. The complete data set is available from the Appendices. In Appendix A, spectra showing the selected methylamine bands in ice mixtures are presented for selected temperatures. The FWHM values versus peak positions are graphically shown for different ice mixtures and temperatures. The relative band strength values (see Eq. (7)) for different matrices are also given. The peak positions and FWHMs of the selected bands are organized in Tables B1-B15, and the integrated absorbance of the methylamine in different ice mixtures is listed in Tables C1-C15 (see notes in Appendices B and $\mathrm{C}$ ).

This section is organized as follows: firstly, the overall spectra of methylamine ice in amorphous $(15 \mathrm{~K})$ and crystalline (101 K) form are presented. According to data found in the literature, the infrared features are assigned to the corresponding vibrational modes, and the most prominent features in the spectra 


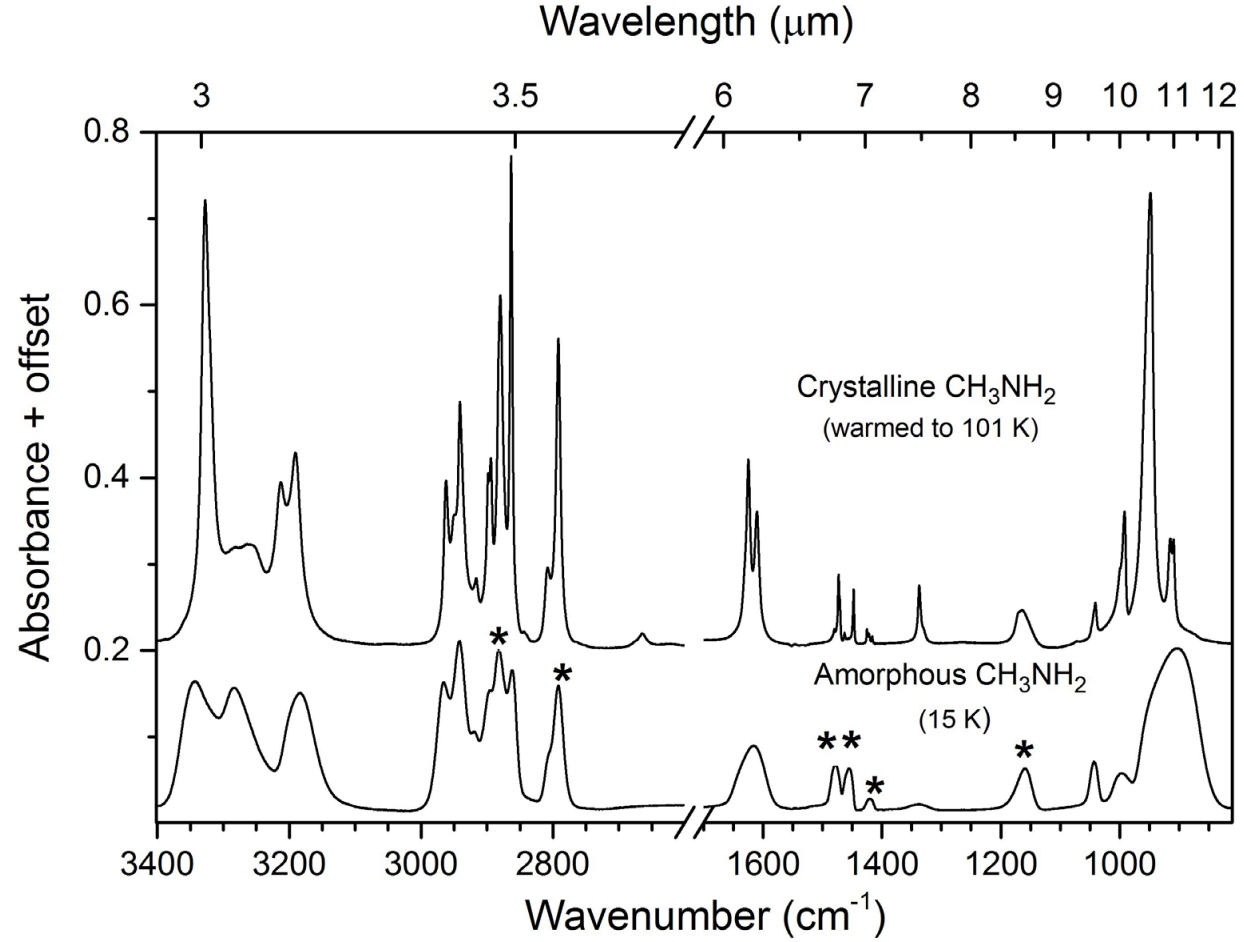

Fig. 3. Infrared spectra of amorphous (bottom spectrum) and crystalline (top spectrum) methylamine ice acquired with resolution of $0.5 \mathrm{~cm}^{-1}$ in the range from 3400 $850 \mathrm{~cm}^{-1}$. The methylamine peaks chosen for in-depth characterization are marked with an asterisk. are described. In the next subsections, profiles of specific methylamine bands are analyzed. These infrared features are selected based on a minimal overlap with bands of abundant molecules detected in water-rich interstellar ices (i.e., $\mathrm{CO}_{2}, \mathrm{CH}_{4}$, and $\mathrm{NH}_{3}$ ).

The actual composition of interstellar ices is far more complex than the mixtures presented here. Also, infrared astronomical data exhibit absorption features from the dust material. Thereby, methylamine features may be hidden by absorption of species other than $\mathrm{H}_{2} \mathrm{O}, \mathrm{NH}_{3}$, and $\mathrm{CH}_{4}$, in particular molecules with similar functional groups. In order to maintain our analysis feasible, only a few other typically more abundant species, such as methanol, are explicitly taken into account.

\subsection{Pure methylamine ice}

Figure 3 shows the spectra of methylamine ice deposited at $15 \mathrm{~K}$ (amorphous) and heated to $101 \mathrm{~K}$ (crystalline). The pure $\mathrm{CH}_{3} \mathrm{NH}_{2}$ ice crystallizes around $100 \mathrm{~K}$, and upon heating, this phase transition is spotted by the abrupt sharpening and splitting of the IR absorption bands. These changes are the result of a more organized ice structure, which reduces the diversity of molecular orientations. Table 3 lists the peak positions for amorphous $(15 \mathrm{~K})$ and crystalline $(101 \mathrm{~K})$ methylamine ice measured in this work, along with their tentative assignments (based on the work of Durig \& Zheng 2001) and literature values for methylamine ices.

The $3000-2750 \mathrm{~cm}^{-1}$ region contains the methylamine ice features assigned to the $\mathrm{CH}_{3}$ stretch mode and overtones of the $\mathrm{CH}_{3}$ deformation modes. In pure methylamine, the bands in this region are strong, including the overtone modes, whose intensities are enhanced due to Fermi resonance (Durig et al. 1968; Wolff 1970; Lavalley \& Sheppard 1972).

The peaks at 1455.0 and $1478.6 \mathrm{~cm}^{-1}$ are assigned to the $\mathrm{CH}_{3}$ antisymmetric deformation mode. By warming up the ices, the peak positions do not change significantly until the ice crystallizes. Upon the phase transition, both peaks narrow abruptly: the FWHM changes from 16.8 and $13.8 \mathrm{~cm}^{-1}$ at $15 \mathrm{~K}$ to 4.7 and $2.7 \mathrm{~cm}^{-1}$ at $100 \mathrm{~K}$ for the 1478.6 and $1455.0 \mathrm{~cm}^{-1}$ features, respectively (see Fig. 3 and Table B.7).

In pure methylamine ice, the symmetric deformation of the $\mathrm{CH}_{3}$ group appears as a single feature at $1420.3 \mathrm{~cm}^{-1}$ (Fig. 3). As the temperature increases, the peak position and FWHM do not change significantly at temperatures lower than $100 \mathrm{~K}$. At $100 \mathrm{~K}$, the sample crystallizes, and an abrupt narrowing and shift to lower wavenumbers are observed. The narrowing of the $\mathrm{CH}_{3}$ symmetric deformation band peaks reveals three features, at $1416.5,1422.0$, and $1425.4 \mathrm{~cm}^{-1}$, with the former feature being the strongest one.

The feature assigned to the methylamine $\mathrm{CH}_{3}$ rock vibrational mode appears at $1159.2 \mathrm{~cm}^{-1}$ in pure methylamine at $15 \mathrm{~K}$ and shifts to higher wavenumbers when the ice is heated, peaking at $1164 \mathrm{~cm}^{-1}$ at $100 \mathrm{~K}$. The warming of the pure ice causes a slight narrowing of this peak, changing the FWHM from 28.4 at 15 to $26.2 \mathrm{~cm}^{-1}$ at $100 \mathrm{~K}$. Unlike other methylamine bands, no strong and abrupt sharpening and increase in intensity are observed upon crystallization.

Methylamine presents a strong feature at $903.5 \mathrm{~cm}^{-1}$ assigned to the $v_{9}$ mode. Upon crystallization, this feature sharpens and is one of the most strong features in the methylamine spectrum. Despite being a strong feature, this peak is not characterized throughout this work, since it overlaps with the broad libration mode of $\mathrm{H}_{2} \mathrm{O}$ ice (around $760 \mathrm{~cm}^{-1}$ ), being not easy to disentangle in a complex ice mixture. Since the goal of this work is characterizing features that present less overlapping with such abundant ice components, the band at $903.5 \mathrm{~cm}^{-1}$ was not chosen for a more in-depth investigation.

In the upcoming sections, we describe the morphology of methylamine features in pure and mixed ices in more detail. The features selected for in-depth investigation are the $\mathrm{CH}_{3}$ rock mode around $1159 \mathrm{~cm}^{-1}$, the $\mathrm{CH}_{3}$ symmetric deformation around $1420 \mathrm{~cm}^{-1}$, the $\mathrm{CH}_{3}$ antisymmetric deformation modes that give 
M. G. Rachid et al.: Infrared spectra of complex organic molecules in astronomically relevant ice mixtures. IV.

Table 3. Vibrational modes of pure methylamine ice.

\begin{tabular}{|c|c|c|c|c|c|}
\hline Mode & Assignment & $\begin{array}{c}\text { Amorphous }^{(a)} \\
15 \mathrm{~K}\end{array}$ & $\begin{array}{c}\text { Crystalline }^{(a)} \\
101 \mathrm{~K}\end{array}$ & $\begin{array}{l}\text { Solid }^{(b)} \\
10 \mathrm{~K}\end{array}$ & $\begin{array}{c}\text { Solid }^{(c)} \\
120 \mathrm{~K} \\
\end{array}$ \\
\hline$v_{10}$ & $\mathrm{NH}_{2}$ antisymmetric stretch & 3342.8 & 3327.6 & 3348 & 3332 \\
\hline \multirow[t]{4}{*}{$v_{1}$} & $\mathrm{NH}_{2}$ symmetric stretch & 3283.4 & & 3287 & 3260 \\
\hline & & 3183.2 & 3212.8 & 3189 & 3191 \\
\hline & & & 3190.6 & & \\
\hline & & 2965.3 & 2962.4 & 2969 & \\
\hline \multirow[t]{3}{*}{$v_{11}$} & $\mathrm{CH}_{3}$ antisymmetric stretch & 2941.9 & 2941.1 & 2945 & 2942 \\
\hline & & 2896 & 2898.2 & 2899 & \\
\hline & & & 2894.1 & & \\
\hline \multirow[t]{2}{*}{$v_{2}$} & $\mathrm{CH}_{3}$ antisymmetric stretch & 2881.3 & 2879.9 & 2884 & 2881 \\
\hline & & 2862.1 & 2863.3 & 2865 & \\
\hline$v_{3}$ & $\mathrm{CH}_{3}$ symmetric stretch & 2791.8 & 2791.9 & 2794 & 2793 \\
\hline \multirow[t]{2}{*}{$v_{4}$} & $\mathrm{NH}_{2}$ def. & 1616.1 & 1625.0 & 1618 & 1651 \\
\hline & & & 1472.8 & & \\
\hline \multirow[t]{2}{*}{$v_{12}$} & $\mathrm{CH}_{3}$ antisymmetric def. & 1478.6 & 1480.1 & 1479 & 1500 \\
\hline & & & 1610.5 & & \\
\hline \multirow[t]{2}{*}{$v_{5}$} & $\mathrm{CH}_{3}$ antisymmetric def. & 1455.0 & 1447.8 & & \\
\hline & & & 1463.0 & & \\
\hline \multirow[t]{3}{*}{$v_{6}$} & $\mathrm{CH}_{3}$ symmetric def. & 1420.3 & 1425.4 & 1421 & 1441 \\
\hline & & & 1422.0 & & \\
\hline & & & 1416.5 & & \\
\hline \multirow{2}{*}{$\begin{array}{l}v_{13} \\
v_{7}\end{array}$} & $\mathrm{CH}_{3}$ rock/ $\mathrm{NH}_{2}$ twist & 1339.1 & 1337.4 & 1339 & 1353 \\
\hline & $\mathrm{CH}_{3}$ rock & 1159.2 & 1164.3 & 1161 & 1182 \\
\hline$v_{8}$ & $\mathrm{CN}$ stretch & 1043.3 & 1040.9 & 1045 & 1048 \\
\hline$v_{14}$ & $\mathrm{CH}_{3}$ rock $/ \mathrm{NH}_{2}$ & 996.8 & 991.7 & 997 & 1005 \\
\hline \multirow[t]{3}{*}{$v_{9}$} & $\mathrm{NH}_{2}$ wag & 903.5 & 948.1 & 931 & 955 \\
\hline & & & 914.8 & & \\
\hline & & & 909.5 & & \\
\hline
\end{tabular}

References. ${ }^{(a)}$ This work, ${ }^{(b)}$ Oba et al. (2014), ${ }^{(c)}$ Durig et al. (1968).

rise to the bands around 1455.0 and $1478.6 \mathrm{~cm}^{-1}$, the $\mathrm{CH}_{3}$ symmetric stretch band, around $2791.8 \mathrm{~cm}^{-1}$, and the $\mathrm{CH}_{3}$ antisymmetric stretch band, around $2881.3 \mathrm{~cm}^{-1}$. These six peaks are labeled with an asterisk in Fig. 3.

\subsection{Mixed methylamine ices}

\subsection{1. $\mathrm{CH}_{3}$ rock $-1159.2 \mathrm{~cm}^{-1}$}

In the binary $\mathrm{CH}_{3} \mathrm{NH}_{2}: \mathrm{H}_{2} \mathrm{O}$ ice mixtures, the band due to the $\mathrm{CH}_{3}$ rock vibrational modes shifts toward higher wavenumbers, peaking at 1176.8, 1177.5, and $1178.3 \mathrm{~cm}^{-1}$ in the 1:5, 1:10, and 1:20 mixtures, respectively (see Tables B.1, B.2, B.3, and Figs. 4, A.1, and A.2). By warming the $\mathrm{CH}_{3} \mathrm{NH}_{2}: \mathrm{H}_{2} \mathrm{O}$ mixtures, this methylamine band narrows by $1-3 \mathrm{~cm}^{-1}$. In the binary mixtures with $\mathrm{CH}_{4}$, the peak shifts to lower wavenumbers with an increasing $\mathrm{CH}_{4}$ ratio. However, upon heating of the $\mathrm{CH}_{3} \mathrm{NH}_{2}: \mathrm{CH}_{4}$ mixtures, the peak position shifts to higher wavenumbers, and the FWHM increases. These shifts can be due to rearrangements inside the ice and hydrogen bonds forming between methylamine molecules. In the $\mathrm{CH}_{3} \mathrm{NH}_{2}: \mathrm{CH}_{4}(1: 20)$ ice, this feature is visible but it is too weak for quantitative analysis (Fig. A.2).

In the $\mathrm{NH}_{3}$-containing samples, the methylamine $\mathrm{CH}_{3}$ rock band overlaps with the strong feature of the ammonia umbrella vibration (around $1070 \mathrm{~cm}^{-1}$ ), appearing as a weak shoulder in the ammonia feature (see Figs. 4, A.1-A.4 - in some of the panels, the position of the shoulder, when visible, is marked with a dashed vertical line). This band can be observed as a shoulder in binary mixtures with a ratio $1: 5$, some of the $1: 10$ mixtures (including the $\mathrm{CH}_{3} \mathrm{NH}_{2}: \mathrm{H}_{2} \mathrm{O}: \mathrm{CH}_{4}: \mathrm{NH}_{3}(3: 10: 10: 10)$ ) but is almost absent in the 1:20 mixtures. The shoulder becomes more prominent at higher temperatures due to the narrowing of the ammonia band.

\subsection{2. $\mathrm{CH}_{3}$ symmetric deformation $-1420.3 \mathrm{~cm}^{-1}$}

In all the mixed ices, the $\mathrm{CH}_{3}$ symmetric deformation band appears at higher wavenumbers when compared to pure methylamine ice, shifted by around $5 \mathrm{~cm}^{-1}$ (see Tables B.4-B.6 and the rightmost feature in the panels of Figs. 5, A.5-A.8). The more substantial shifts are observed for the $\mathrm{H}_{2} \mathrm{O}$ containing mixtures, for which this feature appears between 1424 and $1425 \mathrm{~cm}^{-1}$. In all the ice samples, this band does not overlap with any bands from $\mathrm{H}_{2} \mathrm{O}, \mathrm{CH}_{4}$, and $\mathrm{NH}_{3}$. Also, this feature is distinguishable in all the samples with exception of the $\mathrm{CH}_{3} \mathrm{NH}_{2}: \mathrm{CH}_{4}(1: 20)$ ice, where it appears as a weak feature.

The peak intensity of the $\mathrm{CH}_{3}$ symmetric deformation is enhanced in the water-containing mixtures. From Figs. 5, A.5, and A.6, it is possible to notice that the peak height of this feature in the $\mathrm{H}_{2} \mathrm{O}$-containing matrices is comparable to the intensity of the $\mathrm{CH}_{3}$ antisymmetric deformation features, located at 1455.0 and $1478.6 \mathrm{~cm}^{-1}$. In the mixtures without water and the pure methylamine ice, the peak height of the $\mathrm{CH}_{3}$ symmetric deformation is less than half of the intensity of the $\mathrm{CH}_{3}$ antisymmetric 
a)

Wavelength $(\mu \mathrm{m})$

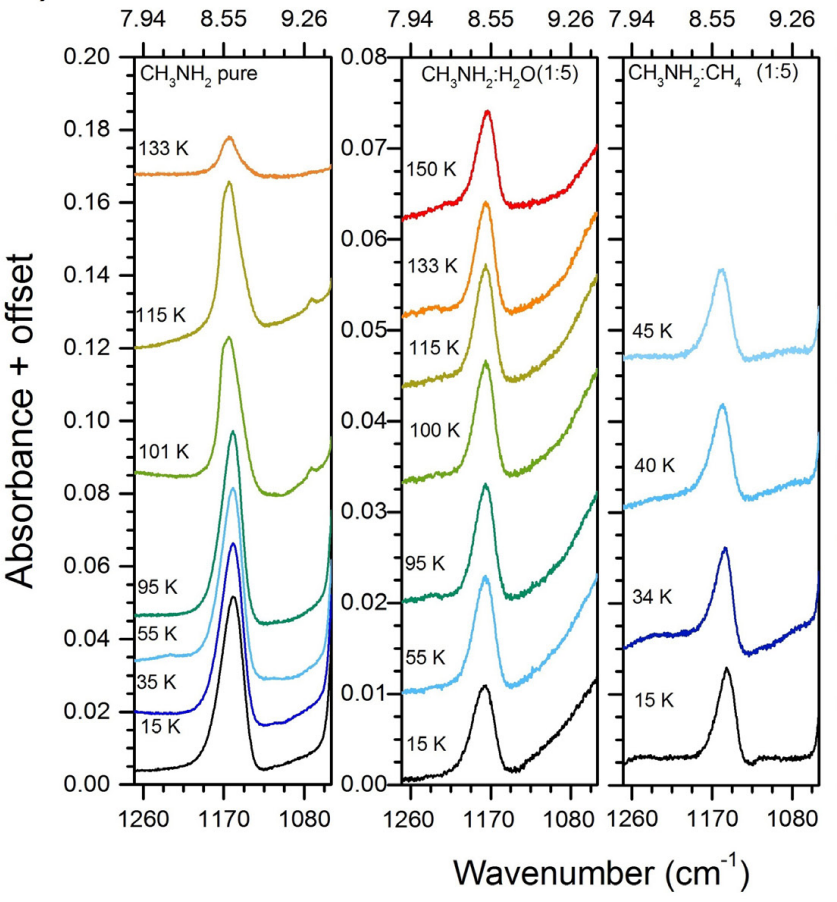

$\begin{array}{lll}7.94 & 8.55 \quad 9.26\end{array}$

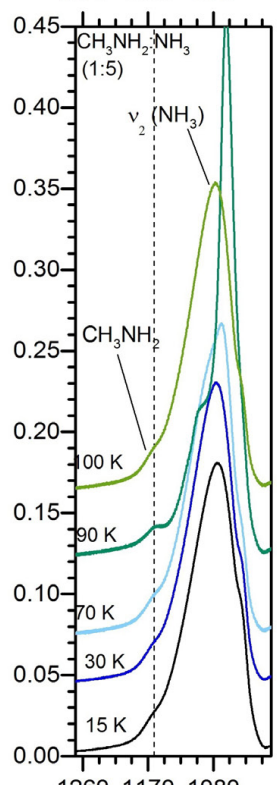

b)

\section{Wavelength $(\mu \mathrm{m})$}

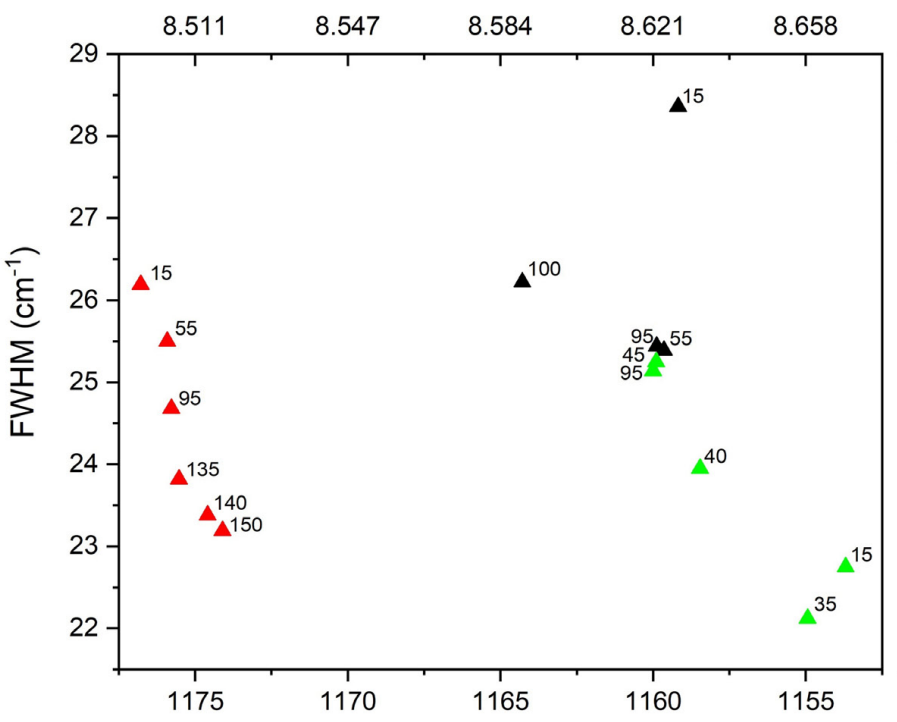

Wavenumber $\left(\mathrm{cm}^{-1}\right)$
A Pure methylamine

$\Delta$ Methylamine: $\mathrm{CH}_{4}(1: 5)$

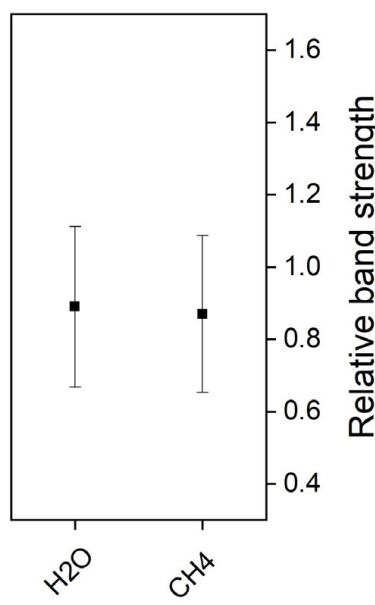

Fig. 4. (a) Infrared profile of the $\mathrm{CH}_{3}$ rock vibrational mode of $\mathrm{CH}_{3} \mathrm{NH}_{2}$, around $1159 \mathrm{~cm}^{-1}$, in different ices, from left to right: pure $\mathrm{CH}_{3} \mathrm{NH}_{2}, \quad \mathrm{CH}_{3} \mathrm{NH}_{2}$ : $\mathrm{H}_{2} \mathrm{O}(1: 5), \quad \mathrm{CH}_{3} \mathrm{NH}_{2}: \mathrm{CH}_{4}(1: 5), \quad$ and $\mathrm{CH}_{3} \mathrm{NH}_{2}: \mathrm{NH}_{3}(1: 5)$. The first and the last panels are displayed at a different $Y$-scale. In the last panel the $\mathrm{CH}_{3} \mathrm{NH}_{2}$ feature (whose position is indicated by the dashed line) appears as a shoulder in the ammonia $v_{2}$ band (umbrella mode). (b) Left panel: peak position vs. FWHM for the $\mathrm{CH}_{3}$ rock band in the ice mixtures displayed in $a$. Different mixtures are indicated by different colors, and the ice temperatures are marked in the graph. Right panel: relative band strength of the $\mathrm{CH}_{3}$ rock vibrational mode in different ice mixtures at $15 \mathrm{~K}$.

deformation features. The enhancing in strength is also noticed in the apparent band strength of this feature, that is around three times higher in $\mathrm{CH}_{3} \mathrm{NH}_{2}: \mathrm{H}_{2} \mathrm{O}$ ice mixtures when compared to the values for pure methylamine ice (see panels displaying the relative band strengths in Figs. 5c, A.5c, and A.6c).

\subsection{3. $\mathrm{CH}_{3}$ antisymmetric deformation -1455.0 and $1478.6 \mathrm{~cm}^{-1}$}

In the ice mixtures, the feature at $1455 \mathrm{~cm}^{-1}$ peaks at higher wavenumbers when compared to the pure methylamine ice, being the most significant shift observed in the water-containing mixtures, in which it peaks between $1462-1464 \mathrm{~cm}^{-1}$ (Tables B.7-B.9 and the two peaks at higher wavenumbers on the panels of Figs. 5, A.5-A.8). By warming the ice mixtures, this peak position does not shift appreciably, but some notable trends in the binary mixtures are observed. With increasing temperature, the peak around $1455 \mathrm{~cm}^{-1}$ narrows in a water environment but becomes broader in $\mathrm{CH}_{4}$ and $\mathrm{NH}_{3}$ matrices. In the water-containing three-component ices and in the fourcomponent ice, a decrease of FWHM is observed, following the trend for the $\mathrm{CH}_{3} \mathrm{NH}_{2}: \mathrm{H}_{2} \mathrm{O}$ ices (see Tables B.7-B.9).

The peak at $1478.6 \mathrm{~cm}^{-1}$, also assigned to the $\mathrm{CH}_{3}$ antisymmetric deformation mode, behaves differently from the peak 
M. G. Rachid et al.: Infrared spectra of complex organic molecules in astronomically relevant ice mixtures. IV.
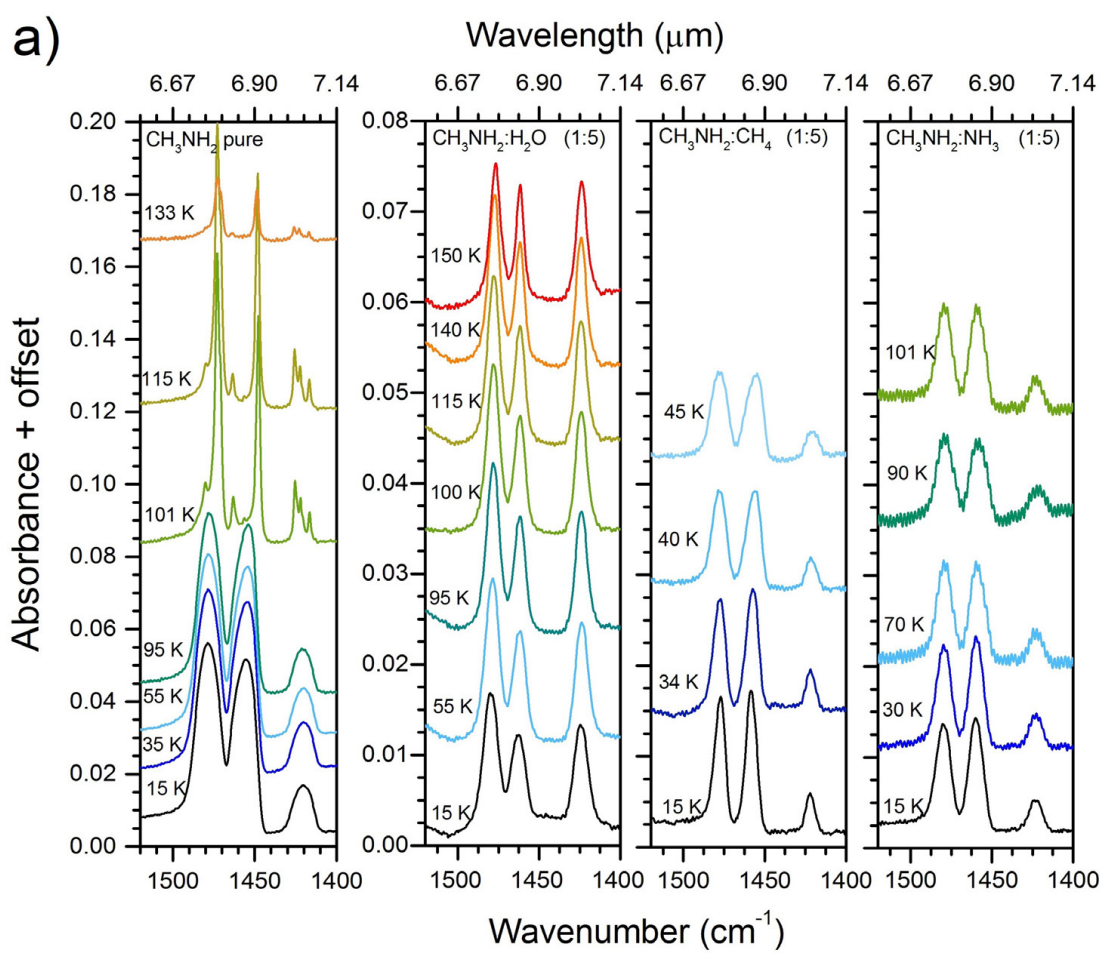

b)

Wavelength $(\mu \mathrm{m})$

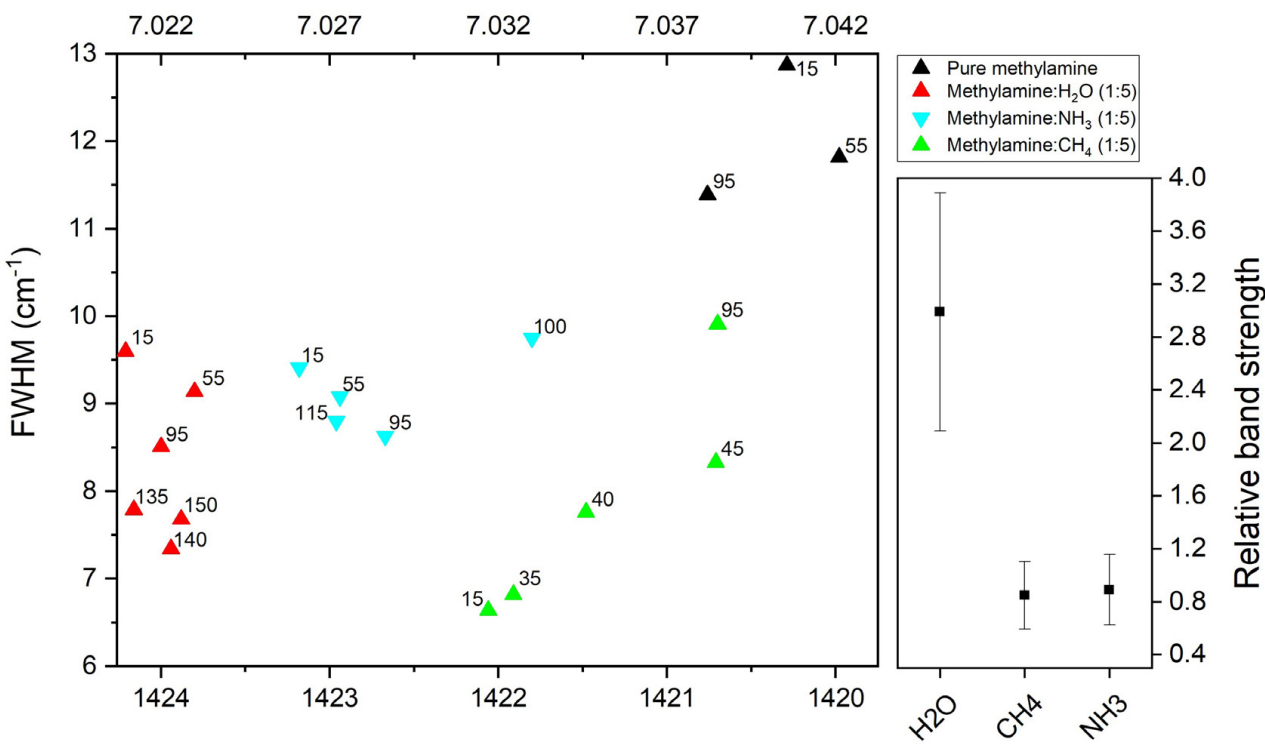

Fig. 5. (a) Infrared profile of the $\mathrm{CH}_{3}$ antisymmetric deformation mode of $\mathrm{CH}_{3} \mathrm{NH}_{2}$ (the peaks around $1478.6 \mathrm{~cm}^{-1}$ and $1455.0 \mathrm{~cm}^{-1}$ ) and the $\mathrm{CH}_{3}$ symmetric deformation mode (around $1420 \mathrm{~cm}^{-1}$ ), in different ices, from left to right: pure $\mathrm{CH}_{3} \mathrm{NH}_{2}, \quad \mathrm{CH}_{3} \mathrm{NH}_{2}: \mathrm{H}_{2} \mathrm{O}(1: 5)$, $\mathrm{CH}_{3} \mathrm{NH}_{2}: \mathrm{CH}_{4}(1: 5)$, and $\mathrm{CH}_{3} \mathrm{NH}_{2}$ : $\mathrm{NH}_{3}(1: 5)$. (b) Left panel: peak position vs. FWHM for the $\mathrm{CH}_{3}$ symmetric deformation band $\left(1420 \mathrm{~cm}^{-1}\right)$ in the ice mixtures displayed in $a$. Different mixtures are indicated by different colors, and the ice temperatures are marked in the graph. Right panel: relative band strength of the $\mathrm{CH}_{3}$ symmetric deformation band $\left(1420 \mathrm{~cm}^{-1}\right)$ in different ice mixtures at $15 \mathrm{~K}$. Panels $c$ and $d$ : same as $b$ for the $\mathrm{CH}_{3}$ antisymmetric deformation modes, $v_{5}$ and $v_{12}$, at 1455 and $1478.6 \mathrm{~cm}^{-1}$, respectively.

at $1455 \mathrm{~cm}^{-1}$. In the two-component ices, this peak appears at higher wavenumbers in the $\mathrm{H}_{2} \mathrm{O}$ and $\mathrm{NH}_{3}$ matrices and lower wavenumbers in the $\mathrm{CH}_{4}$ matrices (Tables B.7-B.9). In all the ice mixtures at $15 \mathrm{~K}$, this feature shifts by a maximum of $2 \mathrm{~cm}^{-1}$ from the position in the pure methylamine ice. Upon heating, this peak slightly narrows and shifts toward low wavenumbers in $\mathrm{H}_{2} \mathrm{O}$ and $\mathrm{NH}_{3}$ and becomes broader and shifts toward higher wavenumbers in $\mathrm{CH}_{4}$. The broadening in the $\mathrm{CH}_{4}$ matrix is probably due to the re-establishment of methylaminemethylamine interactions and is more pronounced when

$\mathrm{CH}_{4}$ starts to desorb. In the 3 and 4 component mixtures, the changes in FWHM are not very pronounced, changing less than $2 \mathrm{~cm}^{-1}$ for all the mixtures with exception of the $\mathrm{CH}_{3} \mathrm{NH}_{2}: \mathrm{CH}_{4}: \mathrm{NH}_{3}$ ices.

Finally, the peak position, FWHM, and intensity of both features assigned to $\mathrm{CH}_{3}$ antisymmetric deformation do not change dramatically after ice matrix crystallization compared to other methylamine bands. These peaks are also detectable even in the most diluted mixtures, offering perspective for use as a methylamine tracer. 


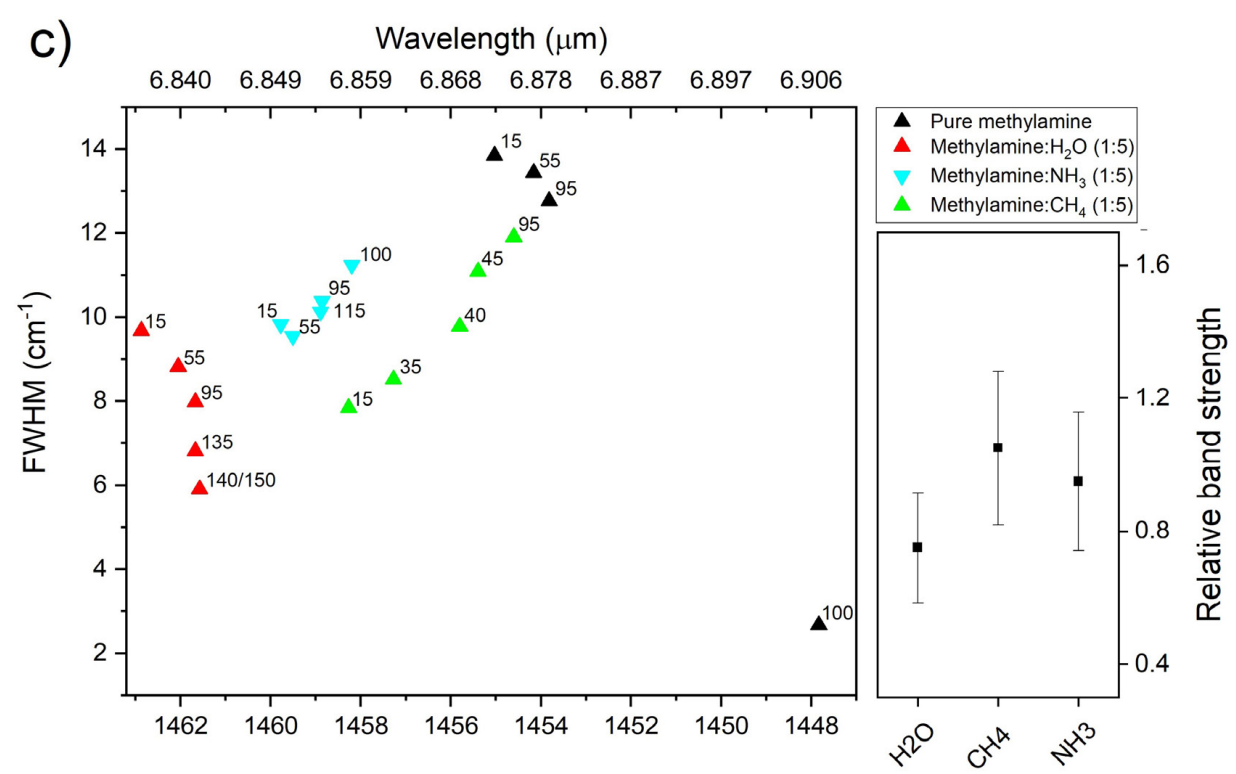

Wavenumber $\left(\mathrm{cm}^{-1}\right)$

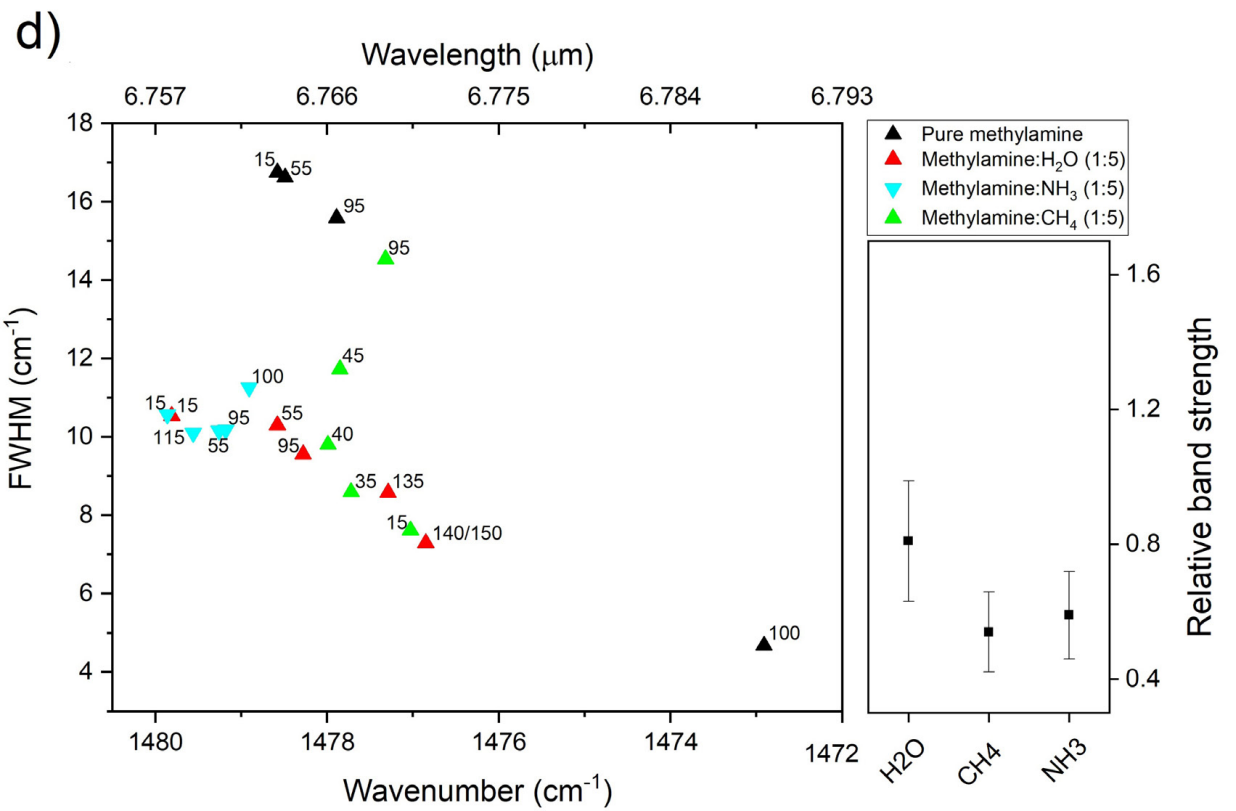

Fig. 5. continued.

\subsubsection{The $3000-2700 \mathrm{~cm}^{-1}$ region}

As previously shown, the IR spectrum of pure methylamine ice shows strong bands in the $3000-2700 \mathrm{~cm}^{-1}$ region (Fig. 3). As can be seen in the spectra of 1:5 mixtures of methylamine with $\mathrm{H}_{2} \mathrm{O}, \mathrm{CH}_{4}$, and $\mathrm{NH}_{3}$ (Fig. 6), bands in this region are blended, but some of the stronger features can be identified. The stretching modes and the overtones of deformation modes in this region have a similar profile as in most of the $\mathrm{CH}_{3}$-bearing molecules, making it very difficult to look for particularities of the methylamine molecule. Figures 6, A.9-A.12 show the spectra in the $3000-2750 \mathrm{~cm}^{-1}$ region for all analyzed ice mixtures. The features that are chosen for characterization in this region are the $\mathrm{CH}_{3}$ antisymmetric stretch $\left(2881.3 \mathrm{~cm}^{-1}\right)$ and $\mathrm{CH}_{3}$ symmetric stretch $\left(2791.8 \mathrm{~cm}^{-1}\right)$ bands. The peak position and FWHM for these bands are measured and presented in Appendix B (Tables B10-B15).
In pure amorphous methylamine ice, the $\mathrm{CH}_{3}$ symmetric stretch, around $2791.8 \mathrm{~cm}^{-1}$, seems to have two overlapping components. In all the ice mixtures, the two components appear as two separate features (see Fig. 6). The component at higher wavenumbers occurs at the same position as the $v_{2}+v_{4}$ combination mode of methane (around $2815 \mathrm{~cm}^{-1}$ ), being difficult to separate (Fig. A.11 and A.12). The component at lower wavenumbers (around $2796 \mathrm{~cm}^{-1}$ ) is visible in all ice spectra, although it appears as a weaker feature in the $\mathrm{H}_{2} \mathrm{O}$ matrix.

In $\mathrm{H}_{2} \mathrm{O}$-containing ices, methylamine features in the 3000 $2750 \mathrm{~cm}^{-1}$ region have an overall different profile compared to similar features in noncontaining $\mathrm{H}_{2} \mathrm{O}$ matrices. This seems to be particular for the $\mathrm{CH}_{3}$ vibrational modes, since such changes are not observed for the other vibrational modes. In $\mathrm{CH}_{3} \mathrm{NH}_{2}: \mathrm{H}_{2} \mathrm{O}$ ices, the strongest peak in this region is due to a $\mathrm{CH}_{3}$ antisymmetric stretch band located at $2898 \mathrm{~cm}^{-1}$. This feature is visible in all the mixtures, and in matrices containing 

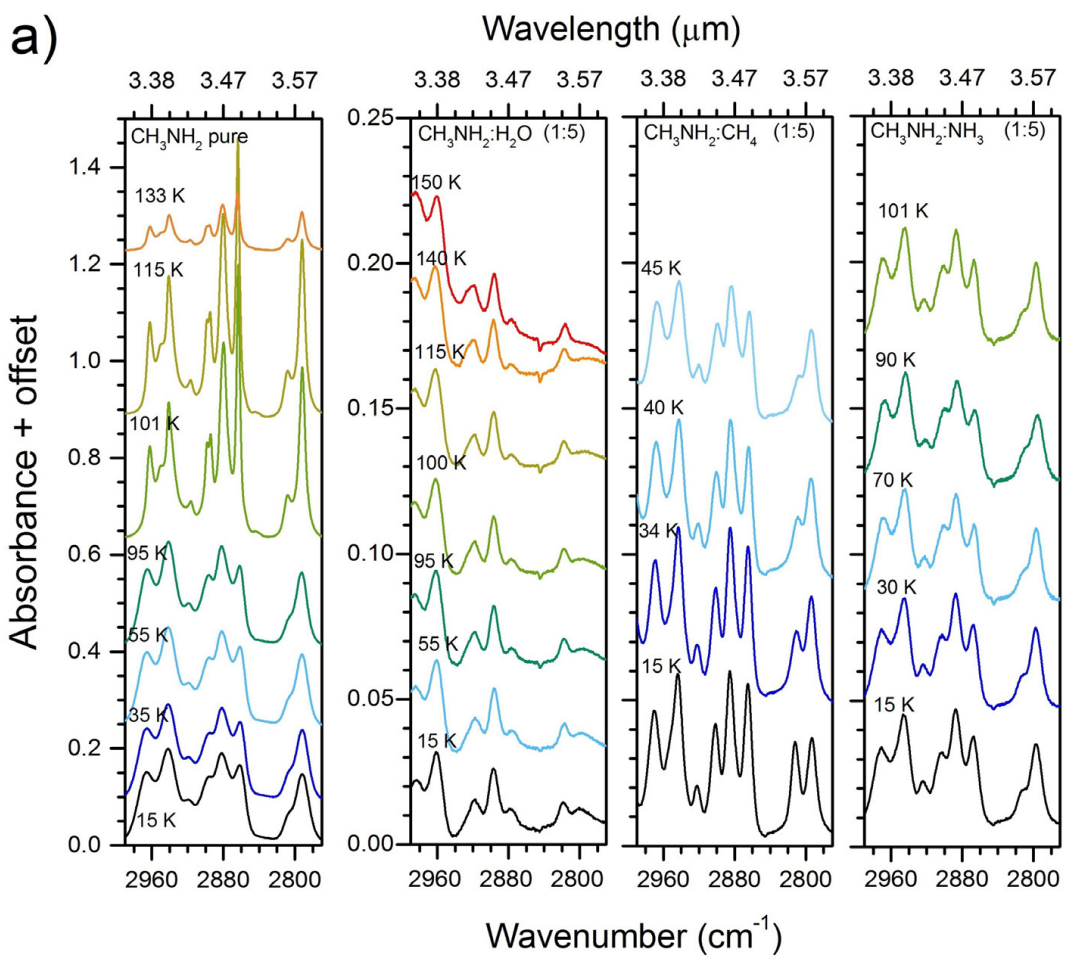

b)

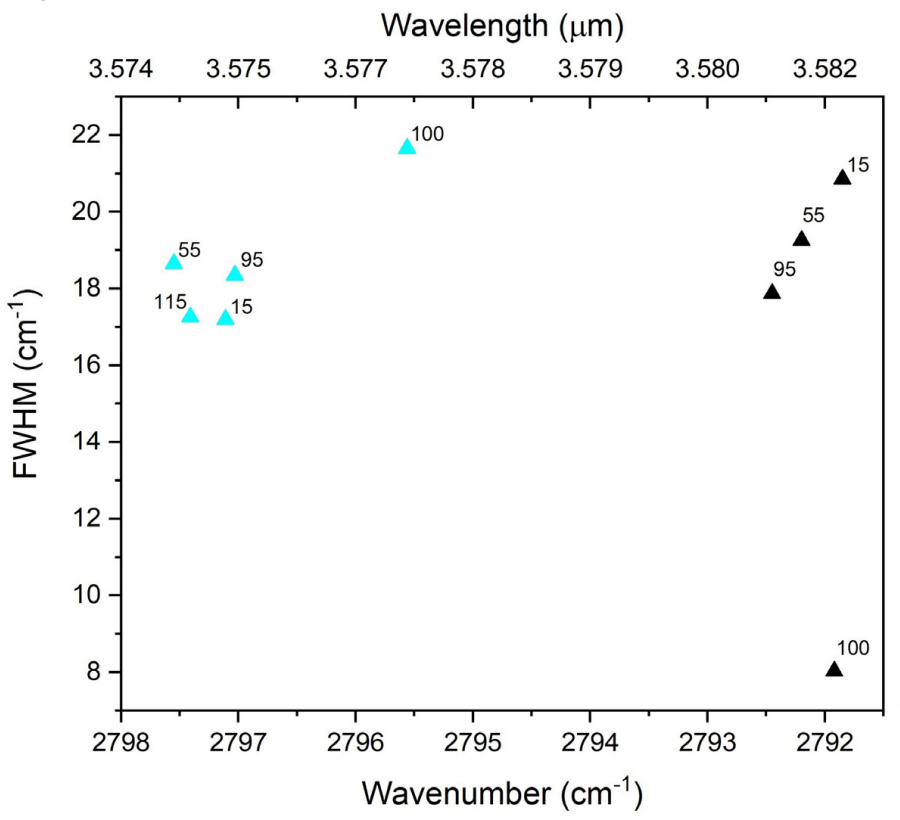

A Pure methylamine Methylamine: $\mathrm{NH}_{3}(1: 5)$

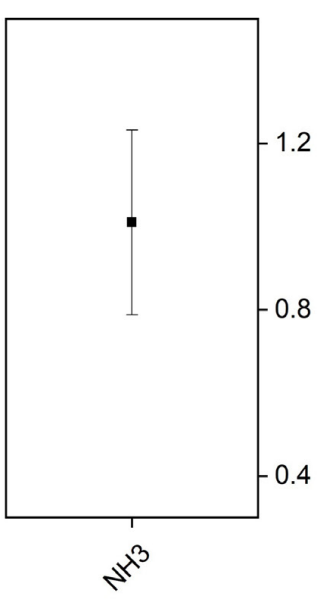

Fig. 6. (a) $2750-3000 \mathrm{~cm}^{-1}$ region with spectra of different ices, from left to right: pure $\mathrm{CH}_{3} \mathrm{NH}_{2}$, $\mathrm{CH}_{3} \mathrm{NH}_{2}: \mathrm{H}_{2} \mathrm{O}(1: 5), \mathrm{CH}_{3} \mathrm{NH}_{2}: \mathrm{CH}_{4}(1: 5)$, and $\mathrm{CH}_{3} \mathrm{NH}_{2}: \mathrm{NH}_{3}(1: 5)$. The $\mathrm{CH}_{3}$ antisymmetric stretch mode of $\mathrm{CH}_{3} \mathrm{NH}_{2}$ (around $2881 \mathrm{~cm}^{-1}$ ) and the $\mathrm{CH}_{3}$ symmetric stretch mode of $\mathrm{CH}_{3} \mathrm{NH}_{2}$ (around $2792 \mathrm{~cm}^{-1}$ ) are displayed in the panels. (b) Left panel: peak position vs. FWHM for the $\mathrm{CH}_{3}$ symmetric stretch band in pure $\mathrm{CH}_{3} \mathrm{NH}_{2}$ and $\mathrm{CH}_{3} \mathrm{NH}_{2}: \mathrm{NH}_{3}(1: 5)$ ices. Different mixtures are indicated by different colors, and the ice temperatures are marked in the graph. Right panel: relative band strength of the $\mathrm{CH}_{3}$ symmetric stretch band in pure $\mathrm{CH}_{3} \mathrm{NH}_{2}$ and $\mathrm{CH}_{3} \mathrm{NH}_{2}: \mathrm{NH}_{3}(1: 5)$ ices at $15 \mathrm{~K}$. Panel $c$ : same as $b$ for the $\mathrm{CH}_{3}$ antisymmetric stretch band (around $2881 \mathrm{~cm}^{-1}$ ) in the ice mixtures displayed in $a$.
$\mathrm{H}_{2} \mathrm{O}$ and $\mathrm{CH}_{4}$ it partially overlaps with the $v_{1}$ mode of $\mathrm{CH}_{4}$ (Herrero et al. 2010). This overlap can be noticed in Figs. A.11 and A.12, where the $2898 \mathrm{~cm}^{-1}$ feature of $\mathrm{CH}_{3} \mathrm{NH}_{2}$ is wider than in $\mathrm{H}_{2} \mathrm{O}, \mathrm{CH}_{4}$ and $\mathrm{NH}_{3}$ matrices at temperatures below $50 \mathrm{~K}$ (Figs. 6, A.9 and A.10). Above $50 \mathrm{~K}, \mathrm{CH}_{4}$ starts to desorb and the remaining feature is similar to the $2898 \mathrm{~cm}^{-1}$ band observed in the $\mathrm{CH}_{3} \mathrm{NH}_{2}: \mathrm{H}_{2} \mathrm{O}$ ices. In $\mathrm{H}_{2} \mathrm{O}: \mathrm{NH}_{3}: \mathrm{CH}_{3} \mathrm{NH}_{2}$ and $\mathrm{H}_{2} \mathrm{O}: \mathrm{NH}_{3}: \mathrm{CH}_{3} \mathrm{NH}_{2}: \mathrm{CH}_{4}$ ices, the bands in the $3000-2700 \mathrm{~cm}^{-1}$ region are difficult to resolve due to the overlap with broad absorption bands from $\mathrm{H}_{2} \mathrm{O}: \mathrm{NH}_{3}$ hydrates (Moore et al. 2007). Some of the methylamine feature are clear in the mixtures with dilution 1:10, but appear as very weak peaks in dilution of 1:20 (Figs. A.10, and A.12).
A particularity of the ices in which methylamine is mixed in water is the appearance of a broad and strong feature centered around $2760 \mathrm{~cm}^{-1}$. Figure 7 shows the feature in all the $\mathrm{CH}_{3} \mathrm{NH}_{2}: \mathrm{H}_{2} \mathrm{O}$ ice mixtures at $15 \mathrm{~K}$. The appearance of such a broad profile is also noticed in the $\mathrm{CH}_{3} \mathrm{NH}_{2}: \mathrm{CH}_{4}$ containing ices and in the $\mathrm{CH}_{3} \mathrm{NH}_{2}: \mathrm{H}_{2} \mathrm{O}: \mathrm{NH}_{3}$ matrices, though this last is less perceptible due to the overlap with the broad ammonia hydrate feature centered around $2900 \mathrm{~cm}^{-1}$. The $2760 \mathrm{~cm}^{-1}$ feature is clearly visible during the warming up of the ice mixtures and disappears only when methylamine desorbs from the ice. This band is likely due to the interaction of the N-H stretch mode of methylamine with the water $\mathrm{O}-\mathrm{H}$ stretch mode and is possibly analogous to the ammonia hydrate feature observed in $\mathrm{H}_{2} \mathrm{O}: \mathrm{NH}_{3}$ 

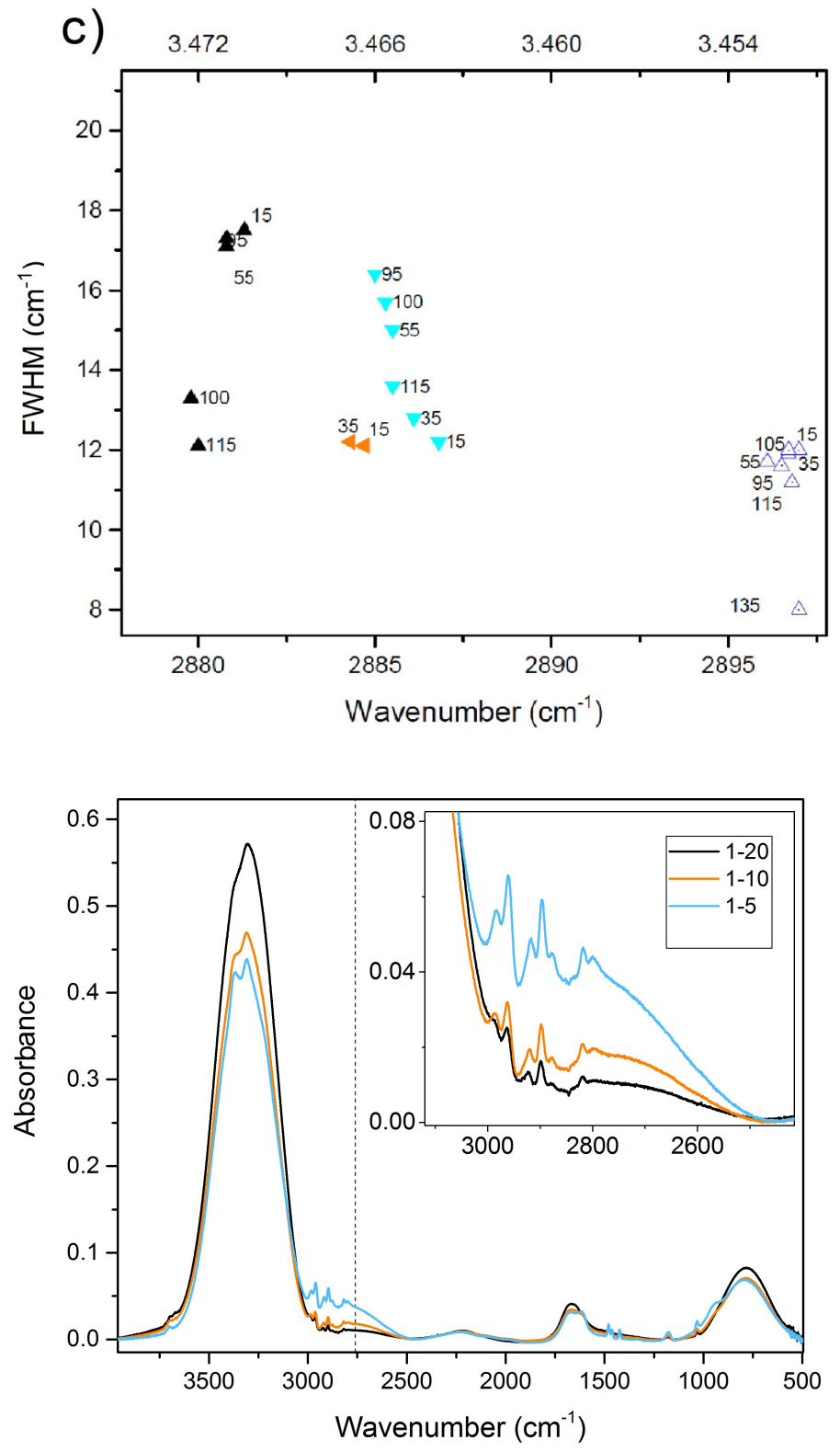

Fig. 7. Infrared spectra of $\mathrm{CH}_{3} \mathrm{NH}_{2}: \mathrm{H}_{2} \mathrm{O}$ at ratios 1:5 (blue), 1:10 (orange) and 1:20 (black) at $15 \mathrm{~K}$. The center of the broad feature at $2760 \mathrm{~cm}^{-1}$ is marked with a dashed line. Top panel: the zoom-in shows the $3100-2400 \mathrm{~cm}^{-1}$ region of the spectra.

ices (Dartois \& d'Hendecourt 2001). Since this feature appears in a region of the mid-infrared spectrum that is free from strong absorption from abundant interstellar ice components, this band could indicate the presence of methylamine in $\mathrm{H}_{2} \mathrm{O}$-rich ices. However, other molecules containing an $\mathrm{N}-\mathrm{H}$ group may show a similar absorption feature when embedded in $\mathrm{H}_{2} \mathrm{O}$ matrix, which makes this band a not unambiguous tracer of any particular species.

\section{Astronomical implications}

In dense molecular clouds, $\mathrm{CH}_{3} \mathrm{NH}_{2}$ is likely to be formed in regions that are rich in atomic $\mathrm{C}, \mathrm{H}$, and $\mathrm{N}$, that is, in the less dense regions, or early in the cloud's life cycle, when also $\mathrm{H}_{2} \mathrm{O}$, $\mathrm{CH}_{4}$, and $\mathrm{NH}_{3}$ are formed (Ioppolo et al. 2021). Using a gasgrain astrochemical kinetic model (Garrod 2013) that involves

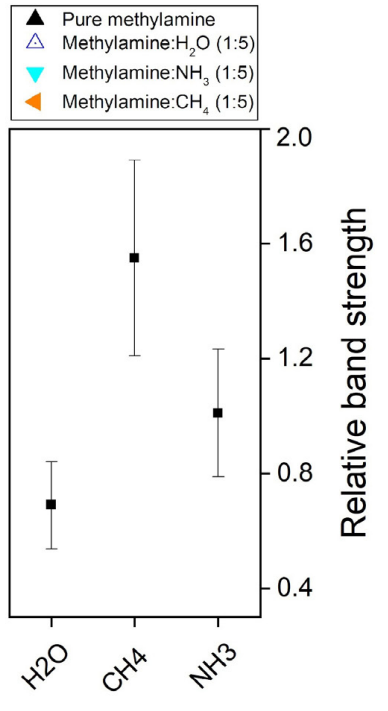

Fig. 6. continued.

only non-energetic reactions, Ioppolo et al. (2021) showed that methylamine can be formed by barrierless reactions on the surface of interstellar icy grains during the prestellar core collapse. After the core collapse, the methylamine abundance in the ice mantle reaches 0.65 percent relative to $\mathrm{H}_{2} \mathrm{O}$, which is comparable to the abundance for solid $\mathrm{CH}_{4}$ in the model. However, significantly higher solid $\mathrm{CH}_{4}$ abundances (1-11 percent relative to $\mathrm{H}_{2} \mathrm{O}$; Öberg et al. 2008) are observed toward Young Stellar Objects (YSOs). This suggests that solid methylamine may also be detectable in dense clouds and YSO envelopes, and the data presented here offer a tool to do so.

The challenge for methylamine identification in interstellar ices is related to the fact that most of its strongest modes, explored in the previous sections, overlap with features from other abundant interstellar ice and dust components (e.g., $\mathrm{CH}_{3} \mathrm{OH}, \mathrm{NH}_{3}$, silicates). In a realistic astronomical scenario, even the features that are easily identified in the laboratory will likely appear blended with bands from other species. The following sections describe the potential of solid methylamine absorption features as tracers of its presence in mid-infrared observations.

\section{1. $\mathrm{CH}_{3} \mathrm{NH}_{2}$ in the 3-4 $\mu \mathrm{m}$ wavelength range}

The methylamine features in the $3400-2500 \mathrm{~cm}^{-1}(2.94-4.0 \mu \mathrm{m})$ region have the advantage of being observable with groundbased telescopes at resolving power $R>1000$, which is much higher than that for spectra in the 5-10 $\mu \mathrm{m}$ range observed with Spitzer/IRS $(R \sim 100)$. Figure 8 shows a comparison of the $\mathrm{CH}_{3} \mathrm{NH}_{2}: \mathrm{H}_{2} \mathrm{O}(1: 10)$ ice spectrum at $15 \mathrm{~K}$ with low and highmass YSO spectra obtained with Keck/NIRSPEC, VLT/ISAAC, and IRTF/SpeX (Boogert et al. 2008, Emerson \& Boogert, in prep.). The peak positions of the methylamine features at $2898 \mathrm{~cm}^{-1}(3.451 \mu \mathrm{m}), 2796 \mathrm{~cm}^{-1}(3.576 \mu \mathrm{m})$, and the broad feature at $2760 \mathrm{~cm}^{-1}(3.623 \mu \mathrm{m})$ are marked with vertical dashed lines. In $\mathrm{H}_{2} \mathrm{O}$ mixtures, the band from the $\mathrm{CH}_{3}$ antisymmetric stretch mode at $2898 \mathrm{~cm}^{-1}$ is the strongest methylamine feature in this region. It appears close to the $\mathrm{CH}_{3}$ stretch bands from other organic molecules (e.g., acetaldehyde, ethanol) and the $v_{1}$ mode of $\mathrm{CH}_{4}$ observed in $\mathrm{CH}_{4}: \mathrm{H}_{2} \mathrm{O}$ ices, as discussed on the previous section. Still, at the high resolving power, this 
M. G. Rachid et al.: Infrared spectra of complex organic molecules in astronomically relevant ice mixtures. IV.

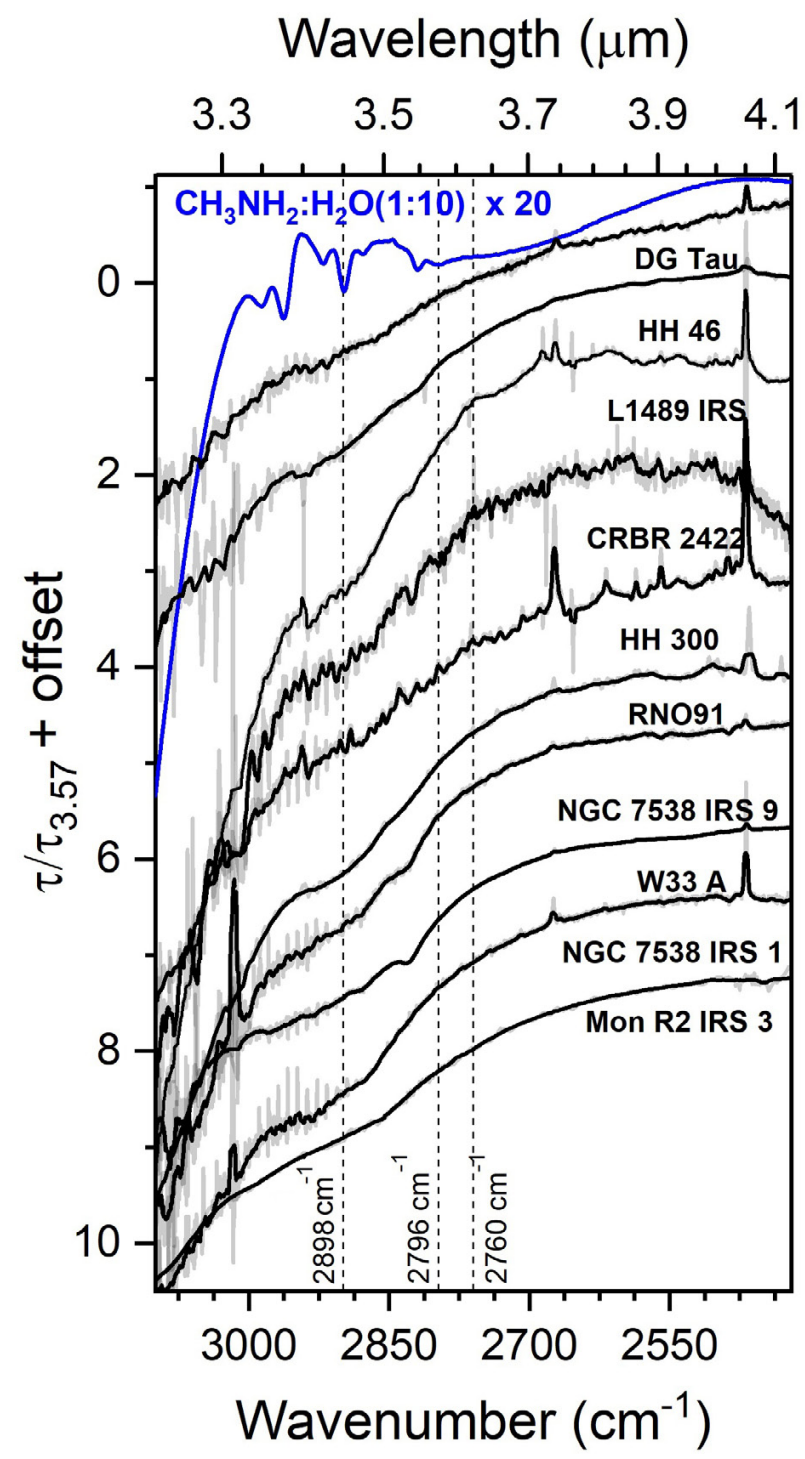

Fig. 8. Comparison between the IR profile of YSOs and the absorption spectra of the $\mathrm{CH}_{3} \mathrm{NH}_{2}: \mathrm{H}_{2} \mathrm{O}(1: 10)$ ice at $15 \mathrm{~K}$ (top blue curve). All the YSO spectra are normalized in relation to the optical depth at $2800 \mathrm{~cm}^{-1}$ $(3.57 \mu \mathrm{m})$. The gray lines are the original spectra and the black lines are the smoothed spectra. The smoothing uses a 15-point boxcar, that corresponds to a window of $4-6 \mathrm{~cm}^{-1}$ in the analyzed spectra. The position of the methylamine bands at 2898,2796 , and the feature at $2760 \mathrm{~cm}^{-1}$ are marked with dashed lines.

relatively narrow absorption feature is best suited to constrain the methylamine abundance. On the other hand, while the methylamine $\mathrm{CH}_{3}$ antisymmetric stretch feature at $2796 \mathrm{~cm}^{-1}$ peaks at wavenumbers lower than most of the $\mathrm{CH}_{3}$ stretch vibrations of abundant ice species, its strength is significantly suppressed in $\mathrm{H}_{2} \mathrm{O}$ matrices.

The broad feature at $2760 \mathrm{~cm}^{-1}$ is observed in $\mathrm{CH}_{3} \mathrm{NH}_{2}: \mathrm{H}_{2} \mathrm{O}$ ice samples with a methylamine abundance as low as $5 \%$ relative to $\mathrm{H}_{2} \mathrm{O}$ and is in a spectral region where few abundant interstellar ice molecules have absorption peaks. As can be seen from Fig. 8, such a broad feature centered at $2760 \mathrm{~cm}^{-1}$ is not promptly identified in the YSO spectra. We find that abundances estimates from this shallow band are strong limited by the baseline choice, and stronger constraints are obtained from the $\mathrm{CH}_{3}$ antisymmetric stretch mode at $2898 \mathrm{~cm}^{-1}$. In an alternative scenario where methylamine is embedded in an apolar ice environment, the $2760 \mathrm{~cm}^{-1}$ feature would be absent. This seems an unlikely scenario since the formation routes of methylamine may well pass through $\mathrm{NH}_{2}$ and $\mathrm{CH}_{3}$ radicals in a $\mathrm{H}_{2} \mathrm{O}$ matrix (Garrod 2013; Ioppolo et al. 2021).

\section{2. $\mathrm{CH}_{3} \mathrm{NH}_{2}$ in the 5-8 $\mu \mathrm{m}$ wavelength range}

In the $1700-1250 \mathrm{~cm}^{-1}(\sim 5.9-8.0 \mu \mathrm{m})$ range, airborne and space-based observations revealed a series of ice absorption features (Soifer et al. 1979; Schutte et al. 1996). Among the likely carriers of these features are many hydrocarbons and oxygen-bearing species, such as methanol $\left(\mathrm{CH}_{3} \mathrm{OH}\right)$, formaldehyde $\left(\mathrm{H}_{2} \mathrm{CO}\right)$, formic acid $(\mathrm{HCOOH})$, acetaldehyde $\left(\mathrm{CH}_{3} \mathrm{CHO}\right)$, ethanol $\left(\mathrm{CH}_{3} \mathrm{CH}_{2} \mathrm{OH}\right)$, the formate ion $\left(\mathrm{HCOO}^{-}\right)$and others (Tielens et al. 1984; Schutte et al. 1996; Keane et al. 2001; Knez et al. 2005; Boogert et al. 2008, 2015; Bottinelli et al. 2010; Öberg et al. 2011). Some N-bearing molecules have also been proposed as possible carriers, for example, $\mathrm{NH}_{3}, \mathrm{NH}_{4}^{+}$ (Schutte \& Khanna 2003), HCN, and a few suggestions for larger molecules, such as acetonitrile $\left(\mathrm{CH}_{3} \mathrm{CN}\right)$, urea $\left(\mathrm{H}_{2} \mathrm{NCONH}_{2}\right)$ and formamide $\left(\mathrm{HCONH}_{2}\right.$; Raunier et al. 2004).

Figure 9 shows a comparison of the infrared spectra of methylamine-containing ices with the mid-IR spectra of YSOs obtained by Spitzer/IRS (Boogert et al. 2008). As can be seen from the figure, the $\mathrm{NH}_{2}$ deformation mode and the $\mathrm{CH}_{3}$ symmetric deformation mode of methylamine, around $1613 \mathrm{~cm}^{-1}$ and $1424 \mathrm{~cm}^{-1}$, respectively, coincide with the strong features observed in the YSOs. Methylamine could thus be one of the species that contribute to both of these features. However, because the observed features result from a blending of many absorbing species, it is not possible to significant constrain the methylamine abundance. Future JWST observations at a resolving power of $R \sim 1000-3000$, more than an order of magnitude better than Spitzer, will be better suited to search for weak substructures, possibly providing better ice abundance constraints.

\section{3. $\mathrm{CH}_{3} \mathrm{NH}_{2}$ in the 8-13 $\mu \mathrm{m}$ wavelength range}

In the $1200-800 \mathrm{~cm}^{-1}(\sim 8-12.5 \mu \mathrm{m})$ region, the methylamine bands also overlap with features from abundant interstellar ice molecules. The $\mathrm{CH}_{3}$ rock band, around $1159 \mathrm{~cm}^{-1}$ in pure methylamine, overlaps with the umbrella mode of $\mathrm{NH}_{3}$ at $1070 \mathrm{~cm}^{-1}$, appearing as weak shoulders in the laboratory spectra. Since ammonia is an abundant interstellar ice species, the band around $1159 \mathrm{~cm}^{-1}$ may not be suitable for methylamine identification. However, the presence of a shoulder at higher wavenumbers in the ammonia umbrella feature may be an indication of methylamine, but this again requires a high resolving power.

Methylamine also presents a strong peak around $903.5 \mathrm{~cm}^{-1}$ $(\sim 11.07 \mu \mathrm{m})$, assigned to the $v_{9}$ mode, that was not characterized in this work due to the overlap with the libration band of $\mathrm{H}_{2} \mathrm{O}$ ice. This peak appears in the same region as the broad torsion mode band of $\mathrm{CH}_{3} \mathrm{OH}$ (around $700 \mathrm{~cm}^{-1}$ ) and a feature around $902.5 \mathrm{~cm}^{-1}(11.08 \mu \mathrm{m})$ observed in some YSOs that has been assigned to crystalline silicates Do-Duy et al. (2020). Investigations concerning COMs that can contribute to the astronomical feature around $11.08 \mu \mathrm{m}$ should consider methylamine as a carrier candidate.

\section{4. $\mathrm{CH}_{3} \mathrm{NH}_{2}$ abundances}

With the currently available observations of YSO envelopes, the best estimate of the methylamine abundance is obtained from 


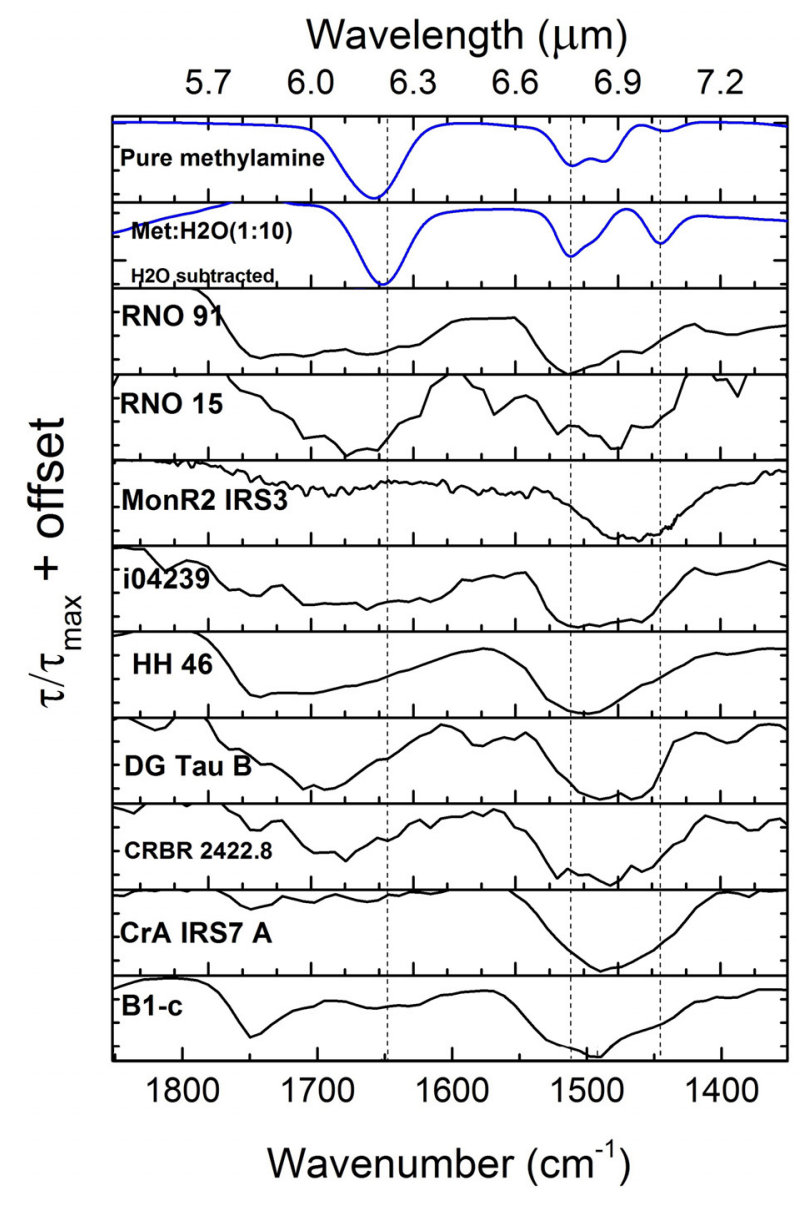

Fig. 9. Comparison between laboratory spectra of methylaminecontaining ices and some Spitzer/IRS spectra of YSOs (with $\mathrm{H}_{2} \mathrm{O}$ subtracted) in the 5.4-7.4 $\mu \mathrm{m}$ range (Boogert et al. 2008). Two top panels: spectra of pure methylamine ice at $15 \mathrm{~K}$ and the $\mathrm{H}_{2} \mathrm{O}$ subtracted $\mathrm{CH}_{3} \mathrm{NH}_{2}: \mathrm{H}_{2} \mathrm{O}(1: 10)$ ice spectra at $15 \mathrm{~K}$. The vertical dashed lines mark the peak positions of the bands in this mixture. The laboratory spectra are convolved with a Gaussian profile with FWHM corresponding to the Spitzer/IRS resolution $(R=100)$. Both the laboratory and YSO spectra are normalized with respect to the $1612.9 \mathrm{~cm}^{-1}(6.2 \mu \mathrm{m})$ feature for better visualization.

the $3000-2700 \mathrm{~cm}^{-1}$ region (Fig. 8). No distinct feature due to methylamine is detected in the ground-based spectra, and the tightest upper-limit can be obtained from the feature around $\mathrm{CH}_{3}$ antisymmetric stretch mode (around $2898 \mathrm{~cm}^{-1}$ in $\mathrm{CH}_{3} \mathrm{NH}_{2}: \mathrm{H}_{2} \mathrm{O}$ ices). The column density upper limit $\left(\mathrm{N}\right.$, in $\left.\mathrm{cm}^{-2}\right)$ of methylamine can be estimated from the FWHM and the band strength $\left(A^{\prime}\right)$ of the $2898 \mathrm{~cm}^{-1}$ feature:

$N \leq \frac{\tau_{v} \times F W H M}{A^{\prime}}$,

where $A^{\prime}=1.48 \times 10^{-18} \mathrm{~cm}$ molecule ${ }^{-1}$ is the band strength for the $2898 \mathrm{~cm}^{-1}$ feature and $F W H M=11.8 \mathrm{~cm}^{-1}$ (adopting the value for the $\mathrm{CH}_{3} \mathrm{NH}_{2}: \mathrm{H}_{2} \mathrm{O}(1: 10)$ ice mixture, see Appendix A), and $\tau_{v}$ is the optical depth of the peak in the YSO spectra. For obtaining the optical depth, a local baseline is subtracted from the region around the $2898 \mathrm{~cm}^{-1}$, and $\tau_{v}$ is taken as the maximum optical depth that is consistent with the absence of a peak centered at $2898 \mathrm{~cm}^{-1}$ (with $F W H M=11.8 \mathrm{~cm}^{-1}$ ) in the YSO spectra. Figure 10 shows an example of this procedure. The derived methylamine upper limits are shown in Table 4 along

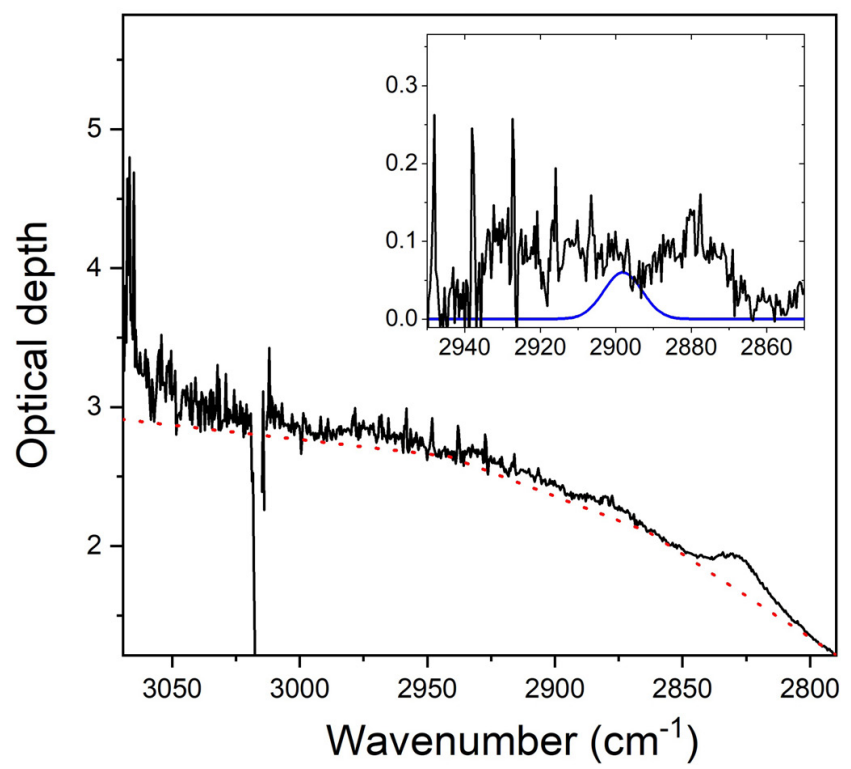

Fig. 10. Example of the adjustment of a local baseline in the W33A spectrum (red dotted line). The top right panel shows the subtracted spectra in the $2850-2950 \mathrm{~cm}^{-1}$ region and the adjusted Gaussian feature (blue) expected from $\mathrm{CH}_{3} \mathrm{NH}_{2}$ in an $\mathrm{H}_{2} \mathrm{O}$ matrix.

Table 4. Methylamine upper limits using the $\mathrm{CH}_{3}$ antisymmetric stretch band at $2898 \mathrm{~cm}^{-1}$.

\begin{tabular}{|c|c|c|}
\hline Source & $\begin{array}{c}\mathrm{N}\left(\mathrm{CH}_{3} \mathrm{NH}_{2}\right) \\
10^{17} \mathrm{~cm}^{-2} \\
\end{array}$ & $\left(\% \mathrm{H}_{2} \mathrm{O}\right)$ \\
\hline CRBR2422.8-342 & $\leq 6.7$ & 16 \\
\hline L1489 IRS & $\leq 2.3$ & 5.3 \\
\hline HH46 & $\leq 8.4$ & 10 \\
\hline DG Tau & $\leq 1.7$ & 7.4 \\
\hline RNO91 & $\leq 2.5$ & 5.9 \\
\hline HН300 & $\leq 2.1$ & 8.0 \\
\hline Mon R2 IRS 3 & $\leq 0.8$ & 5.3 \\
\hline NGC 7538 IRS 1 & $\leq 0.8$ & 3.1 \\
\hline NGC 7538 IRS 9 & $\leq 1.7$ & 2.6 \\
\hline W33 A & $\leq 4.2$ & 3.4 \\
\hline 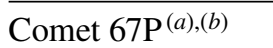 & - & 0.16 \\
\hline Model $^{(c)}$ & - & 0.65 \\
\hline
\end{tabular}

Notes. The methylamine abundances detected in the comet $67 \mathrm{P} /$ Churyumov-Gerasimenko and the predicted abundance for gasgrain astrochemical models of prestellar cores are also presented for comparison.

References. ${ }^{(a)}$ Le Roy et al. (2015); ${ }^{(b)}$ Altwegg et al. (2016); ${ }^{(c)}$ Ioppolo et al. (2021).

with predicted values and the abundance observed in the Comet 67P.

As can be seen in Table 4, the methylamine upper limits values range from 2.6 to 16 percent in relation to water. The higher upper limits obtained for CRBR2422.8-342 and HH46 are a consequence of the lower $\mathrm{S} / \mathrm{N}$ in the spectral region in comparison with some other objects (e.g., NGC 7538 IRS 1, NGC 7538 IRS 9, W33 A). For the YSO spectra with higher $\mathrm{S} / \mathrm{N}$, the abundance of methylamine is constrained to less than a few percent relative to $\mathrm{H}_{2} \mathrm{O}$, which is at the level of tentatively detected COMs (Öberg et al. 2011; Terwisscha van Scheltinga 
M. G. Rachid et al.: Infrared spectra of complex organic molecules in astronomically relevant ice mixtures. IV.

et al. 2018). Still, the calculated values are higher than the methylamine abundance of 0.65 relative to $\mathrm{H}_{2} \mathrm{O}$ from the gas-grain model presented by Ioppolo et al. (2021). This indicates that current IR observations of ices around YSOs are not sensitive enough to probe the solid methylamine budget, and so unable to significantly constrain the accuracy of methylamine formation models. Observations at higher spectral resolution and sensitivity across the full $3-10 \mu \mathrm{m}$ wavelength range with the JWST mission toward a wider variety of dense clouds and YSO targets should provide tighter constraints on the presence of COMs in the ices. The JWST early release program ICE AGE (McClure et al. 2018) targets a search for COM ice features in the wavelength domain studied here. The data presented in this work will support the interpretation of future data, helping to understand the chemical inventory of ices in star-forming regions.

\section{Conclusions}

This work reports a set of systematically measured infrared spectra of methylamine-containing ices in astronomically relevant conditions. The following methylamine features are selected for peak position and FWHM characterization in the studied ices: the $\mathrm{CH}_{3}$ antisymmetric stretch band around $2881.3 \mathrm{~cm}^{-1}(3.453 \mu \mathrm{m})$, the $\mathrm{CH}_{3}$ symmetric stretch band around $2791.8 \mathrm{~cm}^{-1}(3.582 \mu \mathrm{m})$, the $\mathrm{CH}_{3}$ antisymmetric deformation bands around $1455.0 \mathrm{~cm}^{-1}$ and $1478.6 \mathrm{~cm}^{-1}(6.873 \mu \mathrm{m}$ and $6.761 \mu \mathrm{m})$, the $\mathrm{CH}_{3}$ symmetric deformation band around $1420.3 \mathrm{~cm}^{-1}(7.042 \mu \mathrm{m})$, and the $\mathrm{CH}_{3}$ rock around $1159.2 \mathrm{~cm}^{-1}$ $(8.621 \mu \mathrm{m})$. The mid-IR band strengths of pure methylamine ice (in the transmission mode) for the selected vibrational modes and the refractive index at $632.8 \mathrm{~nm}$ are, to the best of our knowledge, reported here for the first time. The relative band strengths of methylamine in the ice mixtures are also derived. These values are essential for estimating methylamine abundances in astronomical IR spectra. The main conclusions of this work are summarized below:

1. The interaction of methylamine with the $\mathrm{H}_{2} \mathrm{O}$ matrix induces substantial changes in the methylamine absorption profile, such as: an enhancement in the strength of the $\mathrm{CH}_{3}$ antisymmetric stretch (at $2898 \mathrm{~cm}^{-1}$ ) in relation to other methylamine features in the $3000-2700 \mathrm{~cm}^{-1}$ region, an enhancing in the $\mathrm{CH}_{3}$ symmetric deformation mode $\left(1425 \mathrm{~cm}^{-1}\right)$ strength, and the appearance of a broad and strong feature centered at $2760 \mathrm{~cm}^{-1}$. This last feature appears in a region where few abundant interstellar ice species absorb, and therefore may also offer a tool to search for the presence of methylamine in interstellar ices.

2. The comparison of the methylamine-containing ices with mid-infrared spectra of some YSOs shows that despite some overlap between laboratory and astronomical data, no feature can be unambiguously assigned to methylamine. The methylamine bands are hard to be used as tracers due to blending with bands from other molecules. Even the bands that are clearly distinguishable in the laboratory ice data and are characterized in this work have a limited use to identify methylamine.

3. From the work presented here, upper limits for methylamine are derived based on the $\mathrm{CH}_{3}$ antisymmetric stretch mode (at $2898 \mathrm{~cm}^{-1}$ in $\mathrm{CH}_{3} \mathrm{NH}_{2}: \mathrm{H}_{2} \mathrm{O}$ ices). In some of these YSOs, the methylamine abundance in respect to water is less than $4 \%$.

With the upcoming JWST observations of ices, weaker solidstate features, not present in the available ice data, may be revealed. Within the ICE AGE program several targets are envisaged to search for COM ice features in the wavelength domain studied here. The data presented in this work will support the interpretation of future JWST spectra, helping to understand the chemical inventory of ices in star-forming regions.

Acknowledgements. This work has been made possible through financial support by NOVA, the Netherlands Research School for Astronomy. We thank Dr. Jiao He for the helpful discussions about refractive index measurements and Dr. Will Rocha, Nicolas Suas-David, and Dr. Melissa McClure for helpful discussions. G.F. also acknowledges financial support from the Russian Ministry of Science and Higher Education via the State Assignment Contract FEUZ-2020-0038.

\section{References}

Altwegg, K., Balsiger, H., Bar-Nun, A., et al. 2016, Scie. Adv., 2, e1600285 Atoji, M., \& Lipscomb, W. 1953, Acta Crystallograph., 6, 770 Belloche, A., Menten, K., Comito, C., et al. 2008, A\&A, 492, 769

Beltrán, M. D., Molina, R. L., Aznar, M. Á. S., Moltó, C. S., \& Verdú, C. M. 2015, Sensors, 15, 25123

Bøgelund, E. G., McGuire, B. A., Hogerheijde, M. R., van Dishoeck, E. F., \& Ligterink, N. F. W. 2019, A\&A, 624, A82

Boogert, A. C. A., Pontoppidan, K. M., Knez, C., et al. 2008, ApJ, 678, 985

Boogert, A. C. A., Gerakines, P. A., \& Whittet, D. C. B. 2015, ARA\&A, 53, 541 Bossa, J.-B., Duvernay, F., Theulé, P., et al. 2009, A\&A, 506, 601

Bossa, J.-B., Borget, F., Duvernay, F., Theulé, P., \& Chiavassa, T. 2010, J. Phys. Organic Chem., 23, 333

Bottinelli, S., Boogert, A. C. A., Bouwman, J., et al. 2010, ApJ, 718, 1100

Dartois, E., \& d'Hendecourt, L. 2001, A\&A, 365, 144

Denbigh, K. 1940, Transac. Faraday Soc., 36, 936

Do-Duy, T., Wright, C. M., Fujiyoshi, T., et al. 2020, MNRAS, 493, 4463

Durig, J. R. \& Zheng, C. 2001, Struc. Chem., 12, 137

Durig, J., Bush, S., \& Baglin, F. 1968, J. Chem. Phys., 49, 2106

Elsila, J. E., Dworkin, J. P., Bernstein, M. P., Martin, M. P., \& Sandford, S. A. 2007, ApJ, 660, 911

Fedoseev, G., Ioppolo, S., Zhao, D., Lamberts, T., \& Linnartz, H. 2015, MNRAS, 446, 439

Förstel, M., Bergantini, A., Maksyutenko, P., Góbi, S., \& Kaiser, R. I. 2017, ApJ, 845,83

Fourikis, N., Takagi, K., \& Morimoto, M. 1974, ApJ, 191, L139

Gardner, E. P., \& McNesby, J. R. 1980, J. Photochem., 13, 353

Garrod, R. T. 2013, ApJ, 765, 60

Garrod, R. T., Weaver, S. L. W., \& Herbst, E. 2008, ApJ, 682, 283

Glavin, D. P., Dworkin, J. P., \& Sandford, S. A. 2008, Meteorit.Planet. Sci., 43, 399

Goesmann, F., Rosenbauer, H., Bredehöft, J. H., et al. 2015, Science, 349, aaa9816

Herbst, E. 1985, ApJ, 292, 484

Herrero, V. J., Gálvez, Ó., Maté, B., \& Escribano, R. 2010, Phys. Chem. Chem. Phys., 12, 3164

Hudson, R., Loeffler, M., \& Gerakines, P. 2017, J. Chem. Phys., 146, 024304

Hudson, R. L., Loeffler, M. J., Ferrante, R. F., Gerakines, P. A., \& Coleman, F. M. 2020, ApJ, 891, 22

Ioppolo, S., Fedoseev, G., Chuang, K.-J., et al. 2021, Nat. Astron., 5, 197

Kaifu, N., Morimoto, M., Nagane, K., et al. 1974, ApJ, 191, L135

Kayi, H., Kaiser, R. I., \& Head, J. D. 2011, Phys. Chem. Chem. Phys., 13, 11083

Keane, J. V., Tielens, A. G. G. M., Boogert, A. C. A., Schutte, W. A., \& Whittet, D. C. B. 2001, A\&A, 376, 254

Kim, Y. S., \& Kaiser, R. I. 2011, ApJ, 729, 68

Knez, C., Boogert, A. C. A., Pontoppidan, K. M., et al. 2005, ApJ, 635, L145

Kvenvolden, K., Lawless, J., Pering, K., et al. 1970, Nature, 228, 923

Lavalley, J., \& Sheppard, N. 1972, Spectrochim. Acta Part A Mol. Spectr., 28, 2091

Le Roy, L., Altwegg, K., Balsiger, H., et al. 2015, A\&A, 583, A1

Leung, C. M., Herbst, E., \& Huebner, W. F. 1984, ApJS, 56, 231

Linnartz, H., Ioppolo, S., \& Fedoseev, G. 2015, Int. Rev. Phys. Chem., 34, 205

Maeda, S., \& Ohno, K. 2006, ApJ, 640, 823

Mahjoub, A., \& Hodyss, R. 2018, ApJ, 869, 98

McClure, M. K., Boogert, A., Linnartz, H., et al. 2018, AAS Meeting Abs., 232, 302

McGuire, B. A., Carroll, P. B., Dollhopf, N. M., et al. 2015, ApJ, 812, 76

Moore, M. H., Ferrante, R., Hudson, R., \& Stone, J. 2007, Icarus, 190, 260

Mumma, M. J., \& Charnley, S. B. 2011, ARA\&A, 49, 471

Noble, J., Theule, P., Duvernay, F., et al. 2014, Phys. Chem. Chem. Phys., 16, 23604 
Oba, Y., Chigai, T., Osamura, Y., Watanabe, N., \& Kouchi, A. 2014, Meteorit Planet. Sci., 49, 117

Öberg, K. I., Boogert, A. C. A., Pontoppidan, K. M., et al. 2008, ApJ, 678, 1032 Öberg, K. I., Boogert, A. C. A., Pontoppidan, K. M., et al. 2011, ApJ, 740, 109 Ogura, K., Migita, C. T., \& Yamada, T. 1988, Chem. Lett., 17, 1563

Ogura, K., Migita, C., \& Yamada, T. 1989, J. Photochem. Photobiol. A Chem., 49,53

Ohishi, M., Suzuki, T., Hirota, T., Saito, M., \& Kaifu, N. 2019, PASJ, 71, 86

Qasim, D., Fedoseev, G., Chuang, K.-J., et al. 2020, Nat. Astron., 4, 781

Rachid, M. G., Terwisscha van Scheltinga, J., Koletzki, D., \& Linnartz, H. 2020, A\&A, 639, A4

Raunier, S., Chiavassa, T., Duvernay, F., et al. 2004, A\&A, 416, 165

Romanescu, C., Marschall, J., Kim, D., Khatiwada, A., \& Kalogerakis, K. S 2010, Icarus, 205, 695
Schutte, W., \& Khanna, R. 2003, A\&A, 398, 1049

Schutte, W. A., Tielens, A. G. G. M., Whittet, D. C. B., et al. 1996, A\&A, 315, L333

Soifer, B. T., Puetter, R. C., Russell, R. W., et al. 1979, ApJ, 232, L53

Suzuki, T., Ohishi, M., Hirota, T., et al. 2016, ApJ, 825, 79

Tempelmeyer, K., \& Mills Jr. D. 1968, J. Appl. Phys., 39, 2968

Terwisscha van Scheltinga, J., Ligterink, N. F. W., Boogert, A. C. A., van Dishoeck, E. F., \& Linnartz, H. 2018, A\&A, 611, A35

Theulé, P., Borget, F., Mispelaer, F., et al. 2011, A\&A, 534, A64

Tielens, A. G. G. M., Allamandola, L. J., Bregman, J., et al. 1984, ApJ, 287, 697

Vinogradoff, V., Duvernay, F., Danger, G., et al. 2013, A\&A, 549, A40

Wolff, H. 1970, J. Chem. Phys., 52, 2800

Yamada, H., \& Person, W. B. 1964, J. Chem. Phys., 41, 2478 
M. G. Rachid et al.: Infrared spectra of complex organic molecules in astronomically relevant ice mixtures. IV.

\section{Appendix A}

This section presents the infrared spectra of pure and mixed methylamine ices. The spectra are focused on selected bands: the $\mathrm{CH}_{3}$ antisymmetric stretch band around $2881.3 \mathrm{~cm}^{-1}(3.471 \mu \mathrm{m})$, the $\mathrm{CH}_{3}$ symmetric stretch band around $2791.9 \mathrm{~cm}^{-1}(3.582 \mu \mathrm{m})$, the $\mathrm{CH}_{3}$ antisymmetric deformation bands, at 1455.0 and
$1478.6 \mathrm{~cm}^{-1}(6.873 \mu \mathrm{m}$ and $6.761 \mu \mathrm{m})$, the $\mathrm{CH}_{3}$ symmetric deformation band at $1420.3 \mathrm{~cm}^{-1}(7.042 \mu \mathrm{m})$, and the $\mathrm{CH}_{3}$ rock at $1159.2 \mathrm{~cm}^{-1}(8.621 \mu \mathrm{m})$. Graphs displaying the peak position vs. FWHM for the bands and the relative band strengths are displayed at the bottom of each figure. The FWHM and peak position values displayed in the graphs are available from the Tables in Appendix B.

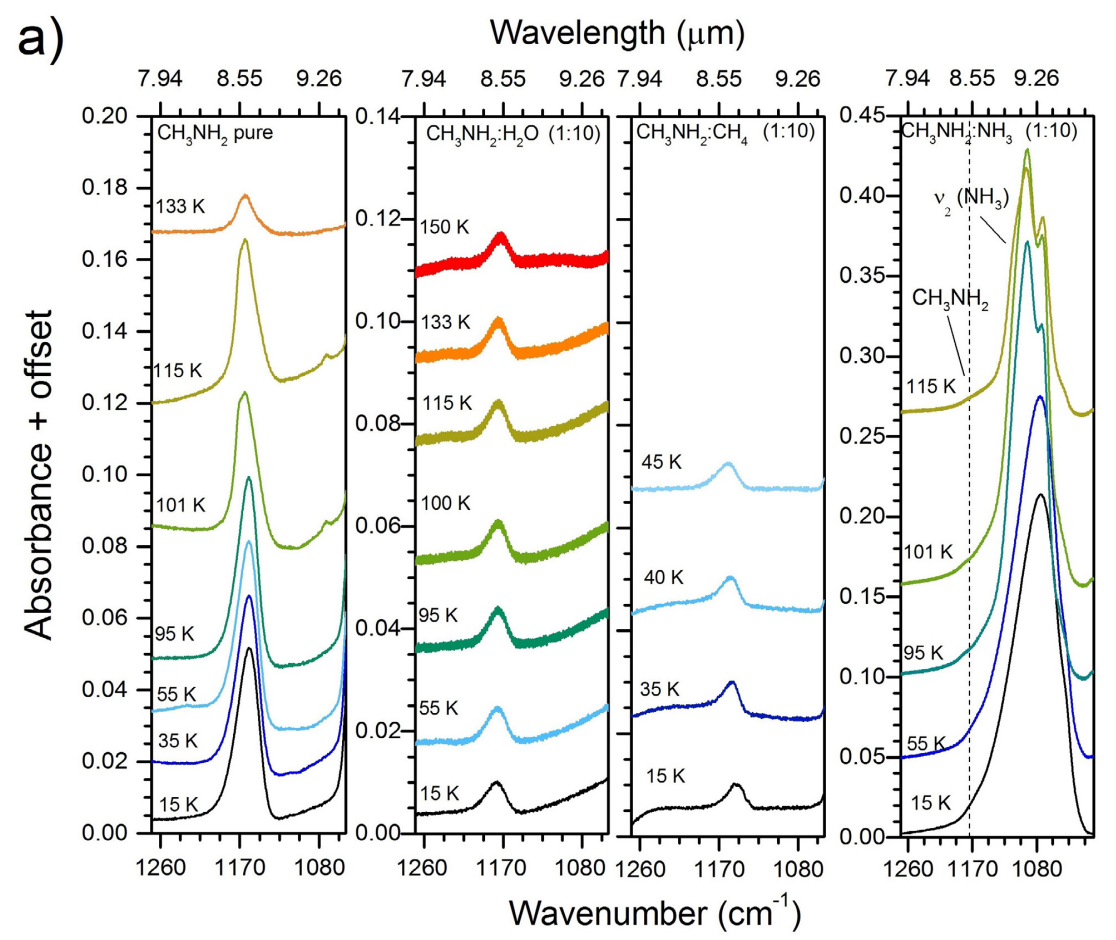

b)

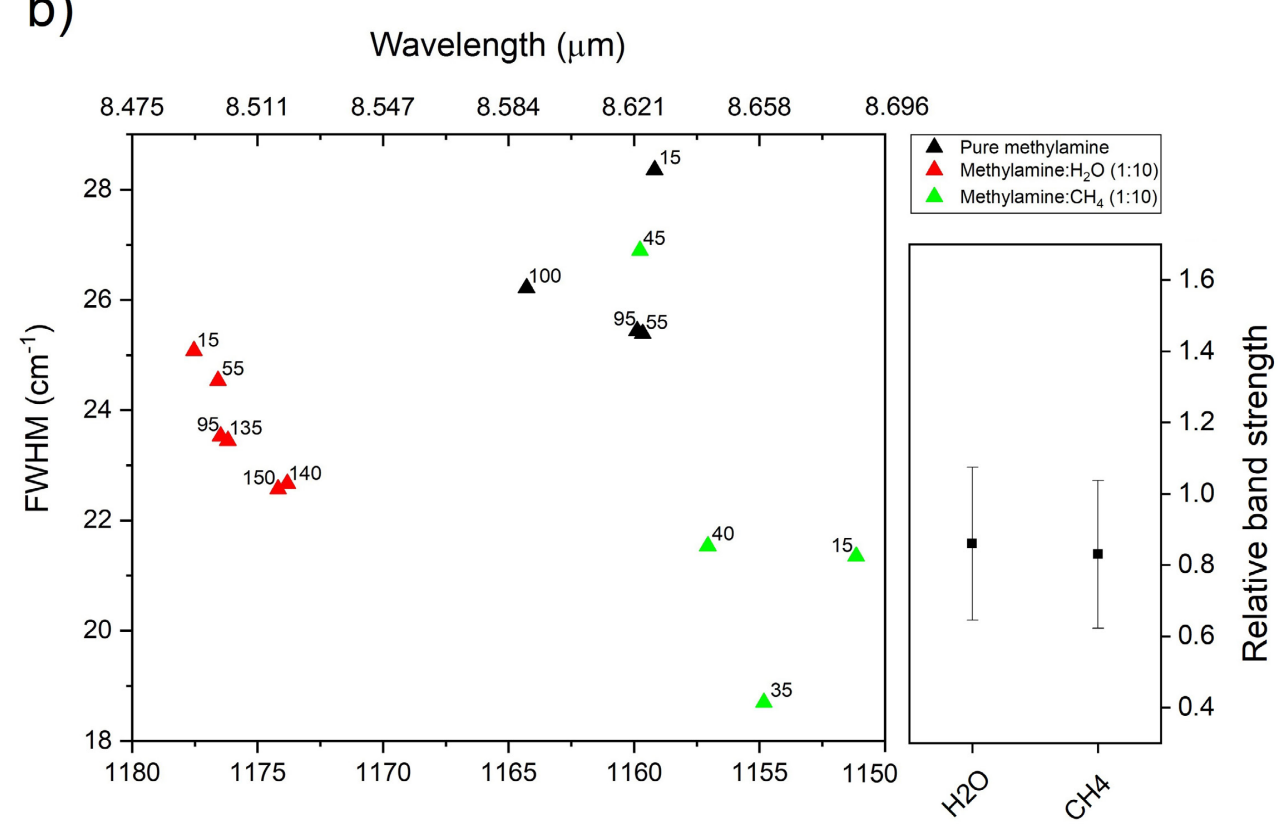

Wavenumber $\left(\mathrm{cm}^{-1}\right)$

Fig. A.1. (a) Infrared band profile of the $\mathrm{CH}_{3}$ rock vibrational mode of $\mathrm{CH}_{3} \mathrm{NH}_{2}$, around $1159 \mathrm{~cm}^{-1}$, in different ices at different temperatures, from left to right: pure $\mathrm{CH}_{3} \mathrm{NH}_{2}, \mathrm{CH}_{3} \mathrm{NH}_{2}: \mathrm{H}_{2} \mathrm{O}(1: 10), \mathrm{CH}_{3} \mathrm{NH}_{2}: \mathrm{CH}_{4}(1: 10)$, and $\mathrm{CH}_{3} \mathrm{NH}_{2}: \mathrm{NH}_{3}$ (1:10). The first and the last panels are displayed at a different $Y$-scale. In the last panel the $\mathrm{CH}_{3} \mathrm{NH}_{2}$ feature (whose position is indicated by the dashed line) appears as a shoulder in the ammonia $v_{2}$ band (umbrella mode). (b) Left panel: peak position vs. FWHM for the $\mathrm{CH}_{3}$ rock band in the ice mixtures displayed in $a$. Different mixtures are indicated by different colors, and the different temperatures are marked in the graph. Right panel: relative band strength of the $\mathrm{CH}_{3}$ rock vibrational mode in different ice mixtures at $15 \mathrm{~K}$. 
a)

Wavelength $(\mu \mathrm{m})$

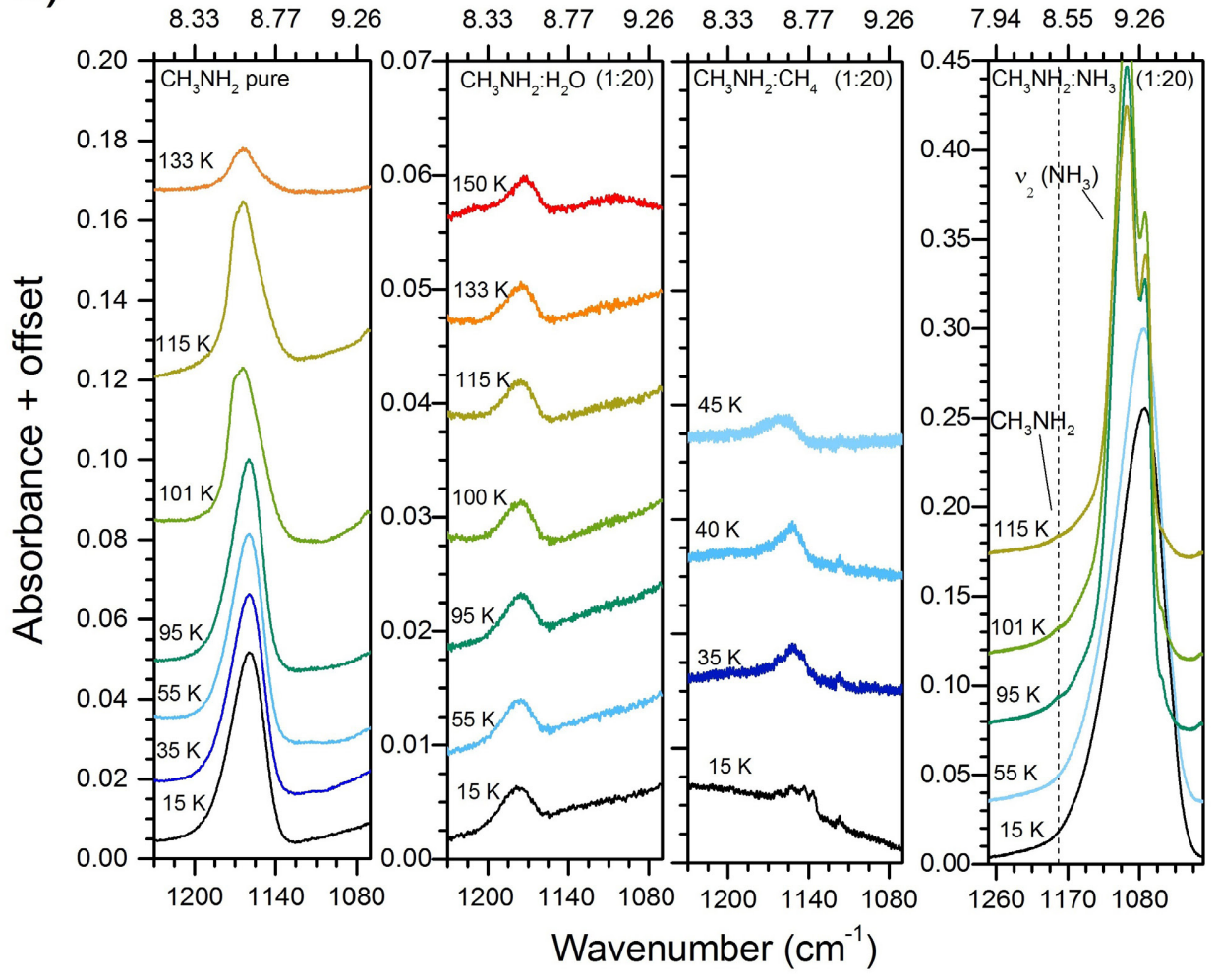

b)

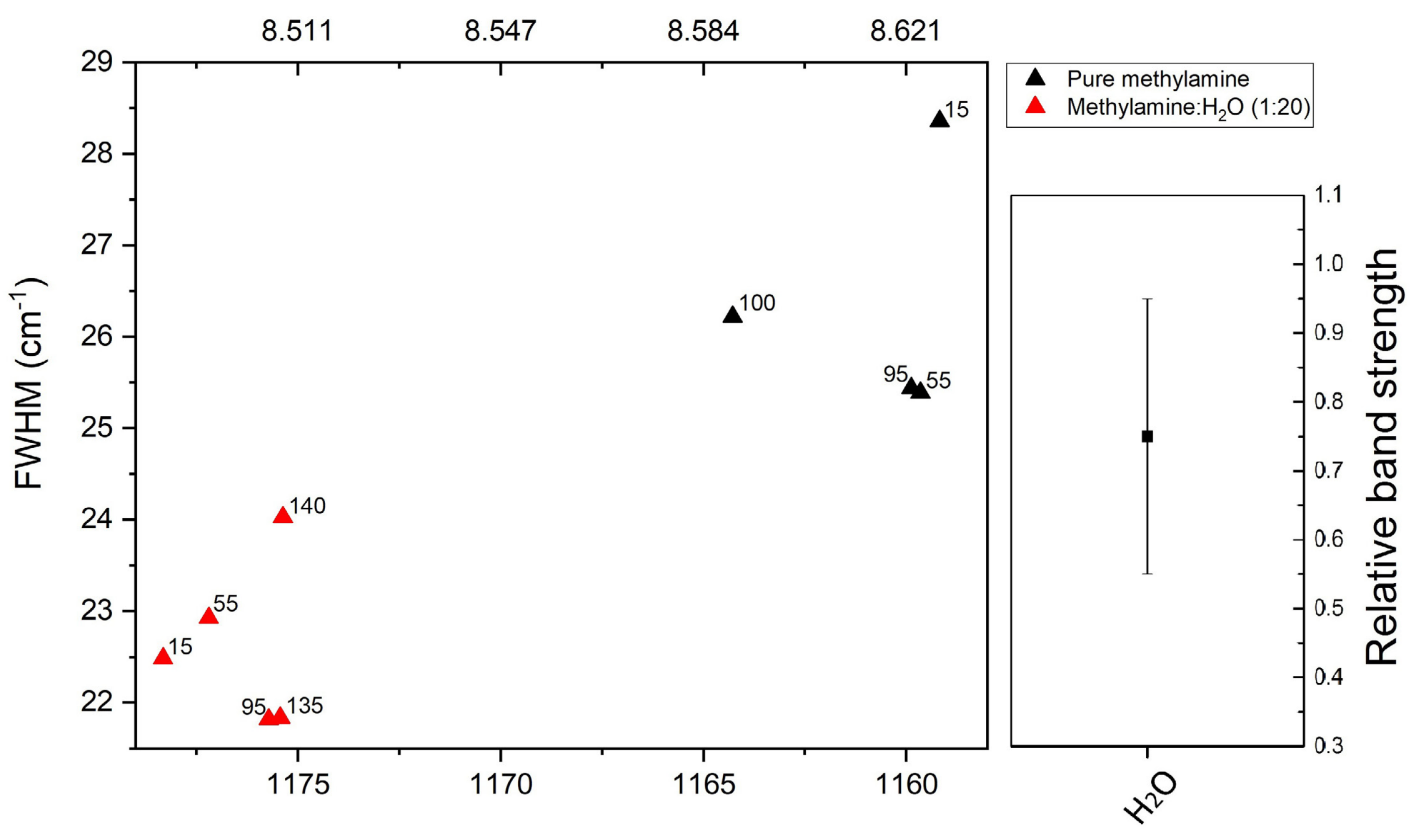

Wavenumber $\left(\mathrm{cm}^{-1}\right)$

Fig. A.2. (a) Infrared band profile of the $\mathrm{CH}_{3}$ rock vibrational mode of $\mathrm{CH}_{3} \mathrm{NH}_{2}$, around $1159 \mathrm{~cm}^{-1}$, in different ices at different temperatures, from left to right: pure $\mathrm{CH}_{3} \mathrm{NH}_{2}, \mathrm{CH}_{3} \mathrm{NH}_{2}: \mathrm{H}_{2} \mathrm{O}$ (1:20), $\mathrm{CH}_{3} \mathrm{NH}_{2}: \mathrm{CH}_{4}$ (1:20), and $\mathrm{CH}_{3} \mathrm{NH}_{2}: \mathrm{NH}_{3}$ (1:20). The first and the last panels are displayed at a different $Y$-scale. In the last panel the $\mathrm{CH}_{3} \mathrm{NH}_{2}$ feature (whose position is indicated by the dashed line) appears as a shoulder in the ammonia $v_{2}$ band (umbrella mode). (b) Left panel: peak position vs. FWHM for the $\mathrm{CH}_{3}$ rock band in the ice mixtures displayed in $a$. Different mixtures are indicated by different color and the different temperatures are marked in the graph. Right panel: relative band strength of the $\mathrm{CH}_{3}$ rock vibrational mode at $15 \mathrm{~K}$. 
M. G. Rachid et al.: Infrared spectra of complex organic molecules in astronomically relevant ice mixtures. IV.

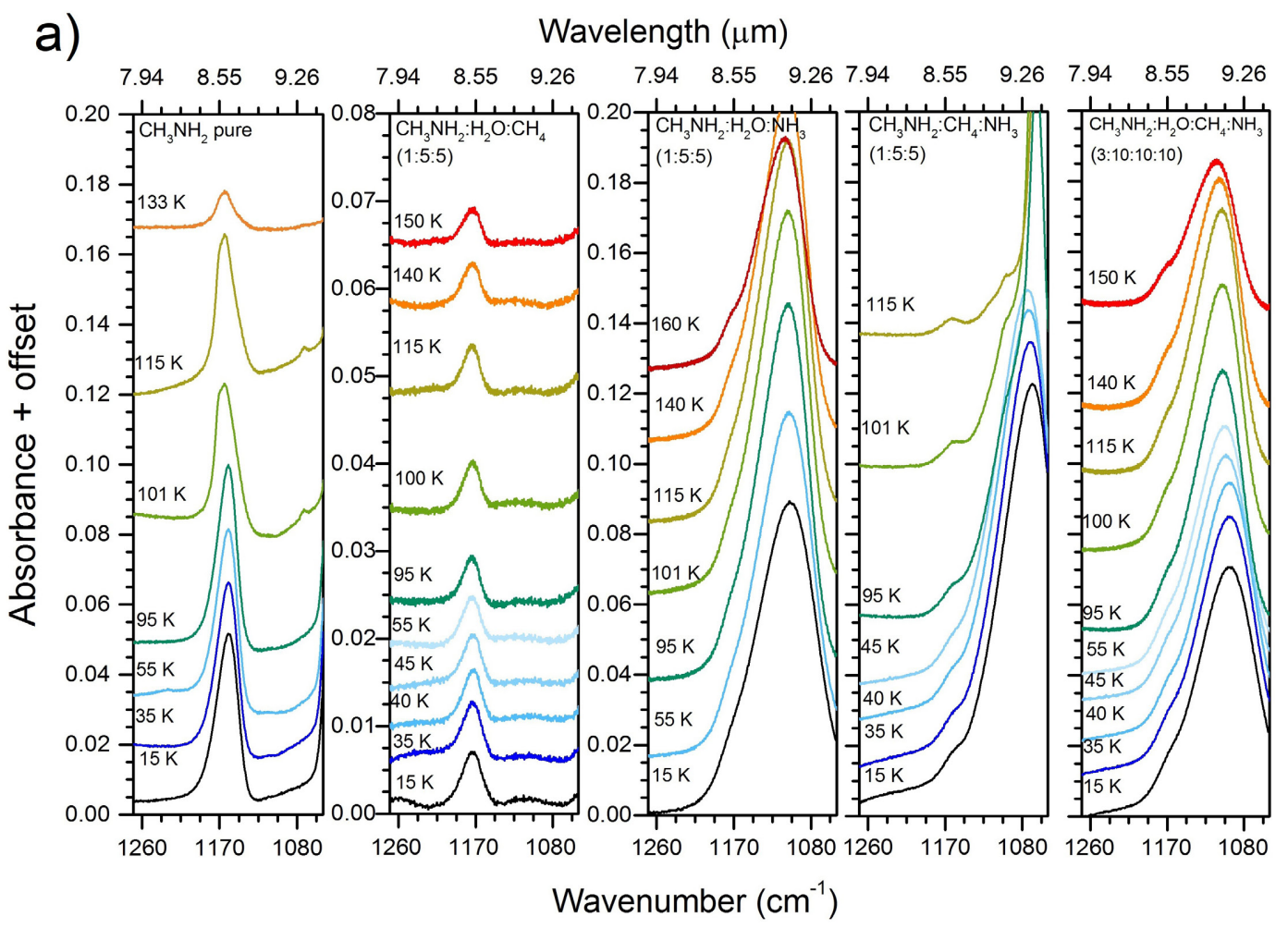

b)

Wavelength $(\mu \mathrm{m})$

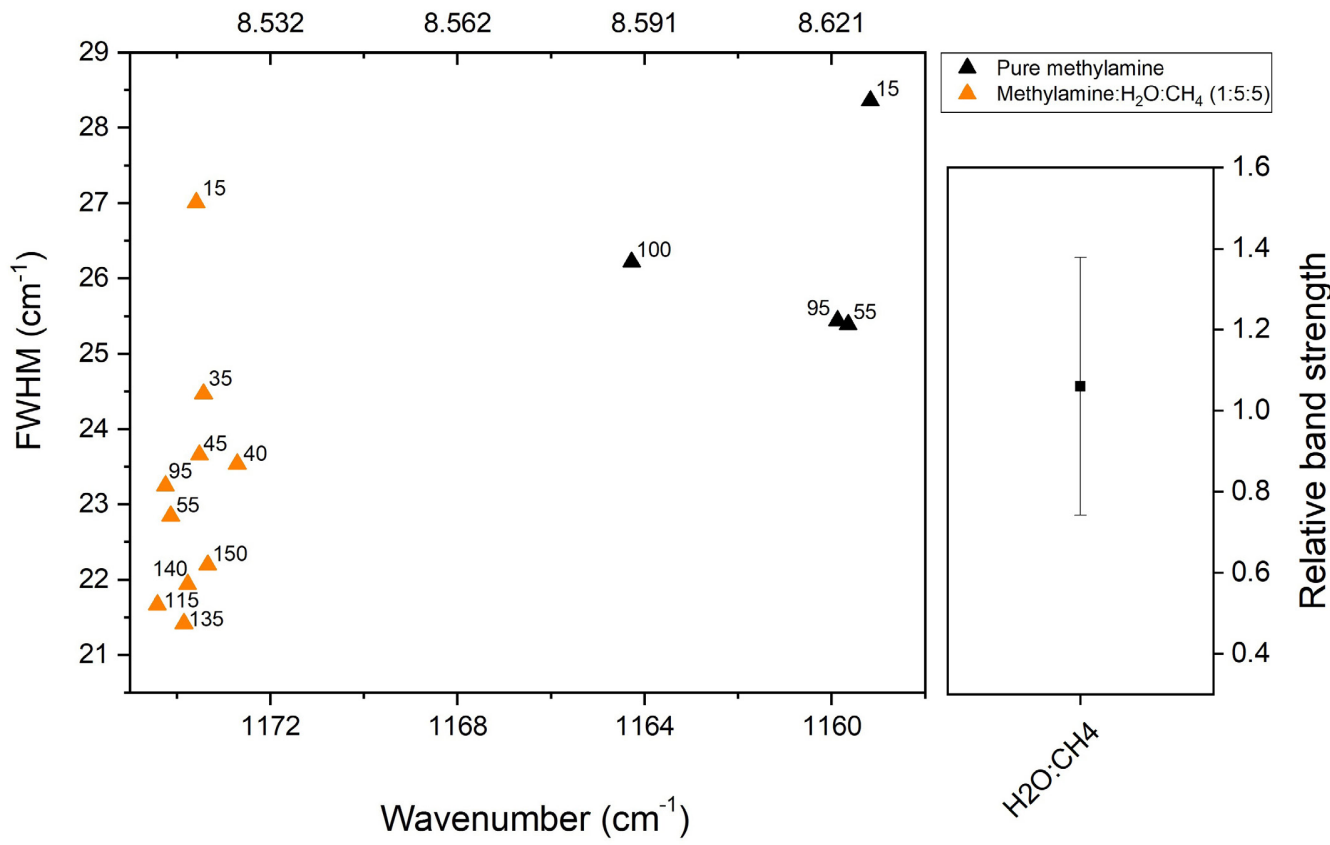

Fig. A.3. (a) Infrared band profile of the $\mathrm{CH}_{3}$ rock vibrational mode of $\mathrm{CH}_{3} \mathrm{NH}_{2}$, around $1159 \mathrm{~cm}^{-1}$, in different ices at different temperatures, from left to right: pure $\mathrm{CH}_{3} \mathrm{NH}_{2}, \mathrm{CH}_{3} \mathrm{NH}_{2}: \mathrm{H}_{2} \mathrm{O}: \mathrm{CH}_{4}$ (1:5:5), $\mathrm{CH}_{3} \mathrm{NH}_{2}: \mathrm{H}_{2} \mathrm{O}: \mathrm{NH}_{3}$ (1:5:5), $\mathrm{CH}_{3} \mathrm{NH}_{2}: \mathrm{CH}_{4}: \mathrm{NH}_{3}$ (1:5:5), and $\mathrm{CH}_{3} \mathrm{NH}_{2}: \mathrm{H}_{2} \mathrm{O}: \mathrm{CH}_{4}: \mathrm{NH}_{3}(3: 10: 10: 10)$. The panels are displayed at a different $Y$-scale. In the last three panels, the $\mathrm{CH}_{3} \mathrm{NH}_{2}$ feature appears as a shoulder in the ammonia $v_{2}$ band (umbrella mode). (b) Left panel: peak position vs. FWHM for the $\mathrm{CH}_{3}$ rock band in the ice mixtures displayed in $a$. Different mixtures are indicated by different colors, and the different temperatures are marked in the graph. Right panel: relative band strength of the $\mathrm{CH}_{3}$ rock vibrational mode at $15 \mathrm{~K}$. 


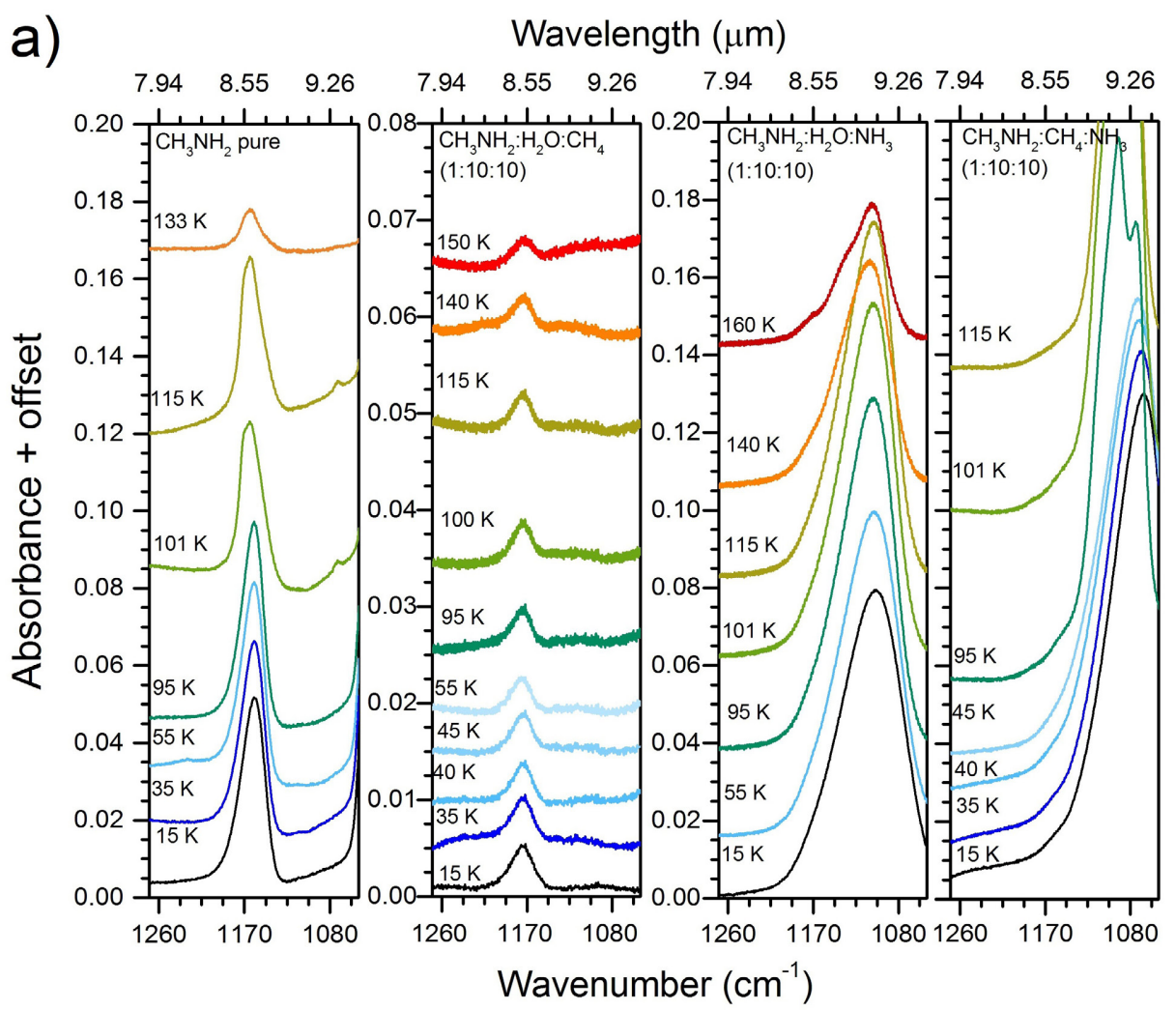

b)

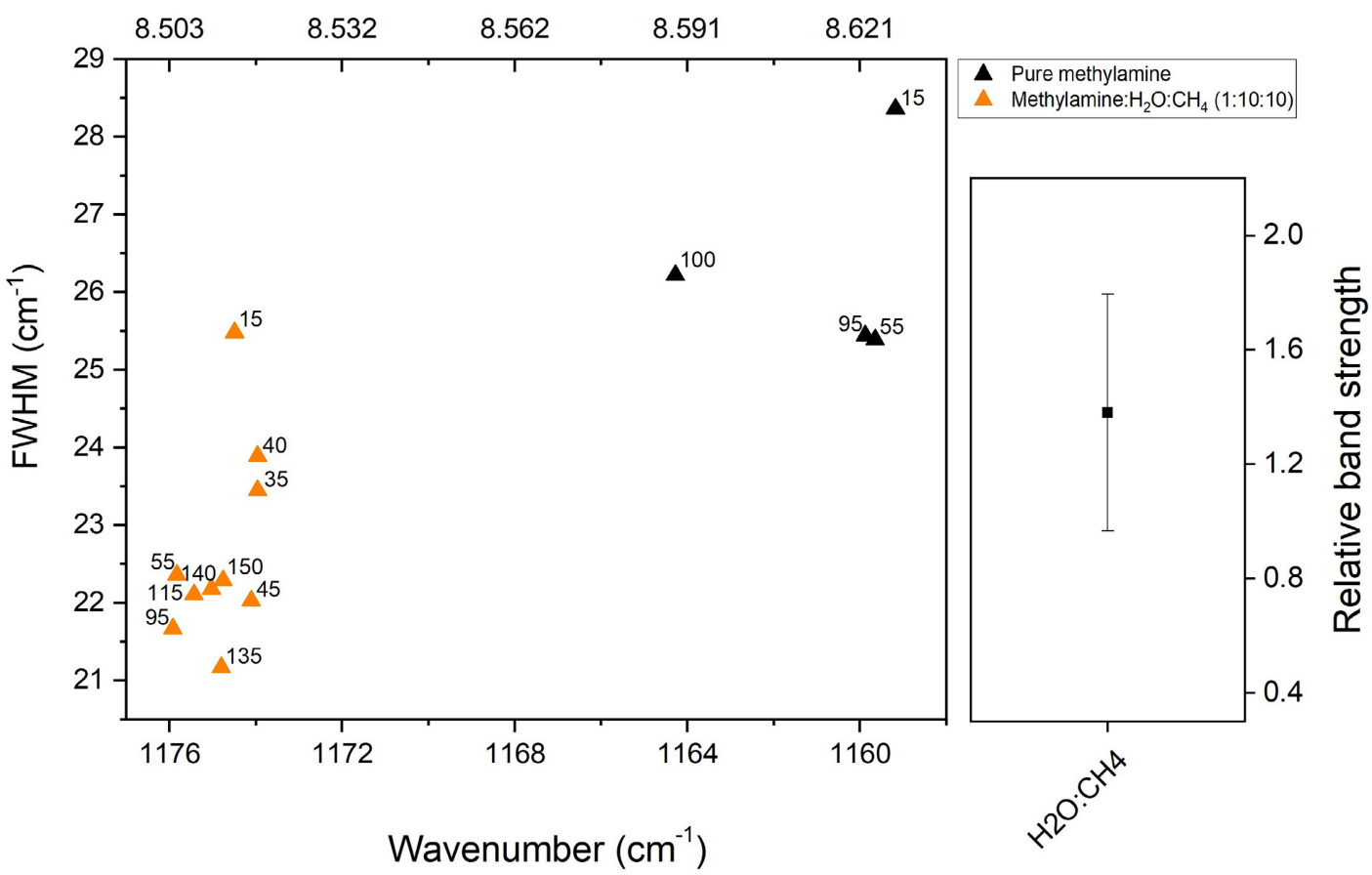

Fig. A.4. (a) Infrared band profile of the $\mathrm{CH}_{3}$ rock vibrational mode of $\mathrm{CH}_{3} \mathrm{NH}_{2}$, around $1159 \mathrm{~cm}^{-1}$, in different ices at different temperatures, from left to right: pure $\mathrm{CH}_{3} \mathrm{NH}_{2}, \mathrm{CH}_{3} \mathrm{NH}_{2}: \mathrm{H}_{2} \mathrm{O}: \mathrm{CH}_{4}(1: 10: 10)$, and $\mathrm{CH}_{3} \mathrm{NH}_{2}: \mathrm{H}_{2} \mathrm{O}: \mathrm{NH}_{3}$ (1:10:10). The last three panels are displayed at a different scale because the $\mathrm{CH}_{3} \mathrm{NH}_{2}$ feature appears as a shoulder in the band of the ammonia $v_{2}$ mode (umbrella). (b) Left panel: peak position vs. FWHM for the $\mathrm{CH}_{3}$ rock band in the ice mixtures displayed in $a$. Different mixtures are indicated by different colors, and the different temperatures are marked in the graph. Right panel: relative band strength of the $\mathrm{CH}_{3}$ rock vibrational mode at $15 \mathrm{~K}$. 
M. G. Rachid et al.: Infrared spectra of complex organic molecules in astronomically relevant ice mixtures. IV.

a)

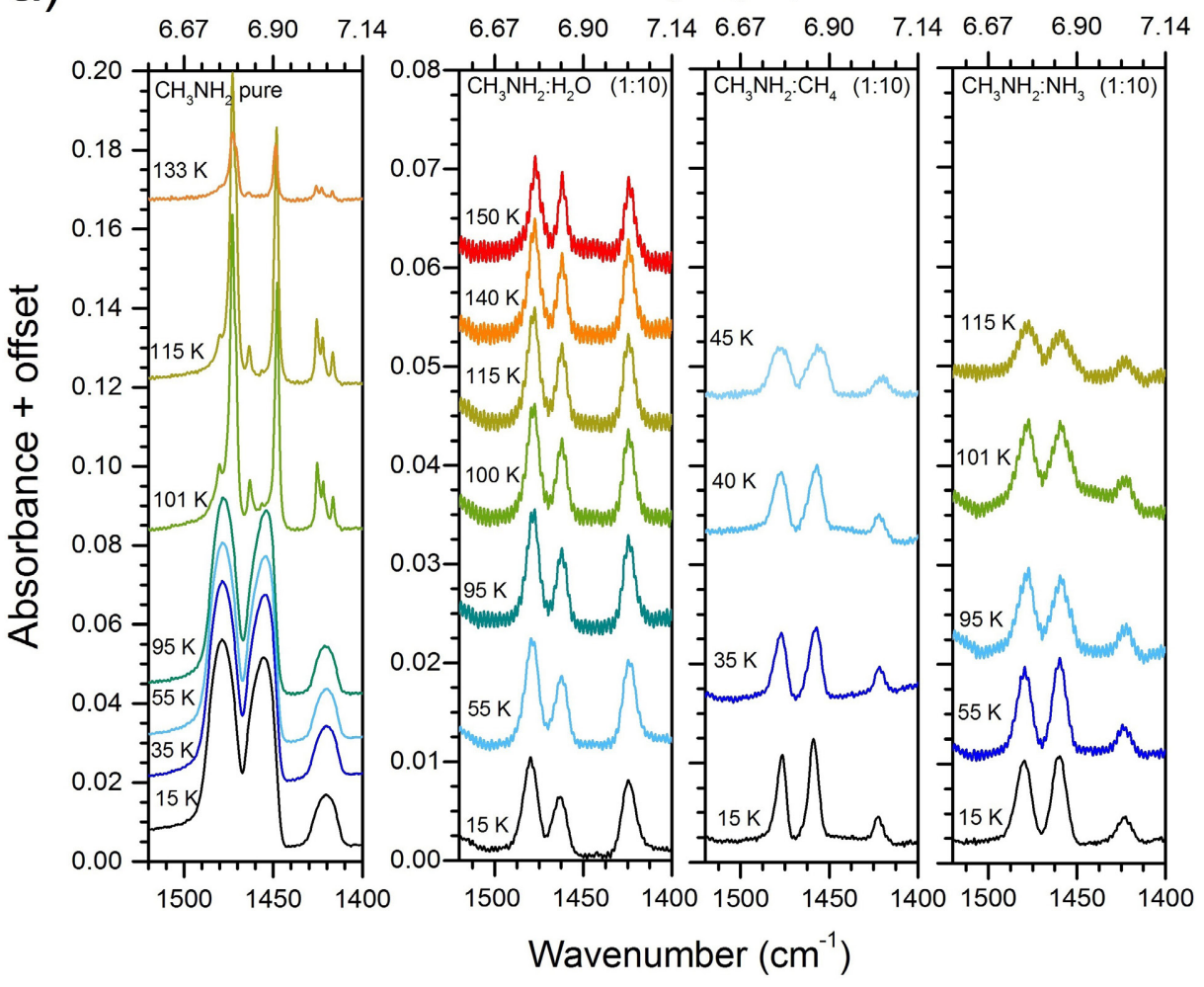

b)

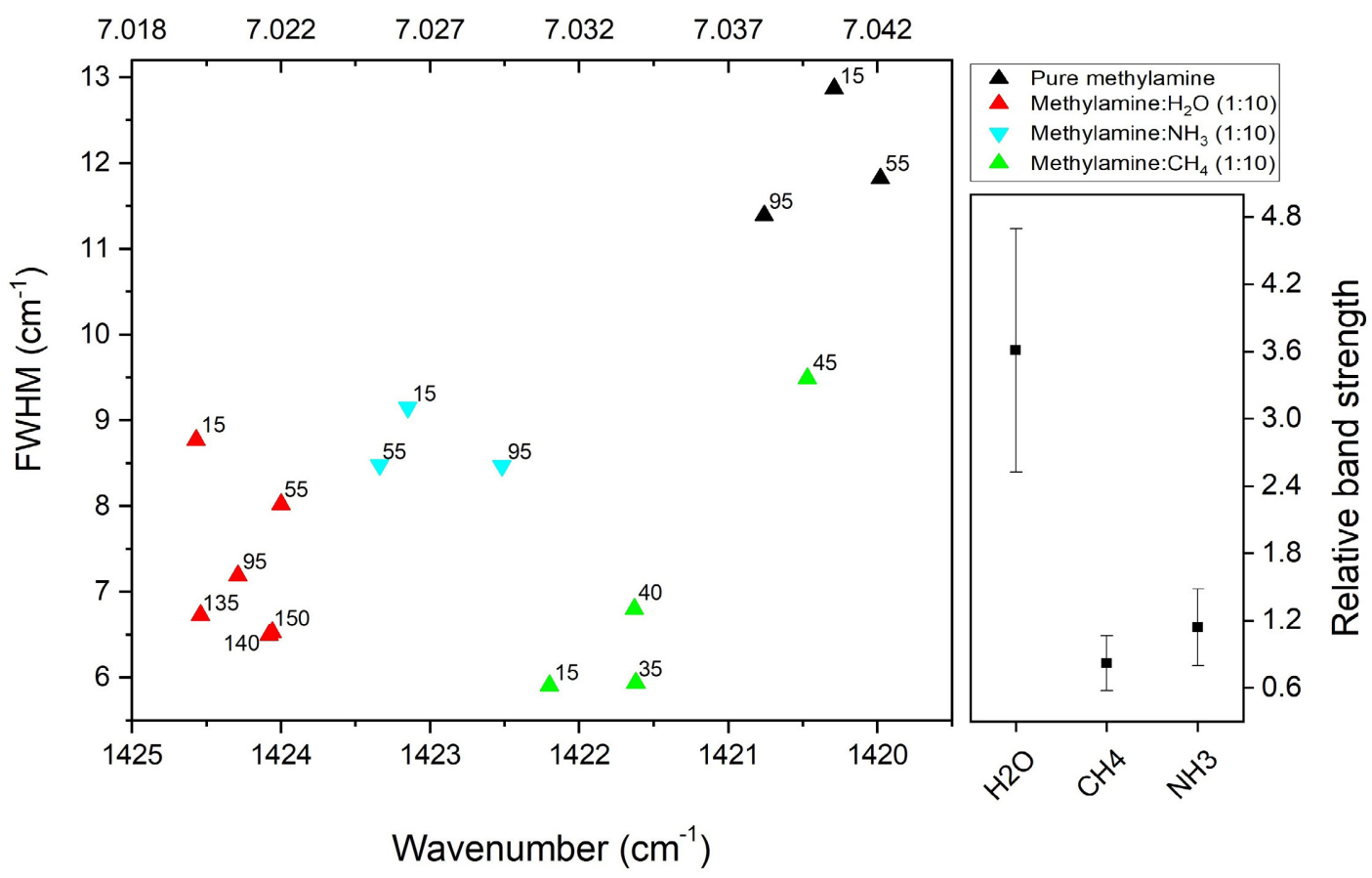

Fig. A.5. (a) Infrared band profile of the $\mathrm{CH}_{3}$ antisymmetric deformation mode of $\mathrm{CH}_{3} \mathrm{NH}_{2}$ (the peaks around $1479 \mathrm{~cm}^{-1}$ and $1455 \mathrm{~cm}^{-1}$ ) and the $\mathrm{CH}_{3}$ symmetric deformation mode (around $1420 \mathrm{~cm}^{-1}$ ), in different ices at different temperatures, from left to right: pure $\mathrm{CH}_{3} \mathrm{NH}_{2}, \mathrm{CH}_{3} \mathrm{NH}_{2}: \mathrm{H}_{2} \mathrm{O}$ (1:10), $\mathrm{CH}_{3} \mathrm{NH}_{2}: \mathrm{CH}_{4}(1: 10)$, and $\mathrm{CH}_{3} \mathrm{NH}_{2}: \mathrm{NH}_{3}$ (1:10). (b) Left panel: peak position vs. FWHM for the $\mathrm{CH}_{3}$ symmetric deformation band in the ice mixtures displayed in $a$. Different mixtures are indicated by different colors, and the different temperatures are marked in the graph. Right panel: relative band strength of the $\mathrm{CH}_{3}$ symmetric deformation band $\left(1420 \mathrm{~cm}^{-1}\right)$ in different ice mixtures at $15 \mathrm{~K}$. Panels $c$ and $d$ : same as $b$ for the $\mathrm{CH}_{3}$ antisymmetric deformation modes, $v_{5}$ and $v_{12}$, at 1455 and $1478.6 \mathrm{~cm}^{-1}$, respectively. 

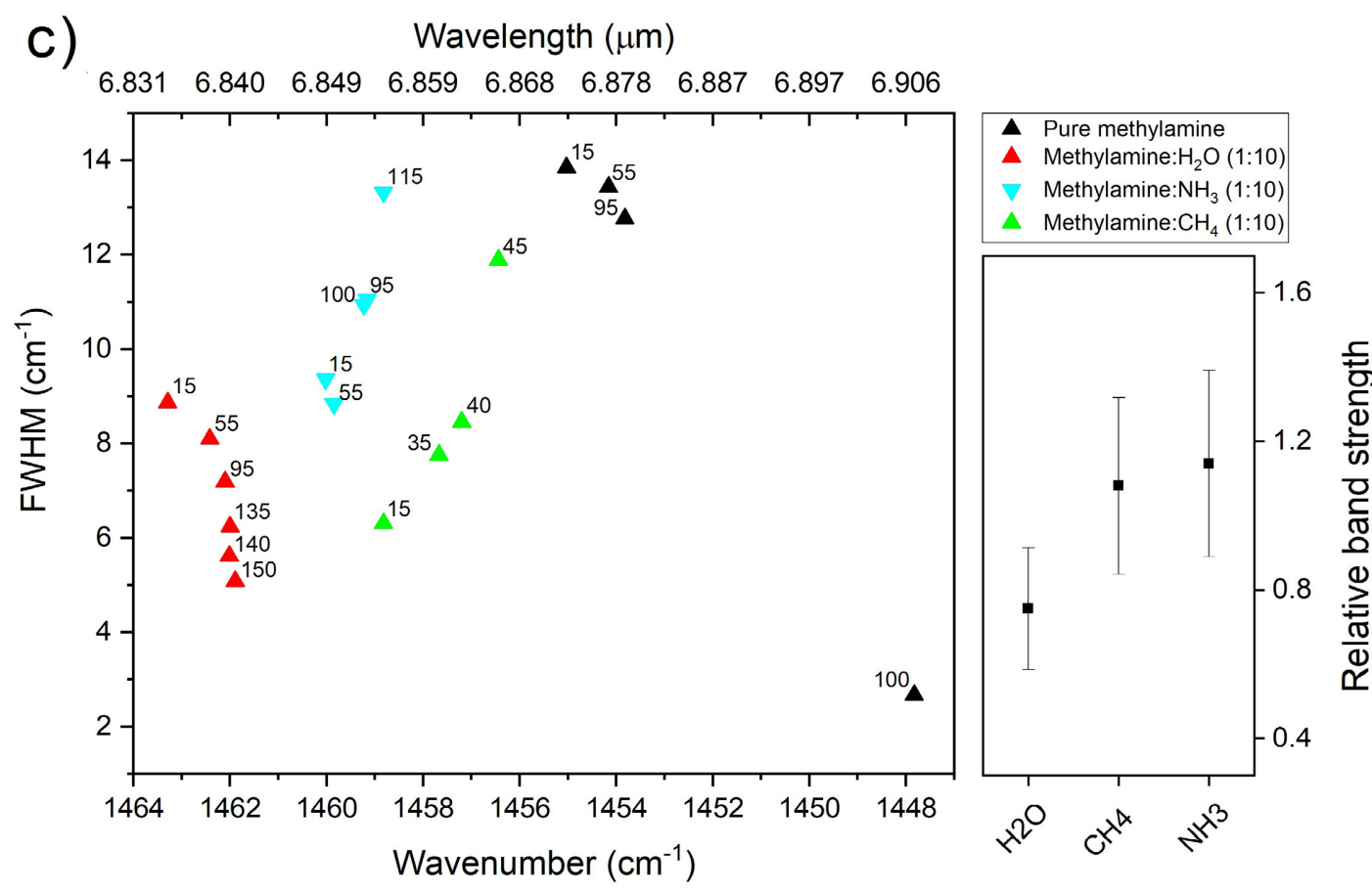

d)

Wavelength $(\mu \mathrm{m})$
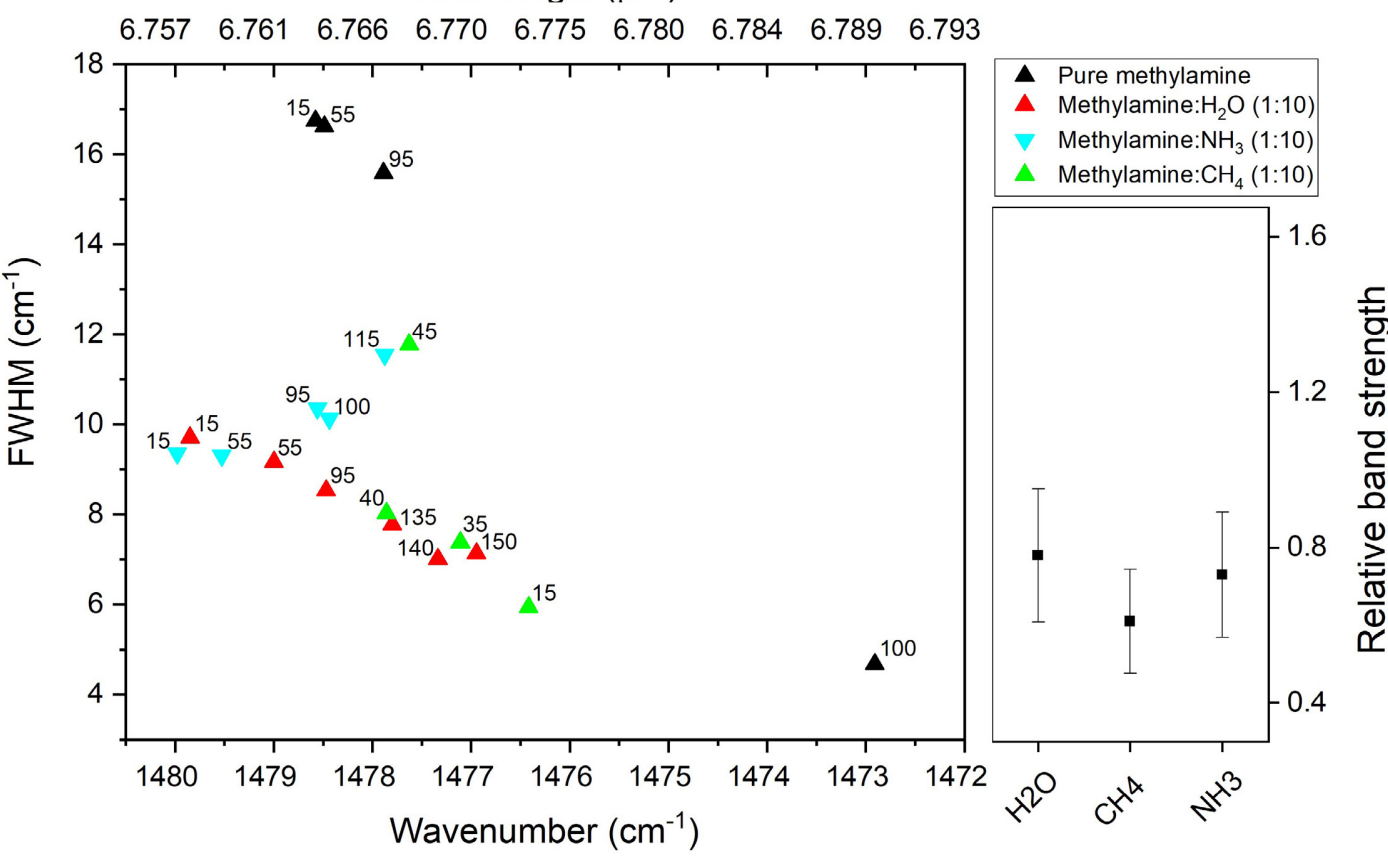

Fig. A.5. continued. 
M. G. Rachid et al.: Infrared spectra of complex organic molecules in astronomically relevant ice mixtures. IV.

a)

Wavelength $(\mu \mathrm{m})$
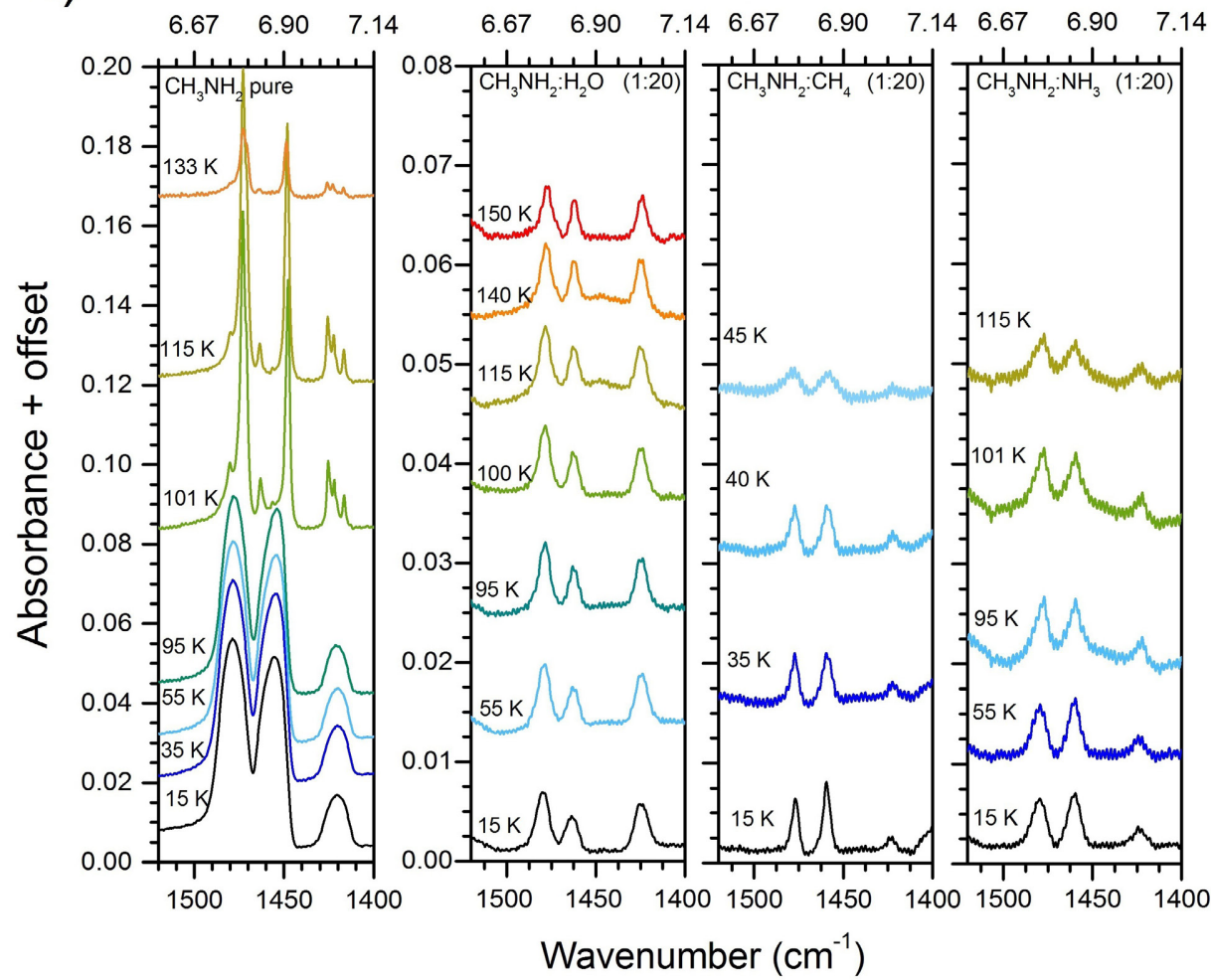

b)

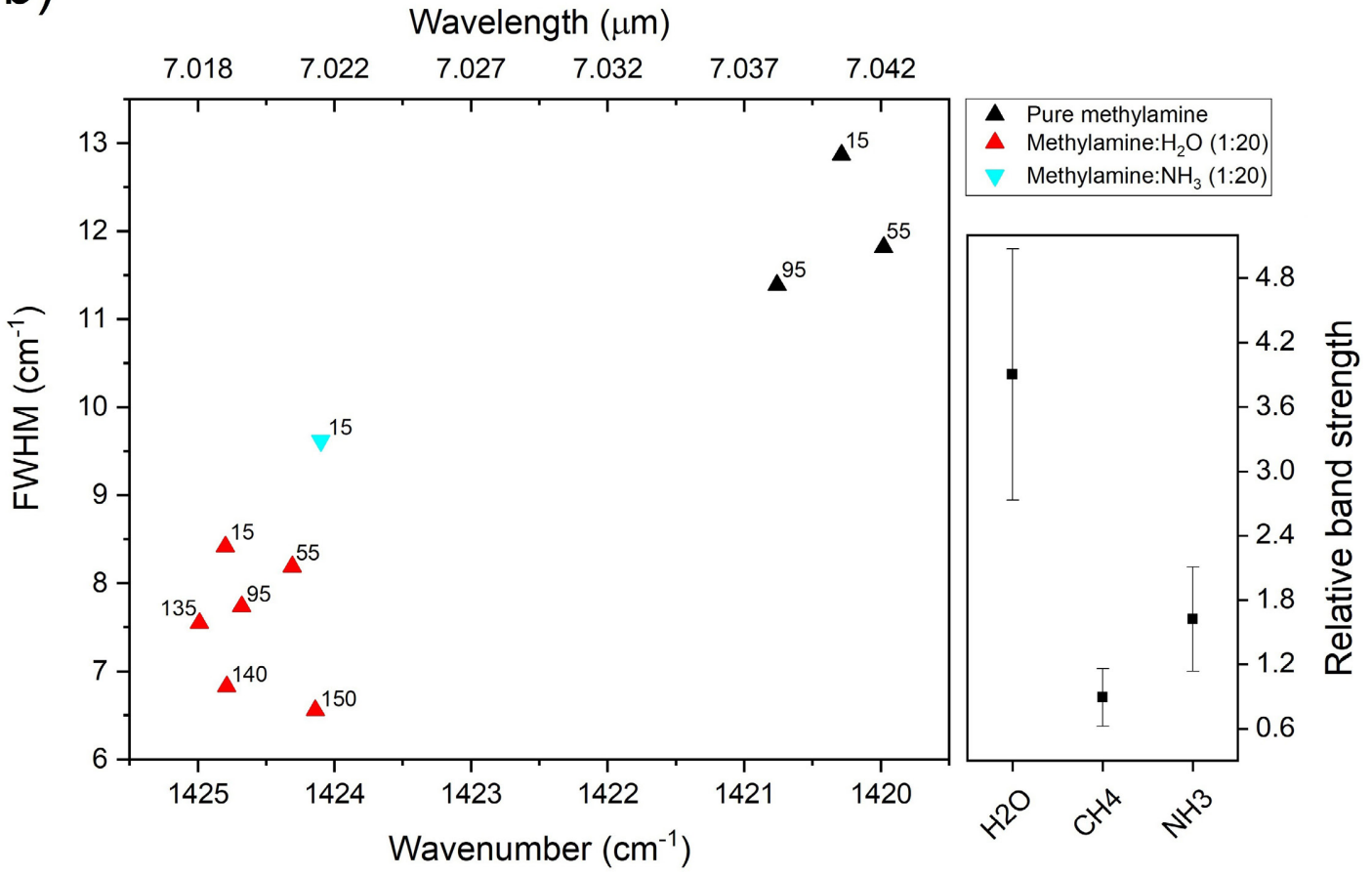

Fig. A.6. (a) Infrared band profile of the $\mathrm{CH}_{3}$ antisymmetric deformation mode of $\mathrm{CH}_{3} \mathrm{NH}_{2}$ (the peaks around $1479 \mathrm{~cm}^{-1}$ and $1455 \mathrm{~cm}^{-1}$ ) and the $\mathrm{CH}_{3}$ symmetric deformation mode (around $1420 \mathrm{~cm}^{-1}$ ), in different ices at different temperatures, from left to right: pure $\mathrm{CH}_{3} \mathrm{NH}_{2}, \mathrm{CH}_{3} \mathrm{NH}_{2}: \mathrm{H}_{2} \mathrm{O}$ (1:20), $\mathrm{CH}_{3} \mathrm{NH}_{2}: \mathrm{CH}_{4}$ (1:20), and $\mathrm{CH}_{3} \mathrm{NH}_{2}: \mathrm{NH}_{3}$ (1:20). (b) Left panel: peak position vs. FWHM for the $\mathrm{CH}_{3}$ symmetric deformation band in the ice mixtures displayed in $a$. Different mixtures are indicated by different colors, and the different temperatures are marked in the graph. Right panel: relative band strength of the $\mathrm{CH}_{3}$ symmetric deformation band $\left(1420 \mathrm{~cm}^{-1}\right)$ in different ice mixtures at $15 \mathrm{~K}$. Panels $c$ and $d$ : same as $b$ for the $\mathrm{CH}_{3}$ antisymmetric deformation modes, $v_{5}$ and $v_{12}$, at 1455 and $1478.6 \mathrm{~cm}^{-1}$, respectively. 


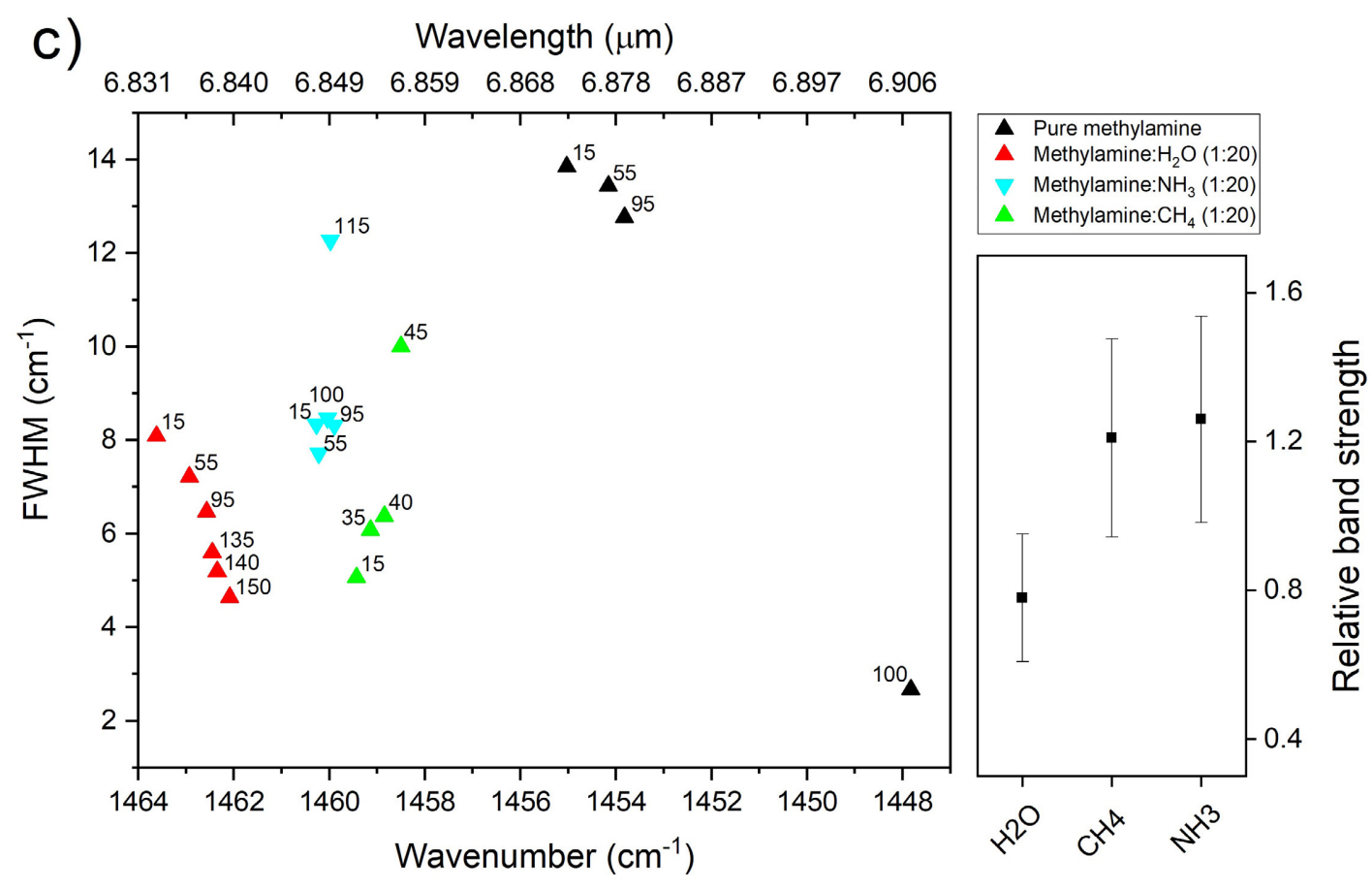

d)

Wavelength $(\mu \mathrm{m})$

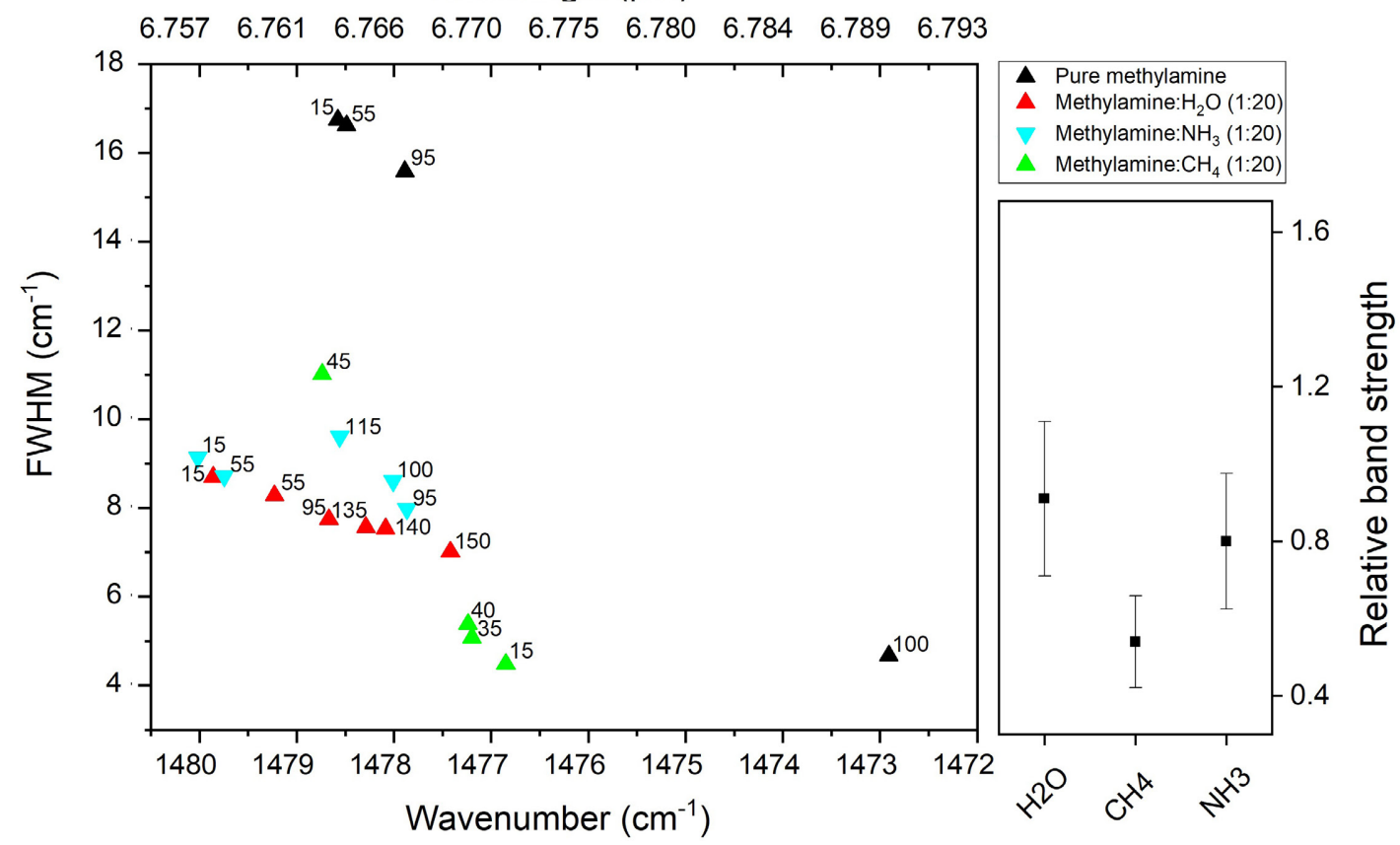

Fig. A.6. continued. 
M. G. Rachid et al.: Infrared spectra of complex organic molecules in astronomically relevant ice mixtures. IV.

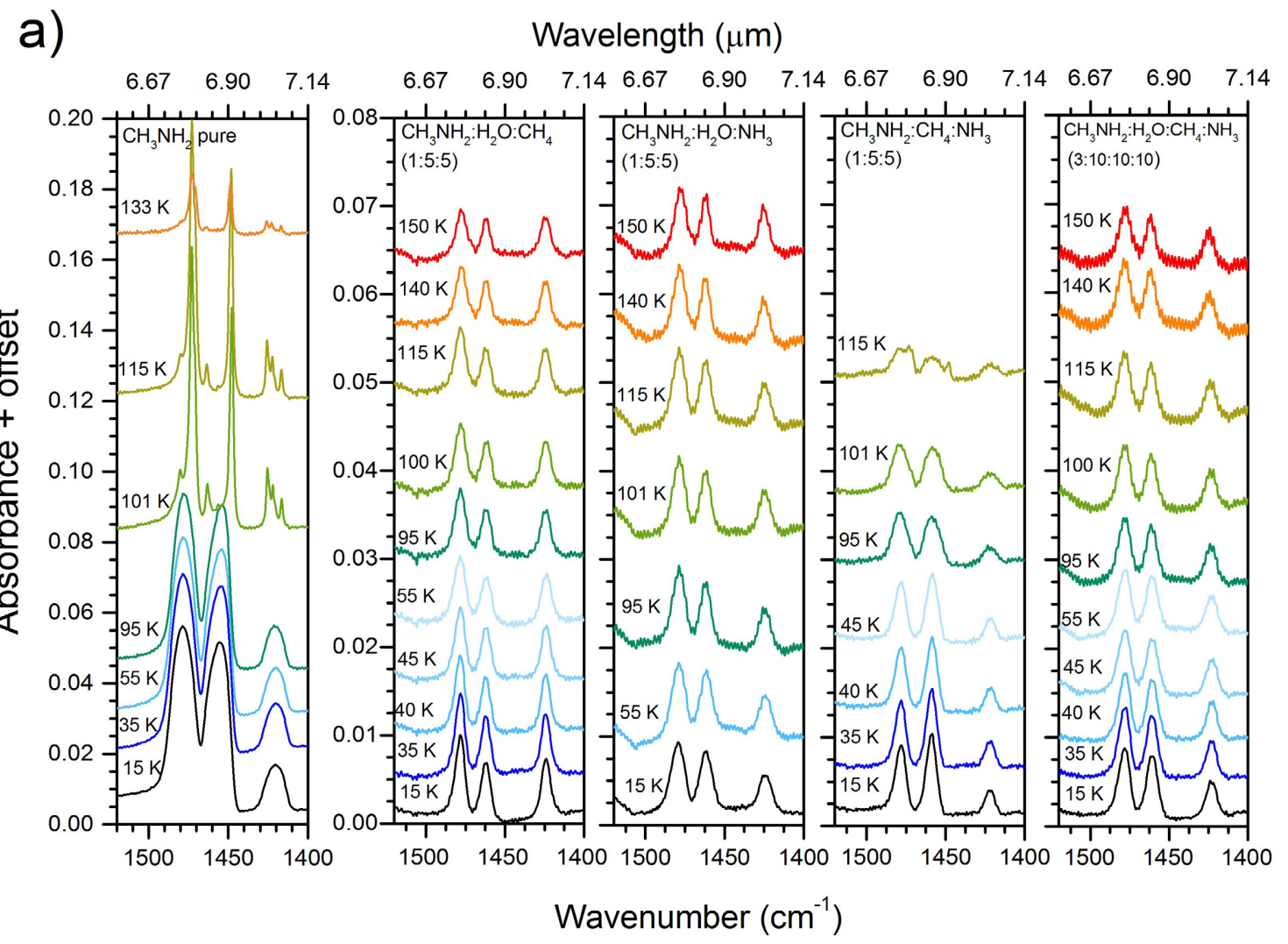

b)

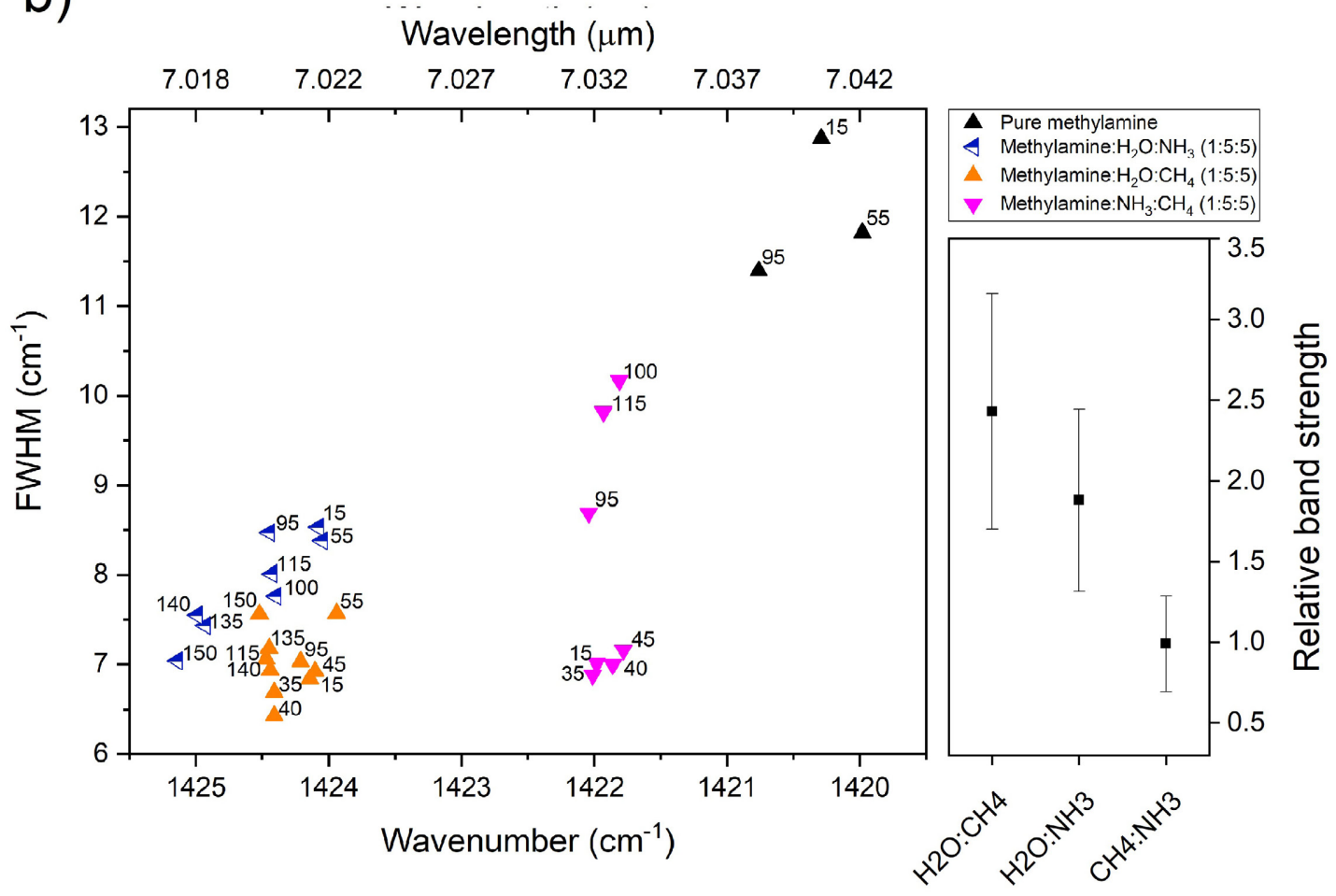

Fig. A.7. (a) Infrared band profile of the $\mathrm{CH}_{3}$ antisymmetric deformation mode of $\mathrm{CH}_{3} \mathrm{NH}_{2}$ (the peaks around $1479 \mathrm{~cm}^{-1}\left(v_{12}\right.$ mode) and $1455 \mathrm{~cm}^{-1}$ $\left(v_{5}\right)$ ) and the $\mathrm{CH}_{3}$ symmetric deformation mode (around $1420 \mathrm{~cm}^{-1}$ ), in different ices at different temperatures, from left to right: pure $\mathrm{CH}_{3} \mathrm{NH}_{2}$, $\mathrm{CH}_{3} \mathrm{NH}_{2}: \mathrm{H}_{2} \mathrm{O}: \mathrm{CH}_{4}$ (1:5:5), $\mathrm{CH}_{3} \mathrm{NH}_{2}: \mathrm{H}_{2} \mathrm{O}: \mathrm{NH}_{3}$ (1:5:5) $\mathrm{CH}_{3} \mathrm{NH}_{2}: \mathrm{CH}_{4}: \mathrm{NH}_{3}$ (1:5:5), and $\mathrm{CH}_{3} \mathrm{NH}_{2}: \mathrm{H}_{2} \mathrm{O}: \mathrm{CH}_{4}: \mathrm{NH}_{3}(3: 10: 10: 10)$. (b) Left panel: peak position vs. FWHM for the $\mathrm{CH}_{3}$ symmetric deformation band $\left(1420 \mathrm{~cm}^{-1}\right)$ in the ice mixtures displayed in $a$. Different mixtures are indicated by different colors, and the different temperatures are marked in the graph. Right panel: relative band strength of the $\mathrm{CH}_{3}$ symmetric deformation band in different ice mixtures at $15 \mathrm{~K}$. Panels $c$ and $d$ : same as $b$ for the $\mathrm{CH}_{3}$ antisymmetric deformation modes, $v_{5}$ and $v_{12}$, at 1455 and $1478.6 \mathrm{~cm}^{-1}$, respectively. 
C) Wavelength $(\mu \mathrm{m})$

C) $6.8216 .831 \quad 6.840 \quad 6.8496 .8596 .868 \quad 6.878 \quad 6.887 \quad 6.897 \quad 6.906$

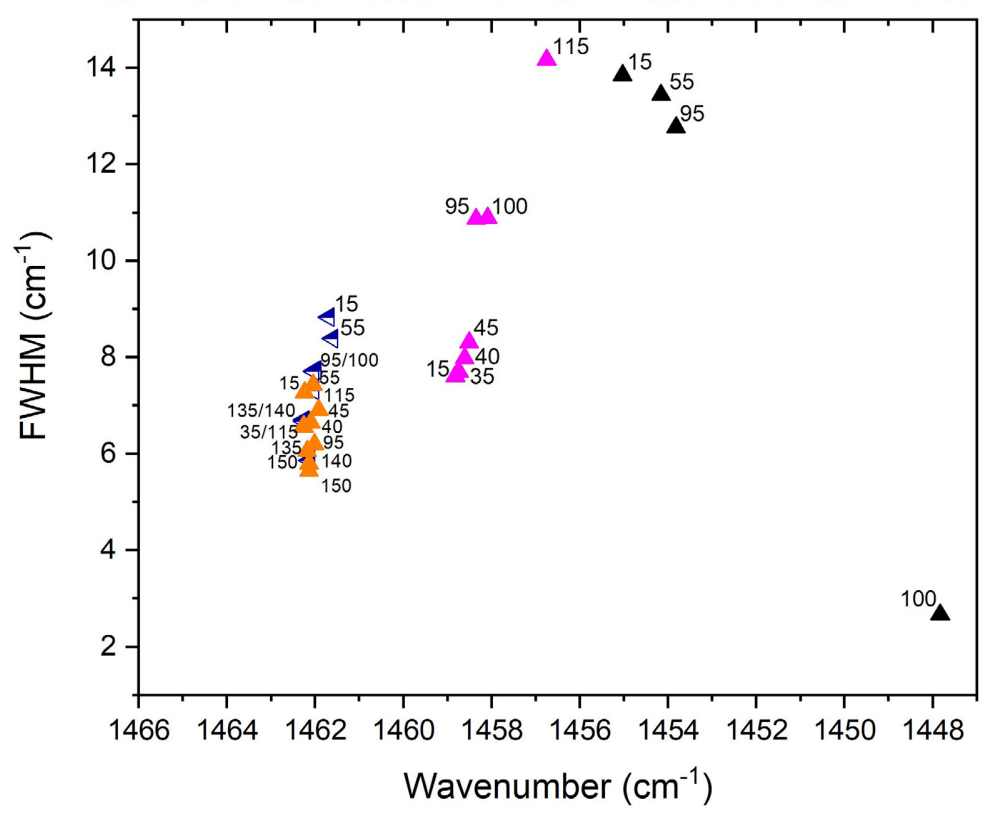

A Pure methylamine

Methylamine: $\mathrm{H}_{2} \mathrm{O}: \mathrm{NH}_{3}(1: 5: 5)$

Methylamine: $\mathrm{H}_{2} \mathrm{O}: \mathrm{CH}_{4}(1: 5: 5)$

Methylamine: $\mathrm{NH}_{3}: \mathrm{CH}_{4}(1: 5: 5)$

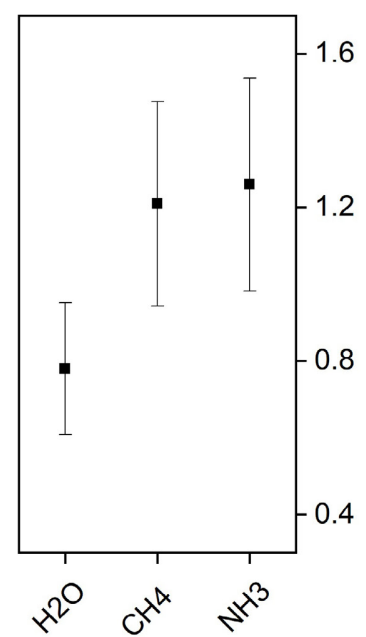

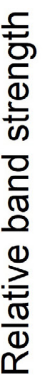

d)

Wavelength $(\mu \mathrm{m})$

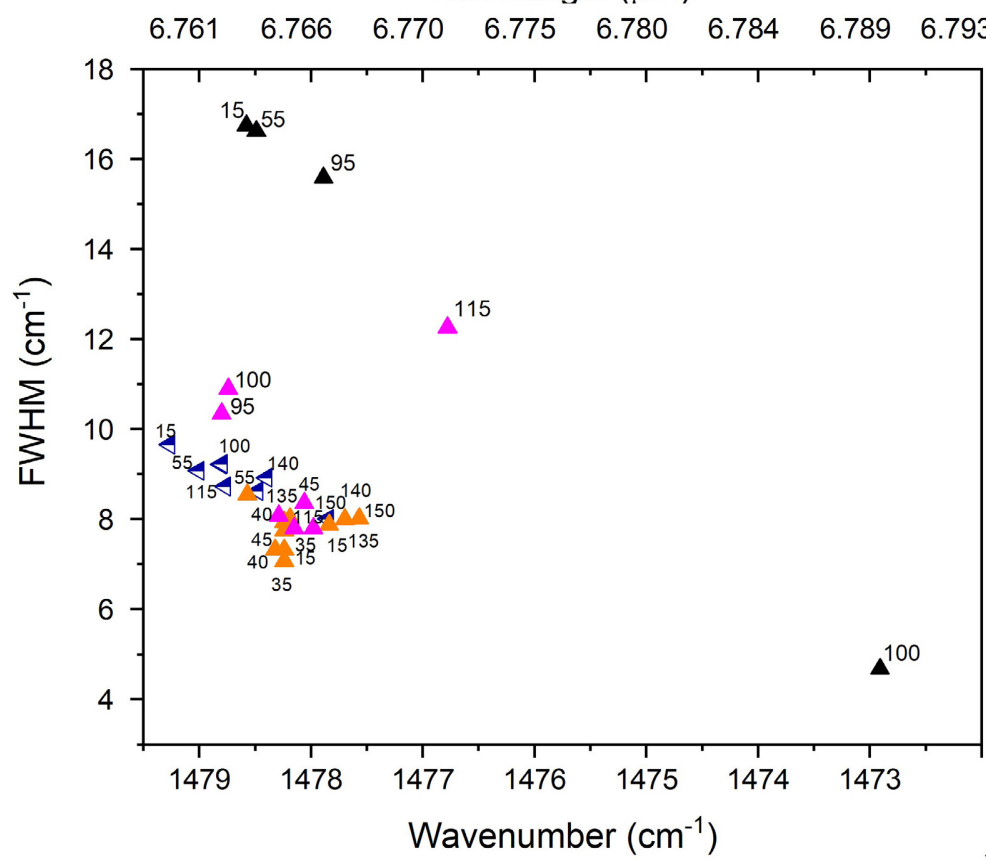

A Pure methylamine

Methylamine: $\mathrm{H}_{2} \mathrm{O}: \mathrm{CH}_{4}(1: 5: 5)$

- Methylamine: $\mathrm{NH}_{3}: \mathrm{CH}_{4}(1: 5: 5)$

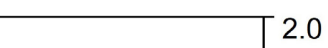

2.0

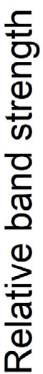

Fig. A.7. continued. 
M. G. Rachid et al.: Infrared spectra of complex organic molecules in astronomically relevant ice mixtures. IV.

a)

Wavelength $(\mu \mathrm{m})$

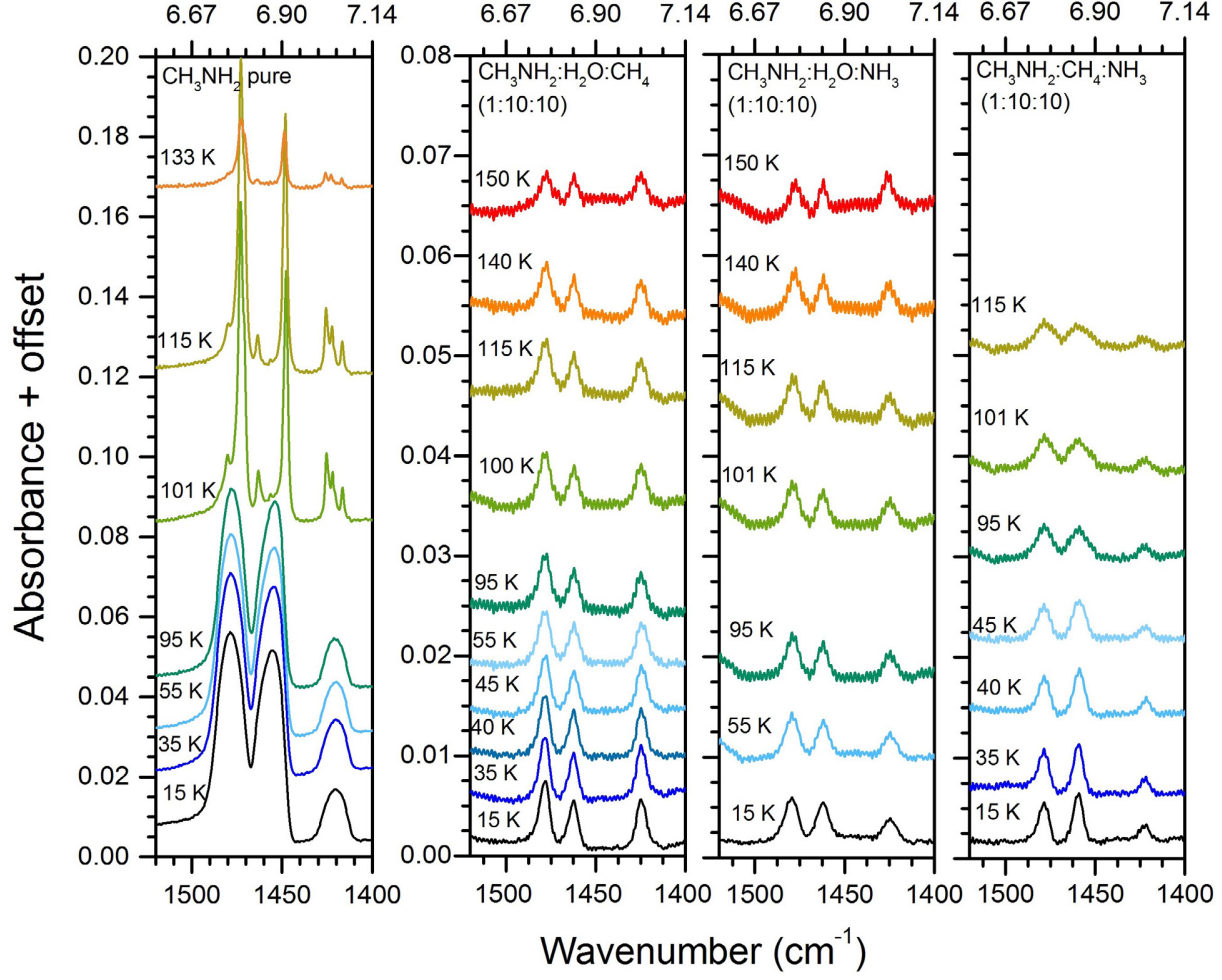

b)

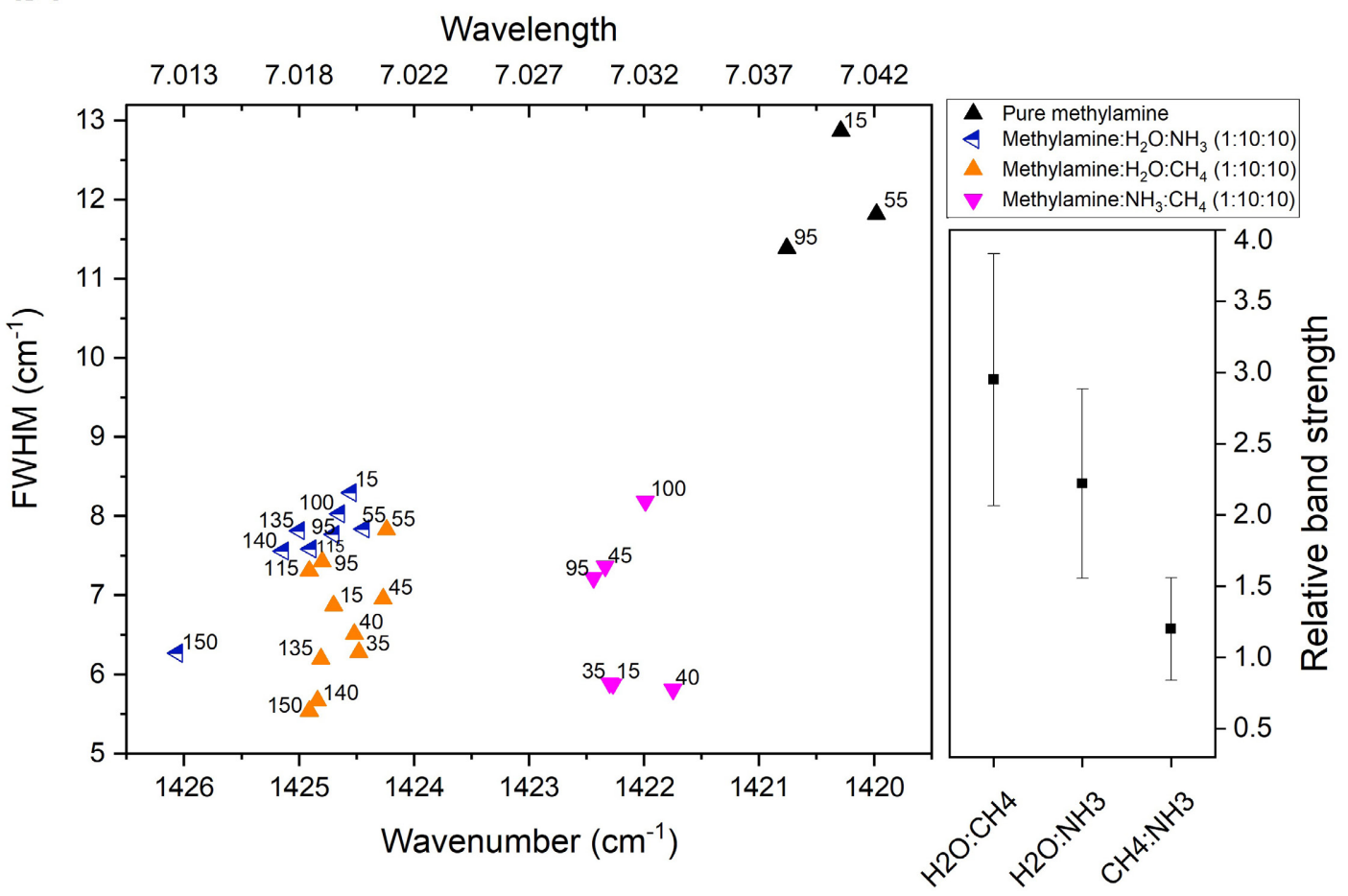

Fig. A.8. (a) Infrared band profile of the $\mathrm{CH}_{3}$ antisymmetric deformation mode of $\mathrm{CH}_{3} \mathrm{NH}_{2}$ (the peaks around 1479 and $1455 \mathrm{~cm}^{-1}$ ) and the $\mathrm{CH}_{3}$

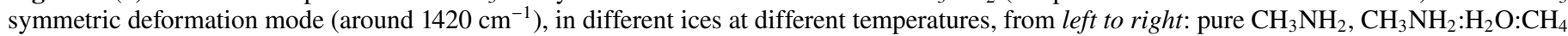
(1:10:10), $\mathrm{CH}_{3} \mathrm{NH}_{2}: \mathrm{H}_{2} \mathrm{O}: \mathrm{NH}_{3}$ (1:10:10), and $\mathrm{CH}_{3} \mathrm{NH}_{2}: \mathrm{CH}_{4}: \mathrm{NH}_{3}$ (1:10:10). (b) Left panel: peak position vs. FWHM for the $\mathrm{CH}_{3}$ symmetric deformation band in the ice mixtures displayed in $a$. Different mixtures are indicated by different colors, and the different temperatures are marked in the graph. Right panel: relative band strength of the $\mathrm{CH}_{3}$ symmetric deformation band $\left(1420 \mathrm{~cm}^{-1}\right)$ in different ice mixtures at $15 \mathrm{~K}$. Panels $c$ and $d$ : same as $b$ for the $\mathrm{CH}_{3}$ antisymmetric deformation modes, $v_{5}$ and $v_{12}$, at 1455 and $1478.6 \mathrm{~cm}^{-1}$, respectively. 

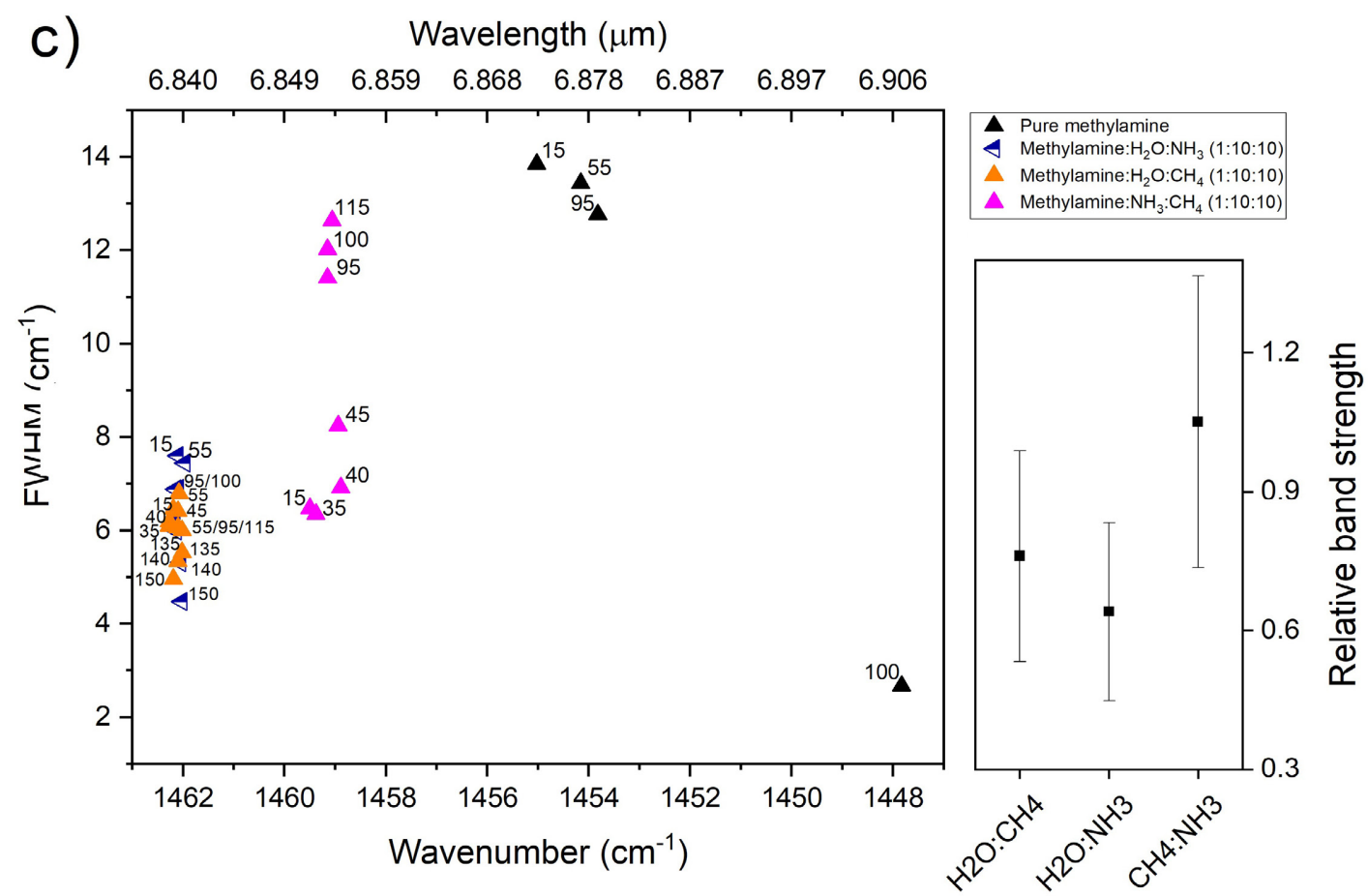

d) Wavelength $(\mu \mathrm{m})$

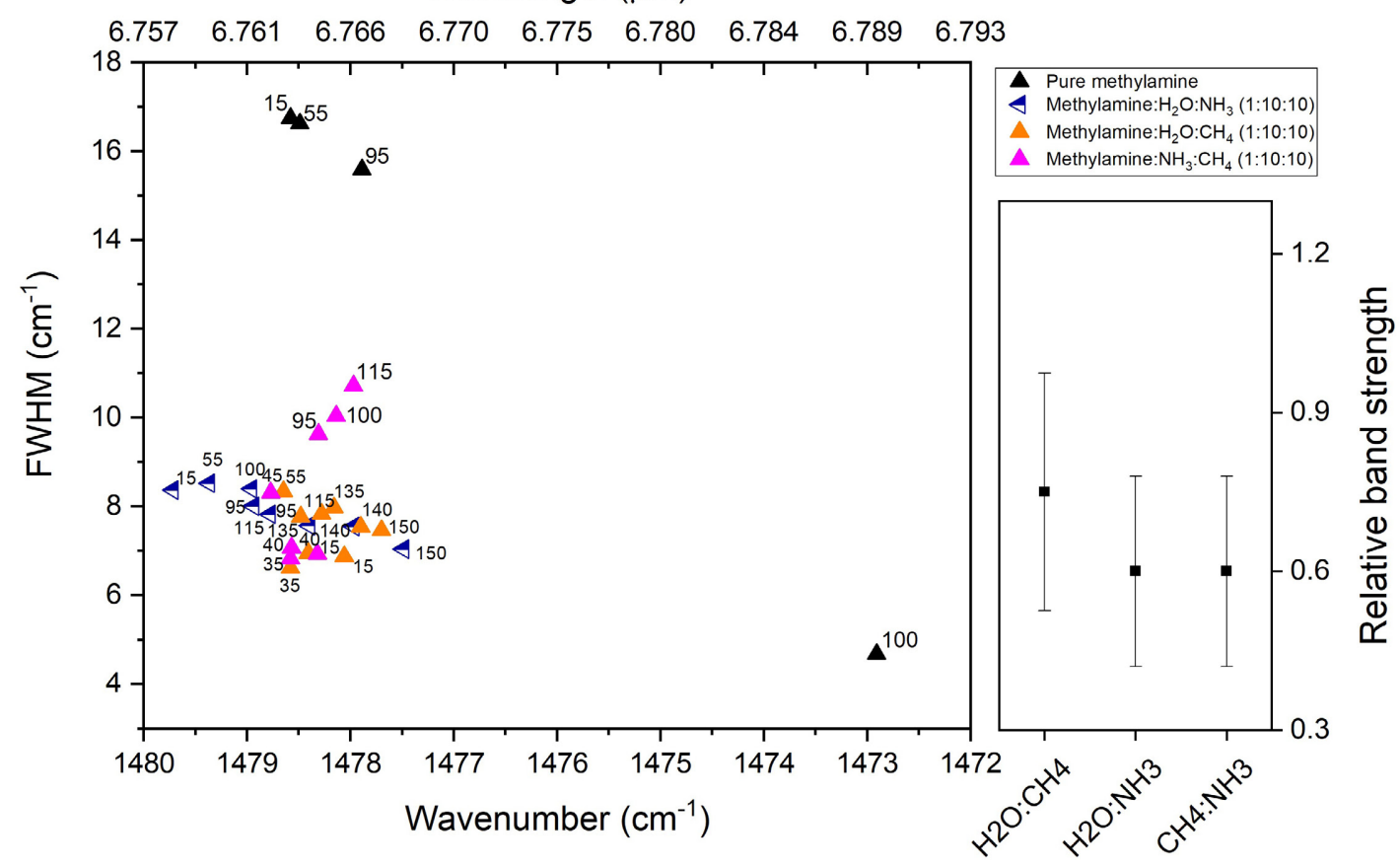

Fig. A.8. continued. 
M. G. Rachid et al.: Infrared spectra of complex organic molecules in astronomically relevant ice mixtures. IV.

a)
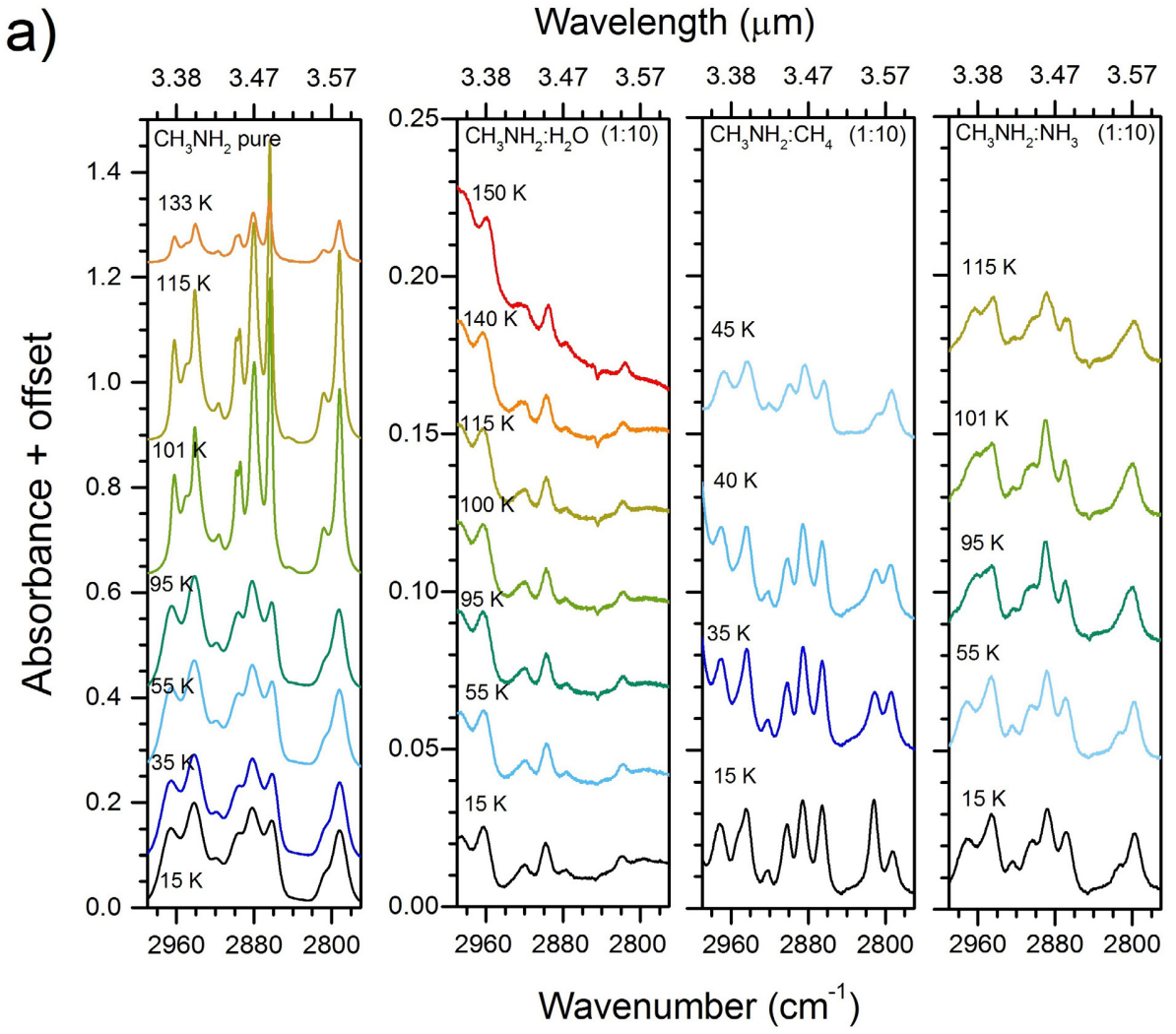

b)

Wavelength $(\mu \mathrm{m})$

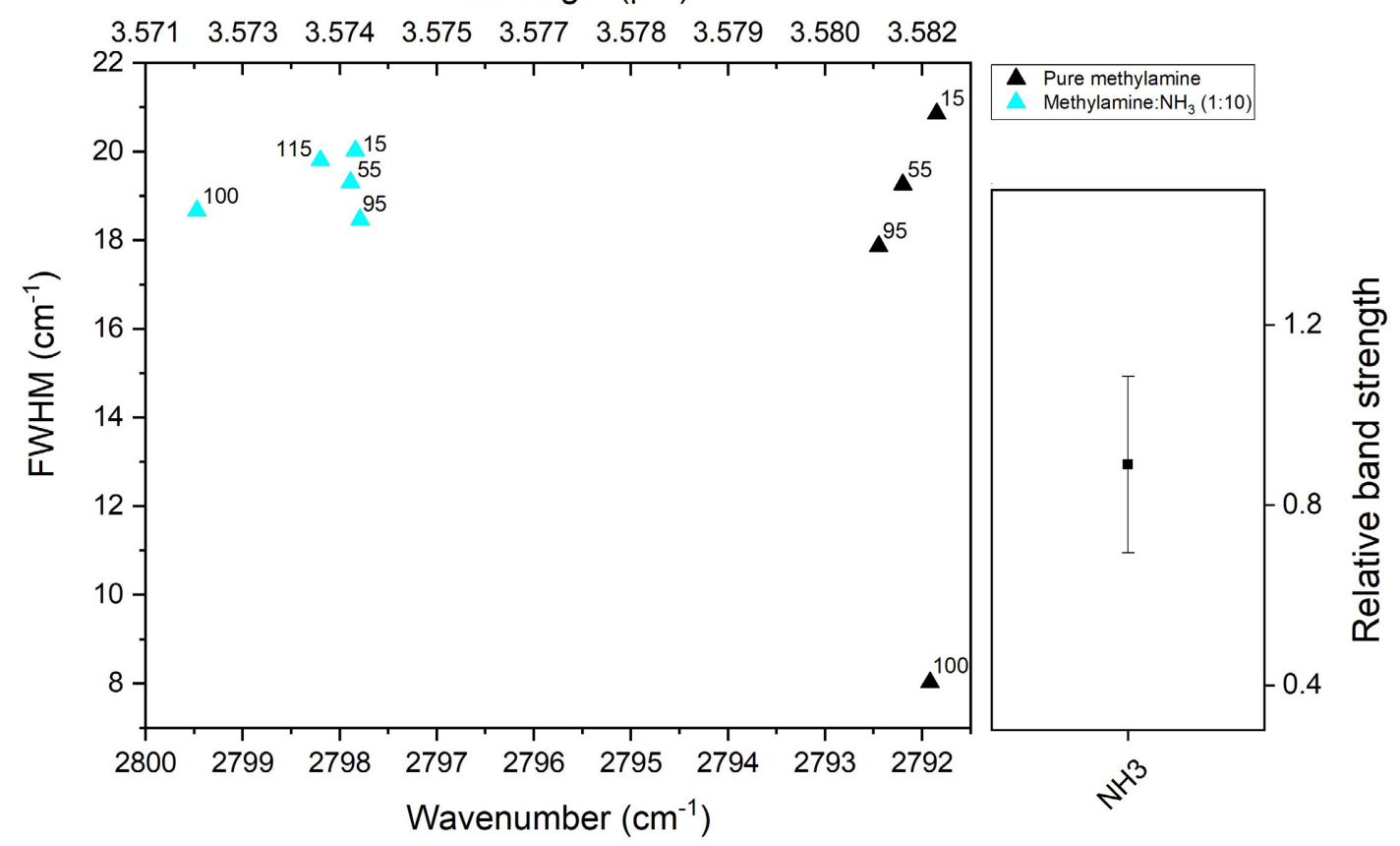

Fig. A.9. (a) $2750-3000 \mathrm{~cm}^{-1}$ region with spectra of different ices, from left to right: pure $\mathrm{CH}_{3} \mathrm{NH}_{2}, \mathrm{CH}_{3} \mathrm{NH}_{2}: \mathrm{H}_{2} \mathrm{O}(1: 10), \mathrm{CH}_{3} \mathrm{NH}_{2}: \mathrm{CH}_{4}(1: 10)$, and $\mathrm{CH}_{3} \mathrm{NH}_{2}: \mathrm{NH}_{3}$ (1:10). The $\mathrm{CH}_{3}$ symmetric stretch mode of $\mathrm{CH}_{3} \mathrm{NH}_{2}$ (around $2792 \mathrm{~cm}^{-1}$ ) lays in the rightmost region in all the panels. (b) Left panel: peak position vs. FWHM for the $\mathrm{CH}_{3}$ symmetric stretch band in the ice mixtures displayed in $a$. Different mixtures are indicated by different colors, and the different temperatures are marked in the graph. Right panel: relative band strength of $\mathrm{CH}_{3}$ antisymmetric stretch of $\mathrm{CH}_{3} \mathrm{NH}_{2}: \mathrm{NH}_{3}$ (1:10) at $15 \mathrm{~K} . c$ same as $b$ for the $\mathrm{CH}_{3}$ antisymmetric stretch band (around $2881 \mathrm{~cm}^{-1}$ ) in the ice mixtures displayed in $a$. 
A\&A 653, A116 (2021)

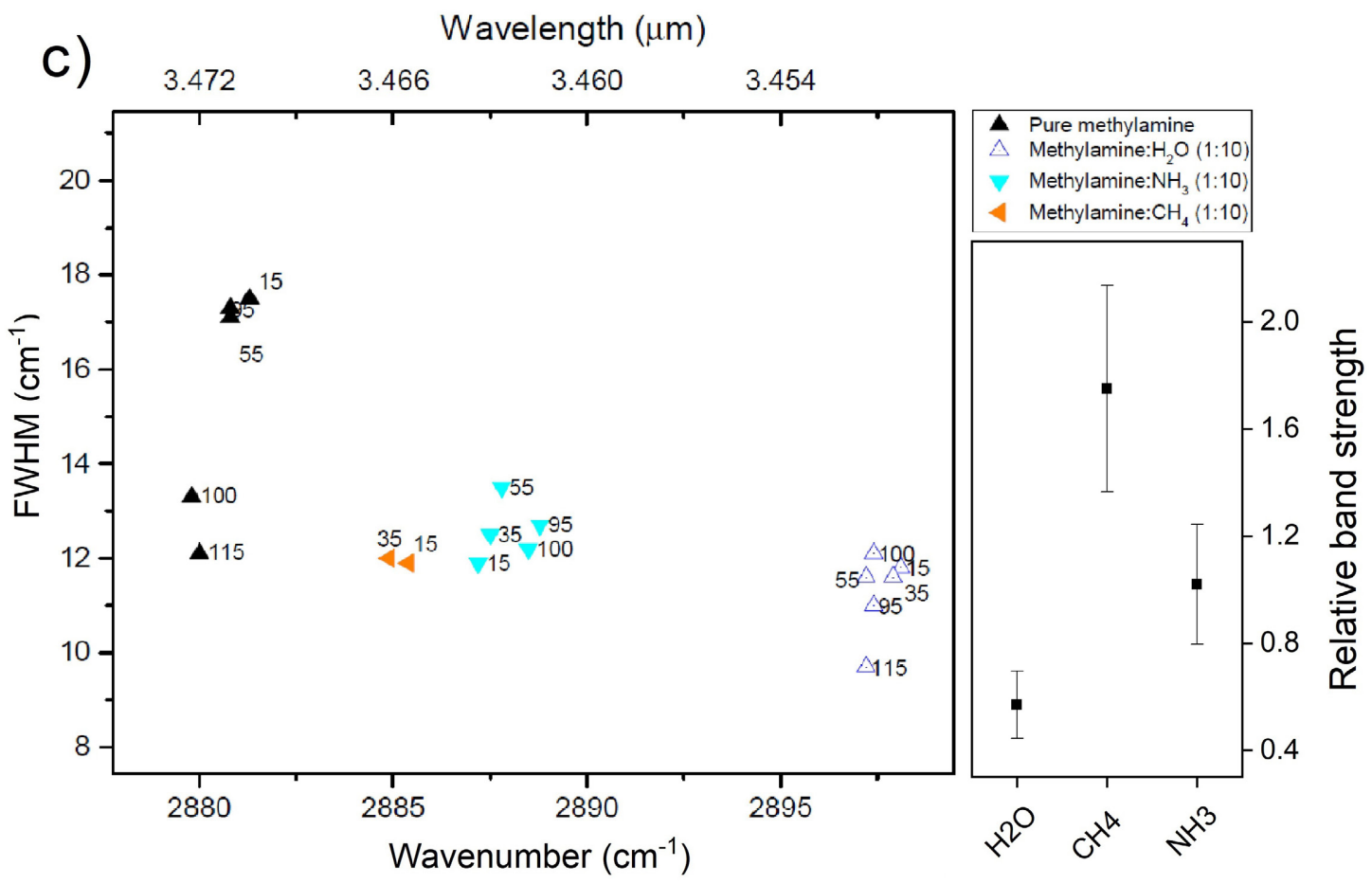

Fig. A.9. continued. 
M. G. Rachid et al.: Infrared spectra of complex organic molecules in astronomically relevant ice mixtures. IV.

a)

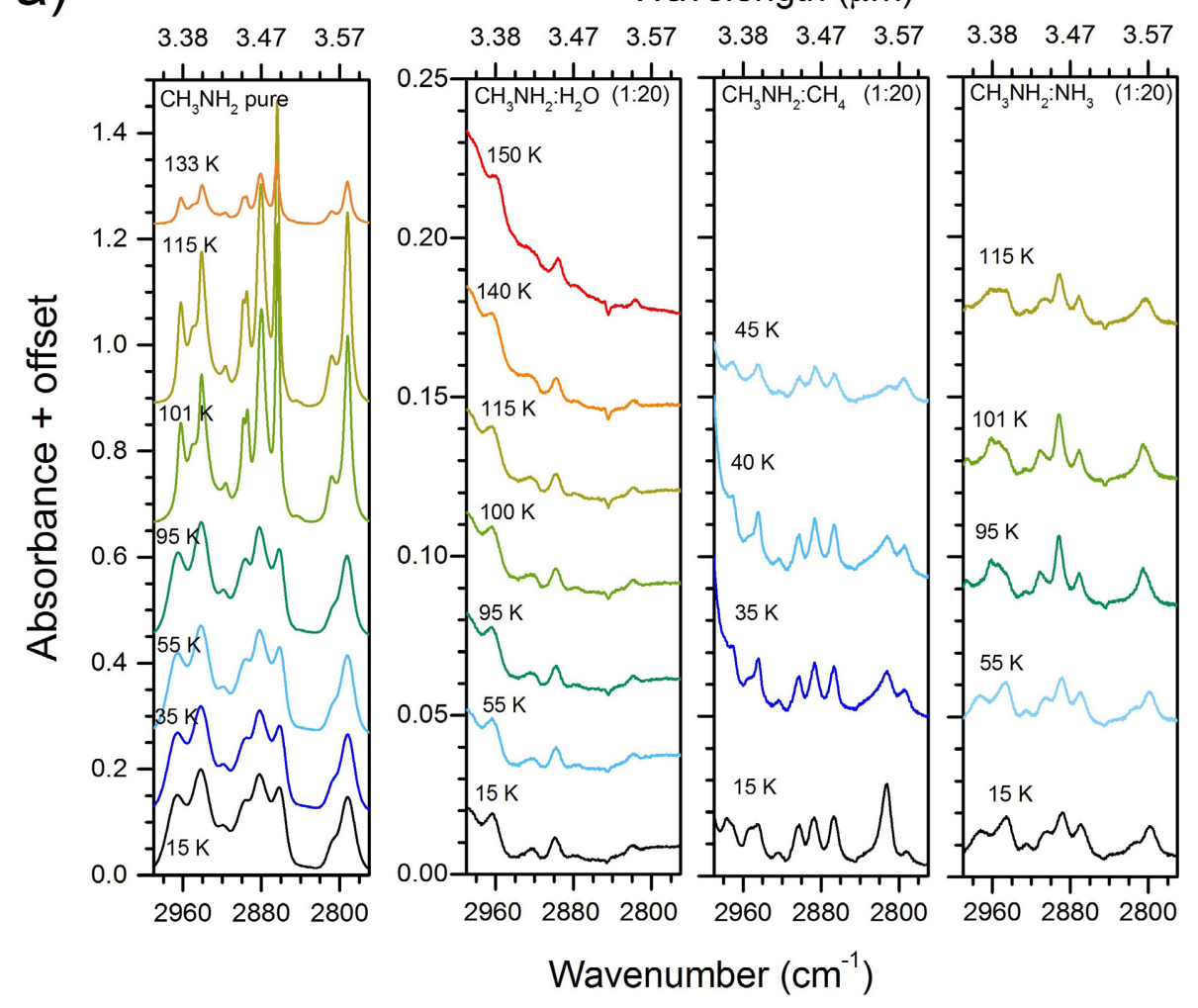

b)

Wavelength $(\mu \mathrm{m})$

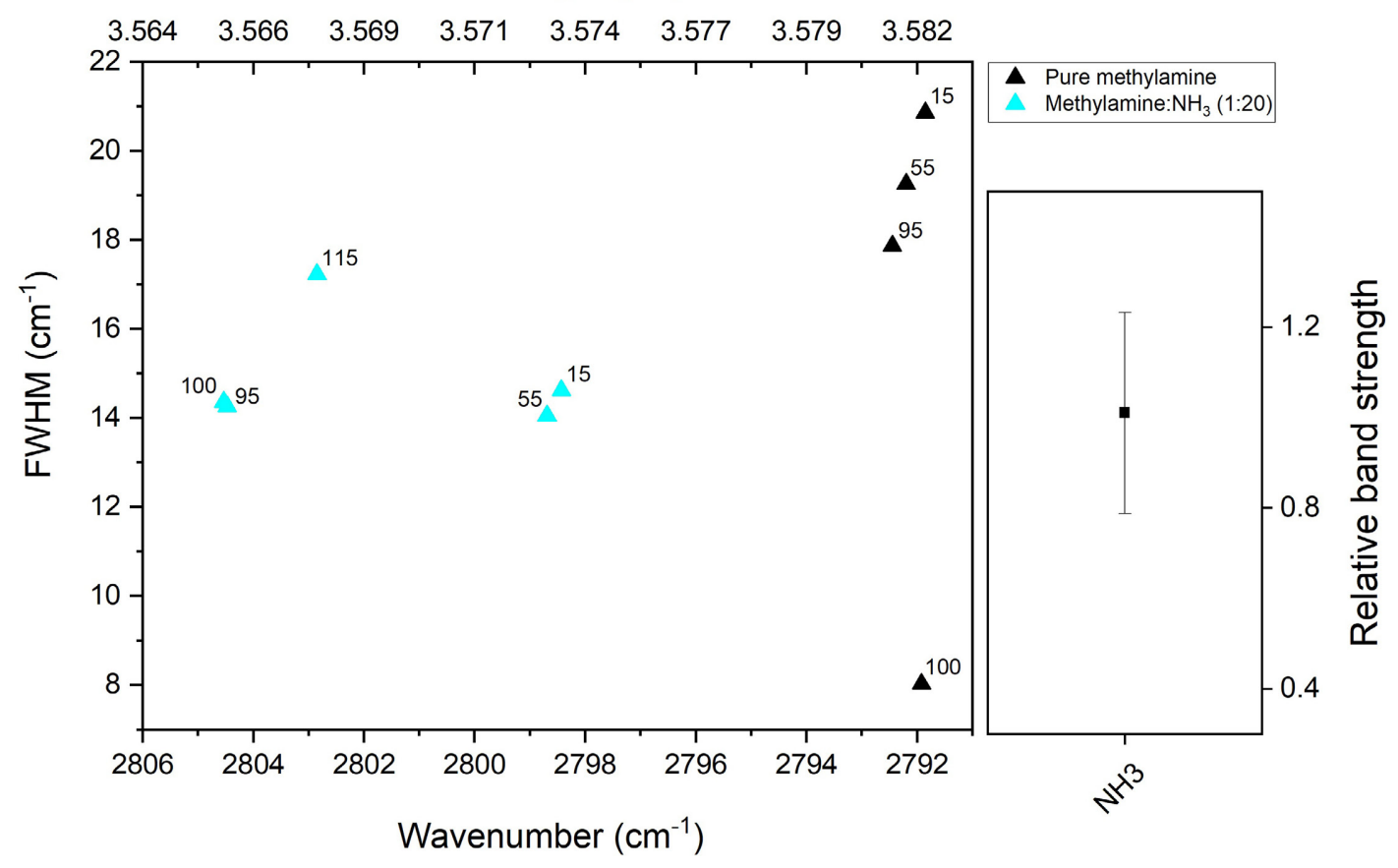

Fig. A.10. (a) 2750-3000 $\mathrm{cm}^{-1}$ region with spectra of different ices, from left to right: pure $\mathrm{CH}_{3} \mathrm{NH}_{2}, \mathrm{CH}_{3} \mathrm{NH}_{2}: \mathrm{H}_{2} \mathrm{O}(1: 20), \mathrm{CH}_{3} \mathrm{NH}_{2}: \mathrm{CH}_{4}(1: 20)$, and $\mathrm{CH}_{3} \mathrm{NH}_{2}: \mathrm{NH}_{3}$ (1:20). The $\mathrm{CH}_{3}$ symmetric stretch mode of $\mathrm{CH}_{3} \mathrm{NH}_{2}$ (around $2792 \mathrm{~cm}^{-1}$ ) lays in the rightmost region in all the panels. (b) Left panel: peak position vs. FWHM for the $\mathrm{CH}_{3}$ symmetric stretch band in pure and $\mathrm{CH}_{3} \mathrm{NH}_{2}: \mathrm{NH}_{3}$ (1:10) ices. Right panel: relative band strength of the $\mathrm{CH}_{3}$ rock vibrational mode in different ice mixtures at $15 \mathrm{~K} . c$ same as $b$ for the $\mathrm{CH}_{3}$ antisymmetric stretch band (around $\left.2881 \mathrm{~cm}^{-1}\right)$ in the ice mixtures displayed in $a$. 


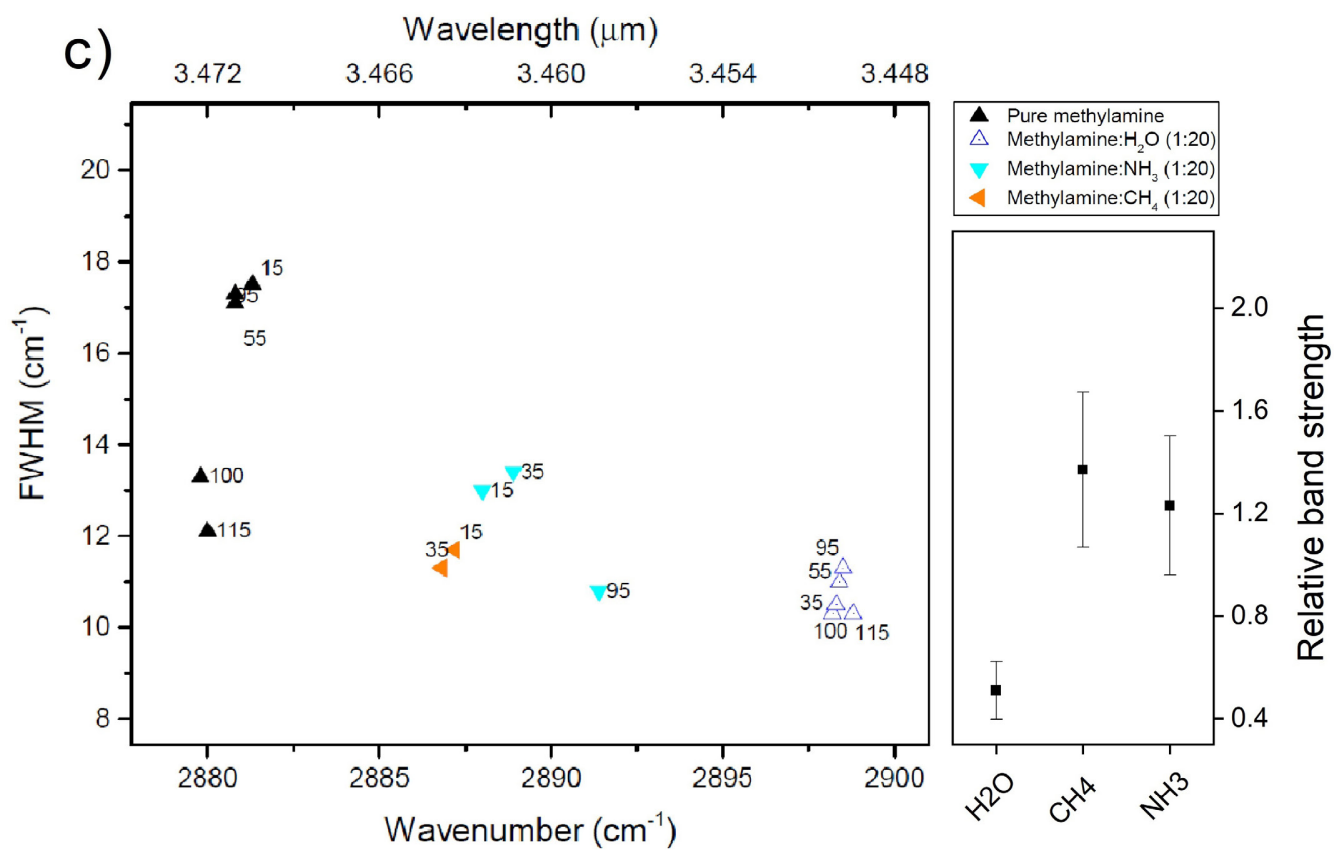

Fig. A.10. continued.
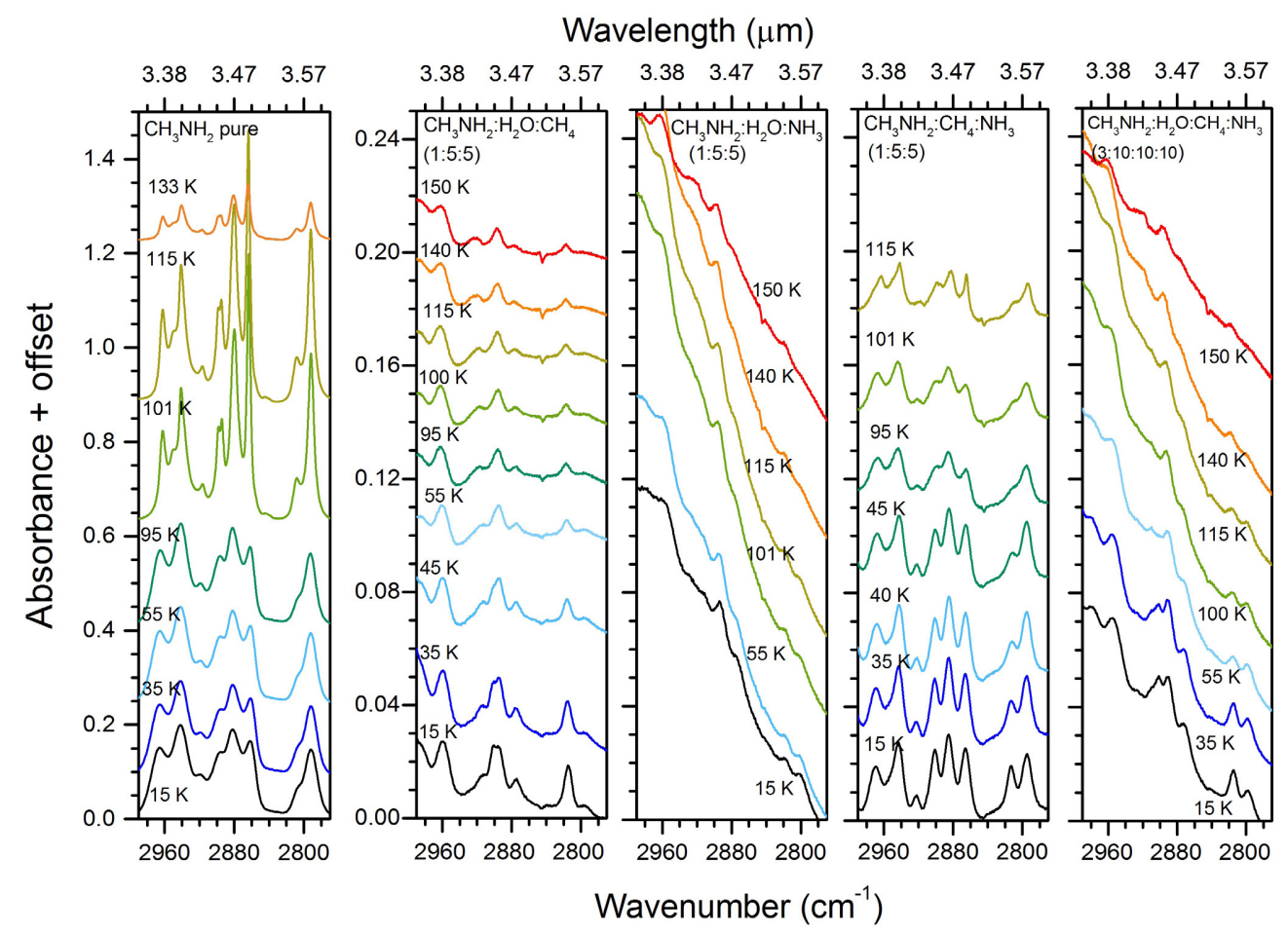

Fig. A.11. $2750-3000 \mathrm{~cm}^{-1}$ region with spectra of different ices, from left to right: pure $\mathrm{CH}_{3} \mathrm{NH}_{2}, \mathrm{CH}_{3} \mathrm{NH}_{2}: \mathrm{H}_{2} \mathrm{O}: \mathrm{CH}_{4}(1: 5: 5), \mathrm{CH}_{3} \mathrm{NH}_{2}: \mathrm{H}_{2} \mathrm{O}: \mathrm{NH}_{3}$ (1:5:5), $\mathrm{CH}_{3} \mathrm{NH}_{2}: \mathrm{CH}_{4}: \mathrm{NH}_{3}$ (1:5:5) and $\mathrm{CH}_{3} \mathrm{NH}_{2}: \mathrm{H}_{2} \mathrm{O}: \mathrm{CH}_{4}: \mathrm{NH}_{3}(3: 10: 10: 10)$. The $\mathrm{CH}_{3}$ antisymmetric stretch mode of $\mathrm{CH}_{3} \mathrm{NH}_{2}\left(\operatorname{around} 2881 \mathrm{~cm}^{-1}\right)$ and the $\mathrm{CH}_{3}$ symmetric stretch mode of $\mathrm{CH}_{3} \mathrm{NH}_{2}$ (around $2792 \mathrm{~cm}^{-1}$ ) are displayed. 
M. G. Rachid et al.: Infrared spectra of complex organic molecules in astronomically relevant ice mixtures. IV.

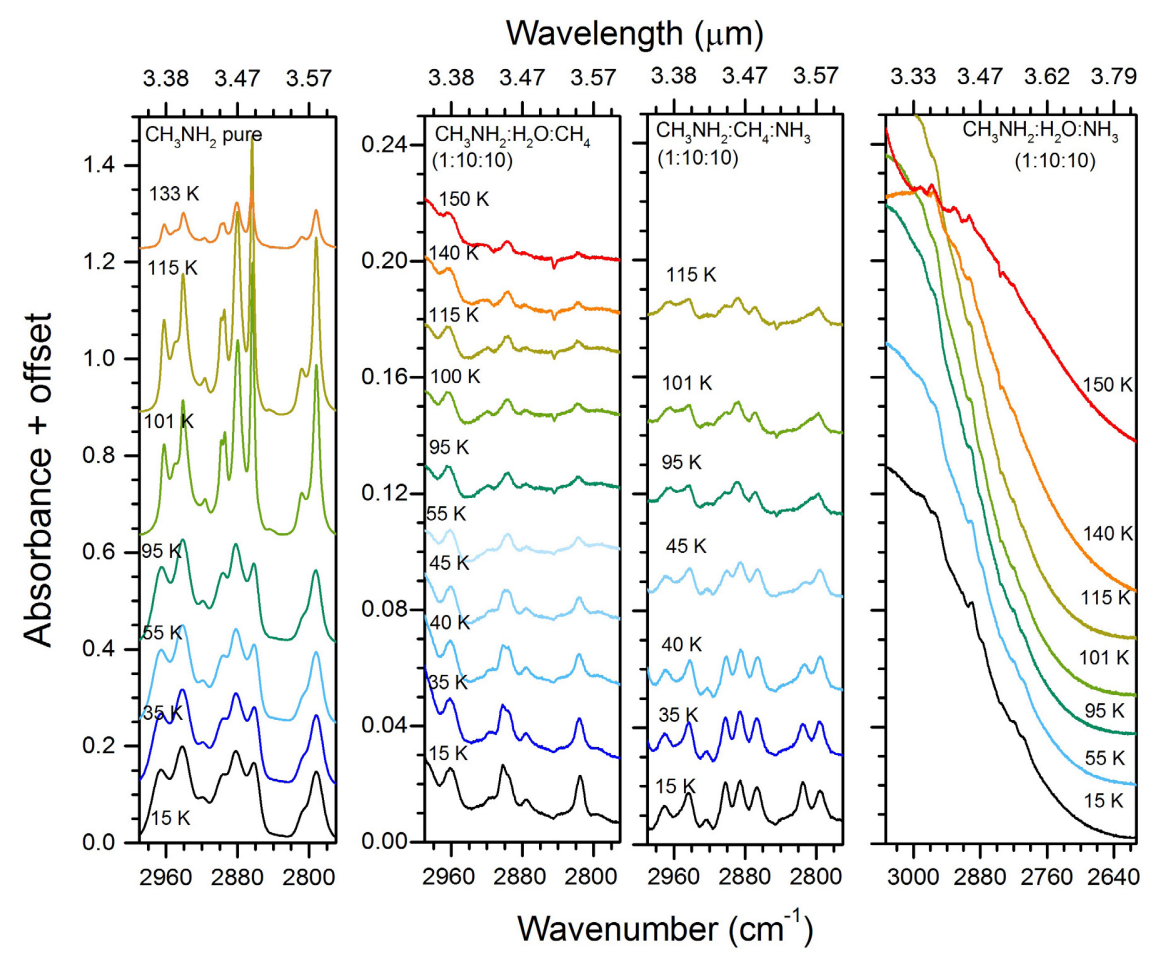

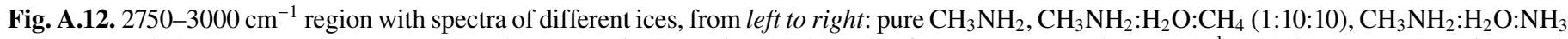
(1:10:10), and $\mathrm{CH}_{3} \mathrm{NH}_{2}: \mathrm{CH}_{4}: \mathrm{NH}_{3}$ (1:10:10). The $\mathrm{CH}_{3}$ antisymmetric stretch mode of $\mathrm{CH}_{3} \mathrm{NH}_{2}$ (around $2881 \mathrm{~cm}^{-1}$ ) and the $\mathrm{CH}_{3}$ symmetric stretch mode of $\mathrm{CH}_{3} \mathrm{NH}_{2}$ (around $2792 \mathrm{~cm}^{-1}$ ) are displayed.

\section{Appendix B}

Tables listing the peak positions and the FWHMs of the bands shown in Appendix A are available in electronic form at the CDS. Each table is composed of the measured peak position and FWHM for a given band in the mixtures with the same methylamine ratio and the pure ice for comparison. The peak position is measured for temperatures up to the desorption temperature of the methylamine ice matrix components (e.g., in the binary mixtures with $\mathrm{CH}_{4}$, the peak position and FWHM are calculated up to $55 \mathrm{~K}$ ). The general uncertainty of peak positions is $0.5 \mathrm{~cm}^{-1}$ for all the measurements, and the typical error of the FWHM values amounts to a maximum of $1 \mathrm{~cm}^{-1}$.

In the cases that the $\mathrm{CH}_{3}$ antisymmetric deformation modes (around 1455 and $1479 \mathrm{~cm}^{-1}$ ) overlap, the band profile is decomposed in two component features and the FWHM and peak position is calculated for each of the individual components.

The absorption profile between 2800 and $2900 \mathrm{~cm}^{-1}$ was decomposed into Gaussian features for the calculation of peak position and FWHM for the $\mathrm{CH}_{3}$ antisymmetric stretch feature $\left(2881.3 \mathrm{~cm}^{-1}\right)$.

In cases where the bands are weak or blended with matrix bands, the FWHM is not determined, and a rough peak position is given and marked with an asterisk $(*)$. The resulting uncertainty is much larger than the peak positions that are derived for features that do not overlap.

\section{Appendix C}

The integrated absorbance of the methylamine bands (i.e., the band areas) in different ice mixtures and at selected temperatures is organized in tables available online at the CDS. Each table displays the data for one specific mixture. The band's integrated absorption is normalized in relation to the $\mathrm{CH}_{3}$ antisymmetric deformation mode, around $1478.6 \mathrm{~cm}^{-1}$, from the given mixture at $15 \mathrm{~K}$. The $\mathrm{CH}_{3}$ antisymmetric deformation mode was chosen for normalization because this feature is distinguishable in all the mixtures and does not overlap with any of the matrix components. 